Portland State University

PDXScholar

Fall 11-28-2018

\title{
A Case Study of Student and Staff Perceptions of the School Breakfast Program: Food for Thought From a College Preparatory High School for Underserved Students
}

Jennifer Lucas Young

Portland State University

Follow this and additional works at: https://pdxscholar.library.pdx.edu/open_access_etds

Part of the Educational Leadership Commons

Let us know how access to this document benefits you.

\section{Recommended Citation}

Young, Jennifer Lucas, "A Case Study of Student and Staff Perceptions of the School Breakfast Program: Food for Thought From a College Preparatory High School for Underserved Students" (2018). Dissertations and Theses. Paper 4655.

https://doi.org/10.15760/etd.6539

This Dissertation is brought to you for free and open access. It has been accepted for inclusion in Dissertations and Theses by an authorized administrator of PDXScholar. Please contact us if we can make this document more accessible: pdxscholar@pdx.edu. 
A Case Study of Student and Staff Perceptions of the School Breakfast Program: Food for Thought From a College Preparatory High School for Underserved Students

by

Jennifer Lucas Young

A dissertation submitted in partial fulfillment of the requirements for the degree of

\author{
Doctor of Education \\ in \\ Educational Leadership: Curriculum and Instruction
}

Dissertation Committee:

Dannelle D. Stevens, Chair

Heather Burns

Micki M. Caskey

Lynn Santelmann

Portland State University

2018 
(C) 2018 Jennifer Lucas Young 


\begin{abstract}
Research suggests that participation in the School Breakfast Program positively impacts academic success by improving student behavior, cognitive functioning, and attendance. Additionally, the School Breakfast Program appears to improve food insecurity, overall health and weight-related issues. However, compared to the National School Lunch Program, participation in the School Breakfast Program has been historically low, especially at the high school level. Using an integrated composite framework, a combination of social cognitive theory and ecological systems theory, as the conceptual model, this qualitative case study explored factors influencing student breakfast eating and participation in the school's breakfast program within a collegepreparatory high school serving culturally diverse, predominantly low-income students. I used an all-staff survey as a qualitative data collection tool, and semi-structured interviews with school staff, student focus groups, and a Draw-A-High-School-StudentBreakfast Test to collect qualitative data. Using thematic networks as an analysis tool, I examined the attitudes, beliefs, and behaviors of school staff and students about breakfast eating and participation in the school's breakfast program. The study found that communication about the School Breakfast Program, arriving to school in time to eat, and relationships with food service staff, influence participation in the School Breakfast Program. The findings are discussed in terms of their significance on practice and policy within both education and public health sectors. The study concludes with recommendations for future research.
\end{abstract}




\section{Acknowledgements}

I am grateful to my dissertation committee: Dannelle D. Stevens, Heather Burns, Micki M. Caskey, and Lynn Santelmann. Your feedback and edits on my earlier work helped me think more broadly, improve my APA, and explore my biases. I truly appreciate your guidance and your willingness to painstakingly read through my work and provide constructive feedback. I am so grateful to have worked with Dannelle as my dissertation chair. For me, Dannelle was the "Auntie Mame" of advisors. From our numerous meetings over the years, I always took away "words of gold" and plants for my garden. I truly appreciate Dannelle's positive attitude, and her everlasting belief that I could get this done. Dannelle is an exceptional role model.

I am also grateful to my friend and colleague, Crista Hawkins, whose passion for increasing participation in the School Breakfast Program focused me on this topic. I am also grateful to my friend and colleague, Robin Stanton, who has been my "other half" in public health, and whose skills I value so much.

Lastly, I dedicate this work to my husband, John, for his patience as I spent the last 4 years sitting next to the gas stove with papers and books strewn around me; my children, Cecelia, Freddy, and Lucy for saying it was "cool" that I was working on another degree; to my friend and colleague, Joyce Dougherty, for her unending encouragement; and to my dear friend Marcie Gowan for being a wonderful inspiration. 
Table of Contents

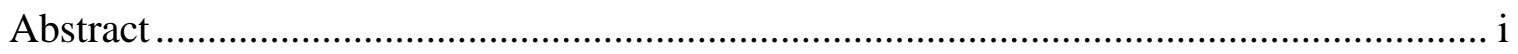

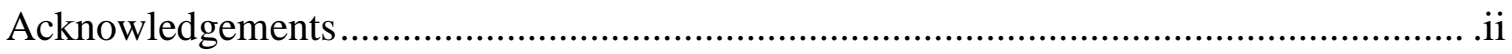

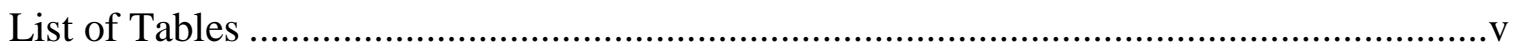

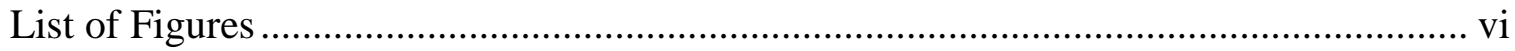

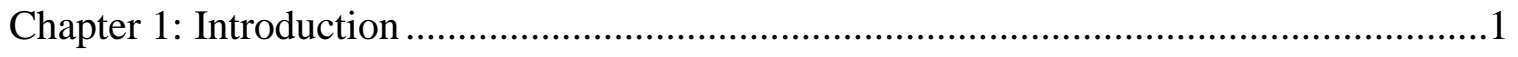

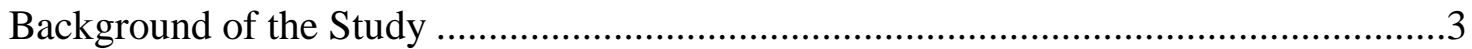

Statement of the Methods and Research Questions ................................................8

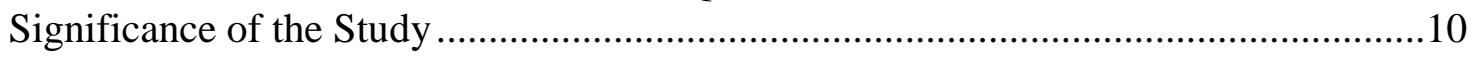

Presentation of Methods and Research Questons ...............................................11

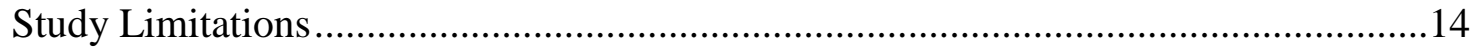

Definition of Key Concepts .............................................................................. 15

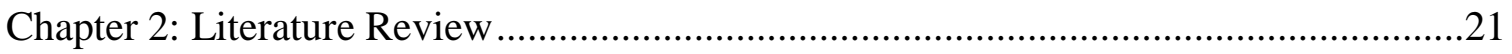

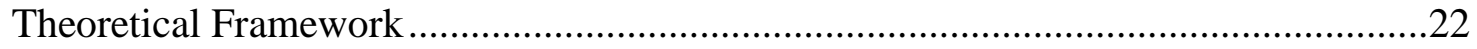

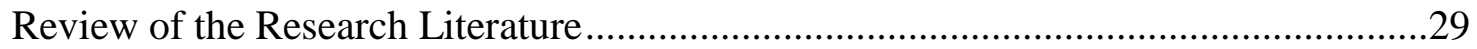

Summary of Research Literature ....................................................................

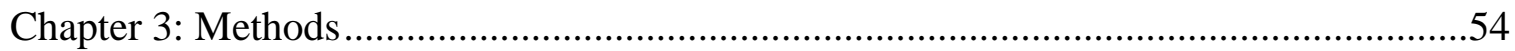

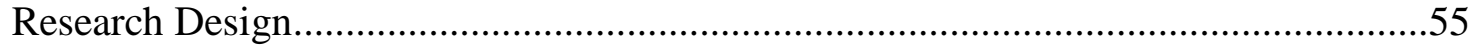

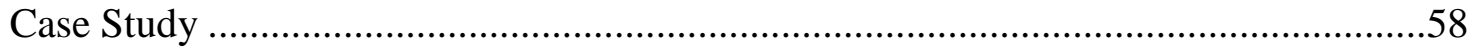

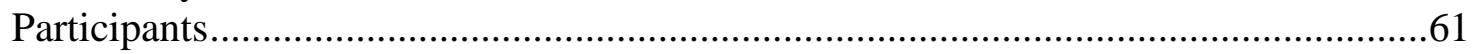

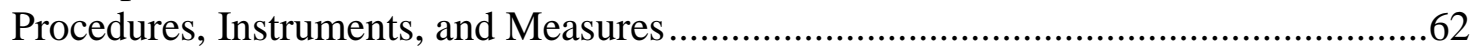

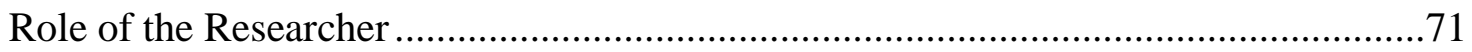

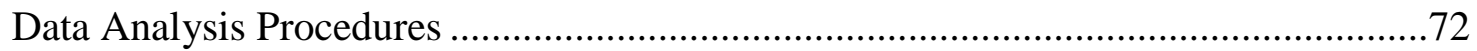

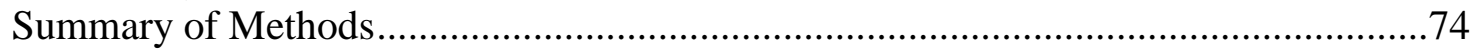

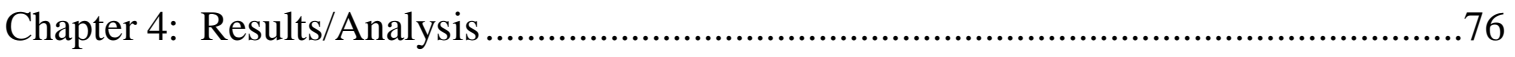

Analysis of the Data and Presentation of the Results ........................................... 77

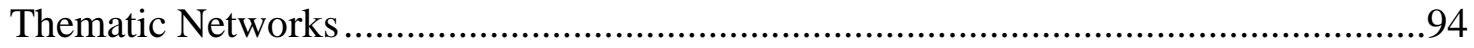

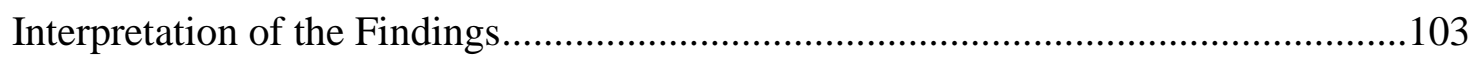

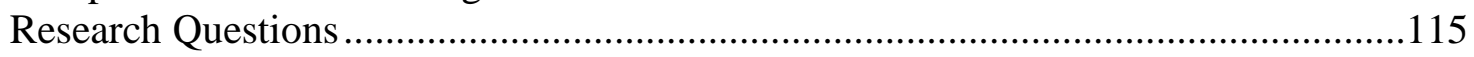

Limitations of the Study and My Role as a Researcher .........................................119

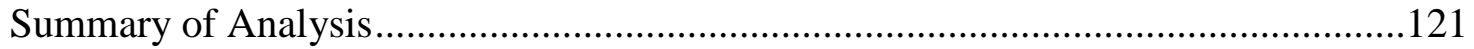




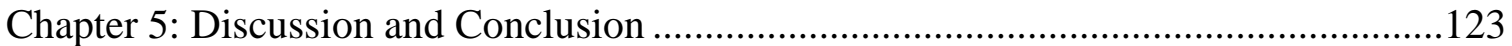

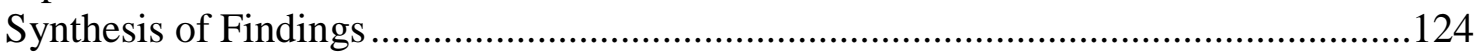

The Case Study Situated in a Larger Context ........................................................130

Implications for Education and Public Health Policy and Practice ............................134

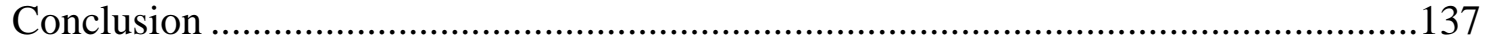

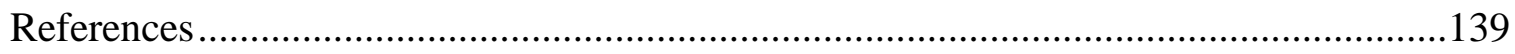

Appendix A. Consent Forms................................................................................ 161

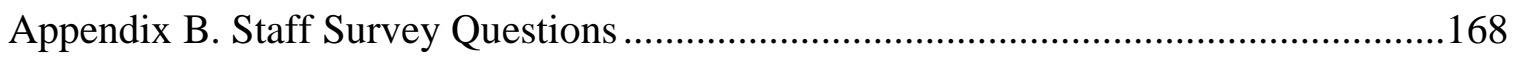

Appendix C. Semi-Structured Interview Questions for Administrators and Staff .........171

Appendix D. Focus Group and DAHSSBT Script...............................................183 
List of Tables

Table 1: Research Question Alignment With Data Collection Methods ..........................14

Table 2: Conceptual Applications of Bronfenbrenner's Ecological Systems Theory

Model on Breakfast-Eating Influences of High School Students .................................28

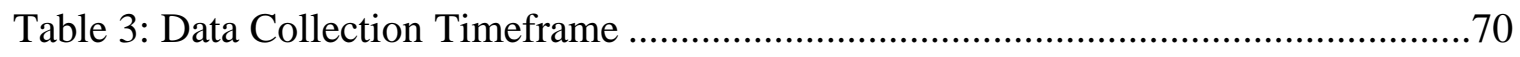

Table 4: Descriptive Statistics for Staff Survey ................................................... 79

Table 5: Pattern Codes and In Vivo Coding Analysis for School Staff Data ...................85

Table 6: Pattern Codes and In Vivo Coding Analysis for Student Data...........................88

Table 7: DAHSSBT Pattern Codes and Pattern Definitions........................................91

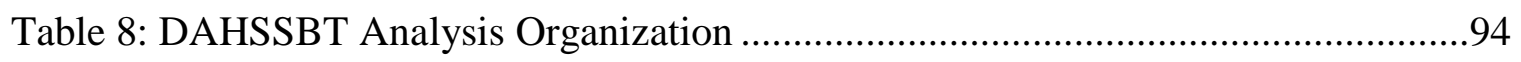

Table 9: Sequence of Pattern Coding to Communication Overarching Theme................96

Table 10: Sequence of Pattern Coding to Relationships Overarching Theme..................97

Table 11: Sequence of Pattern Coding to Transitions in the School Meal Programs

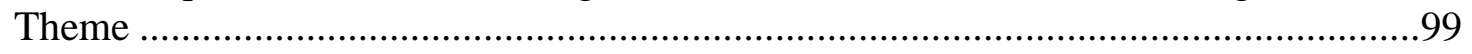

Table 12: Sequence of Pattern Coding to Value Theme..............................................100 
List of Figures

Figure 1: An Illustration of the Components of Breakfast Research That Impacts Educational and Health Outcomes

Figure 2: Bandura's Social Cognitive Theory Model .................................................25

Figure 3: Bronfenbrenner's Ecological Systems Theory Model .................................27

Figure 4: Overview of Student Breakfast Research Components ..................................30

Figure 5: An Example of a Student's DAHSSBT, a Drawing of a Granola Bar..............69

Figure 6: Organization of Data Analysis ............................................................. 74

Figure 7: Q5, Eating Breakfast Helps Me Control My Weight .....................................80

Figure 8: Q8, I Am Familiar With Our School Breakfast Program...............................81

Figure 9: Q9, In My Role Within the School, I Promote the Importance of Eating

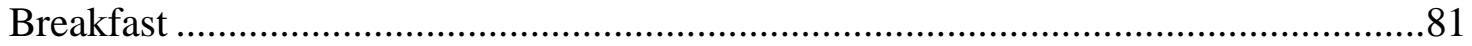

Figure 10: Q10, The School Promotes the Importance of Eating Breakfast ...................82

Figure 11: On a Typical School/Work Day I Eat Breakfast .......................................83

Figure 12: DAHSSBT Drawing of Water and Air Molecules .....................................92

Figure 13: DAHSSBT Drawing of an Egg Sandwich and Milk ...................................93

Figure 14: DAHSSBT Drawing of Good and Bad Days for Breakfast ..........................93

Figure 15: Communication Strand of the Thematic Network ....................................96

Figure 16: Relationships Strand of the Thematic Network ........................................98

Figure 17: Transitions Strand of the Thematic Network .............................................99

Figure 18: Value Strand of the Thematic Network.................................................101

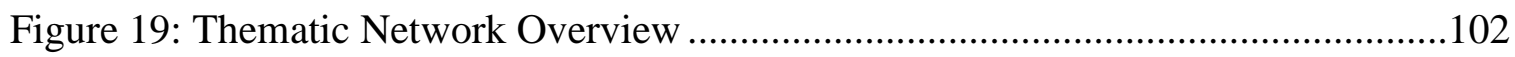




\section{CHAPTER 1: INTRODUCTION}

When I close my eyes and think back on my years spent as an elementary, middle, and high school student during the 1960s and 1970s, a rush of memories fills my mind of friends, teachers, tuna sandwiches sitting till noon in a brown lunch bag, and chapter books read aloud after lunch recess. I lived in the country and my grade school did not have a cafeteria. Every day 30 minutes before lunch, a school district van pulled into the gravel parking lot, and foil wrapped hot lunches were unloaded for the students. I brought my lunch most days, but ordered a hot lunch whenever tacos were on the menu. I attended high school in town, and have sharp memories of the heavy warm smell of the school cafeteria that shared space with the school gym, and the cacophony of clanging pans, chaotic chatter, and the wheels of the long tables and benches rolling out on the polished floor. By sophomore year, most of my friends and I purchased oversized cinnamon rolls and chocolate milk from the a-la-carte line instead of the hot "healthy" school lunch. But a few of my friends, paid with the "red ticket" which meant they received their lunch free. There was no cinnamon roll for them-the red ticket was only good for the school lunch. I did not think of it back then, or, I was not aware that I was thinking of it, but the school food environment served as a form of nutrition and food system pedagogy.

During my years as a public school student, my schools participated in the School Milk and National School Lunch Programs, but they did not serve breakfast. I ate breakfast at home, and assumed that every other student was doing the same. However, it 
was during this same time period that the School Breakfast Program was started and later authorized (United States Department of Education, Food and Nutrition Service [USDA FNS], 2017a).

The School Breakfast Program began in 1966 as a 2-year pilot program for schools located in poor areas or in areas where students had to travel a long way to get to school. The program was extended and expanded several times in the following years, and in 1971, Congress added the priority consideration that the School Breakfast Program improve the nutrition and dietary practices of children of working mothers and lowincome families. In 1975, the School Breakfast Program received permanent authorization, joining the National School Lunch Program and the School Milk Program core school food assistance programs sponsored by the USDA FNS (2017a).

Today, roughly $20 \%$ of U.S. elementary-age students start their day without breakfast. By adolescence, this number increases significantly (Kant \& Graubard, 2011). Participation in the School Breakfast Program is noted as a proven or promising approach to addressing health and education disparities (Basch, 2011b). School districts across the U.S. are implementing strategies to get more students to eat school breakfast. While student breakfast rates appear overall to be increasing, high school breakfast participation rates are still relatively low-even in schools where many students are considered food insecure (Food Research and Action Center, 2018; USDA FNS, 2012). In theory, the School Breakfast Program could play a critical role in reducing health disparities and narrowing the achievement gap. However, to be effective in practice, it is essential to 
understand the underlying beliefs and attitudes about school breakfast, and the breakfasteating behaviors, of those it is meant to help.

\section{Background of the Problem}

A reciprocal relationship exists between health and education. The Centers for Disease Control (2014) has established through summaries of research (Health Disparities, 2014) that good health is associated with academic success and academic success leads to better lifelong health outcomes. While poor health can lead to missed school days, less learning, and a greater risk of academic struggle, improved health has a favorable influence on educational attainment (Montez, Hummer, \& Hayward, 2012). Because of the powerful connection between health and positive educational outcomes, student health, especially P-12, has gained importance in educational policy considerations, public health priorities, and social science research (Basch, 2011b). According to the Robert Wood Johnson Foundation's Commission to Build a Healthier America, the gap between educational attainment and poor health outcomes continues to widen (Egerter, Braveman, Sadegh-Nobari, Grossman-Kahn, \& Dekker, 2009). Americans without a high school degree are more likely to have serious health issues and a less healthy lifestyle compared to their better-educated counterparts. In turn, lack of educational attainment of one generation can negatively impact health and educational outcomes of the next, creating a pattern that continues to increase social, educational, and health disparities for future generations (Egerter et al., 2009). Emerging literature suggests that children's health factors may explain the influence of low socioeconomic status on academic achievement and educational attainment (Case \& 
Paxson, 2006; Crosnoe, 2006; Haas, 2006; Haas \& Fosse, 2008; Heckman, 2008;

Koivusilta, Arja, \& Andres, 2003; Palloni, 2006). The real question is what are strategies that could make a difference in improving student health and simultaneously improving educational outcomes?

Nutrition is a cornerstone of health and wellbeing. Attention to nutrition offers a positive alternative to the impact of negative outcomes or poor health choices. Diet and eating behaviors can have a profound impact on growth and development (Eden, 2005; Skalicky et al., 2006). Deficiencies of certain nutrients can have serious consequences for the developing brain; while dietary patterns such as breakfast-skipping contribute to excess weight gain and obesity (Alaimo, Olson, Frongillo, \& Briefel, 2001; Basch, 2011a).

Although breakfast is lauded as the most important meal of the day, as grade level increases, the percentage of student breakfast skipping rises. Research indicates that $30 \%$ to nearly $60 \%$ of high school students skip breakfast on a given day (Cohen et al., 2003; Kant \& Graubard, 2011; Sweeney \& Horishita, 2005). These percentages vary by the population of adolescent students being studied; for example, females, lower-income, and urban as opposed to rural students tend to skip breakfast most often (Basch, 2011a; Rampersaud, 2009).

Research studies suggest that students who eat breakfast have better concentration, perform better on standardized math tests, have better attendance, display fewer behavioral problems during class, and have lower risk of weight-related health issues than students who skip breakfast (Adolphus, Lawton, \& Dye, 2013; Jones, Jahns, 
Laraia, \& Haughton, 2003; Murphy, 2007; Rampersaud, 2009). Taken together, the studies conducted on breakfast eating and the School Breakfast Program indicate that eating breakfast is more beneficial than skipping breakfast. However, the effect is more apparent in children who come from homes where nutritional status is compromised (Hoyland, Dye, \& Lawton, 2009).

The School Breakfast Program was designed to address the nutritional needs of students coming from food insecure households. The School Breakfast Program has been well-researched, and evidence supports claims that the School Breakfast Program reduces breakfast skipping, and is successful in reducing hunger and improving dietary quality and eating patterns (Bartfeld, 2010). Studies also indicate that the School Breakfast Program decreases student tardiness, absenteeism, disciplinary problems and visits to the school nurse; all outcomes important for student success (Alaimo et al., 2001; Bartfeld, 2010; Murphy, 2007). However, in comparison to the National School Lunch Program, many fewer students who are eligible for low- or no-cost school meals participate in the School Breakfast Program. School districts across the nation are trying out innovative strategies to increase participation in the School Breakfast Program, like providing breakfast in the classroom, and universal (free) breakfast to all students. While states implementing alternative breakfast practices (like community eligibility provision and breakfast after the bell) have seen improvements in school breakfast participation, high school participation rates are still relatively low (Food Research and Action Center, 2018). Figure 1 illustrates the components of breakfast-related research topics that were examined in this study. 


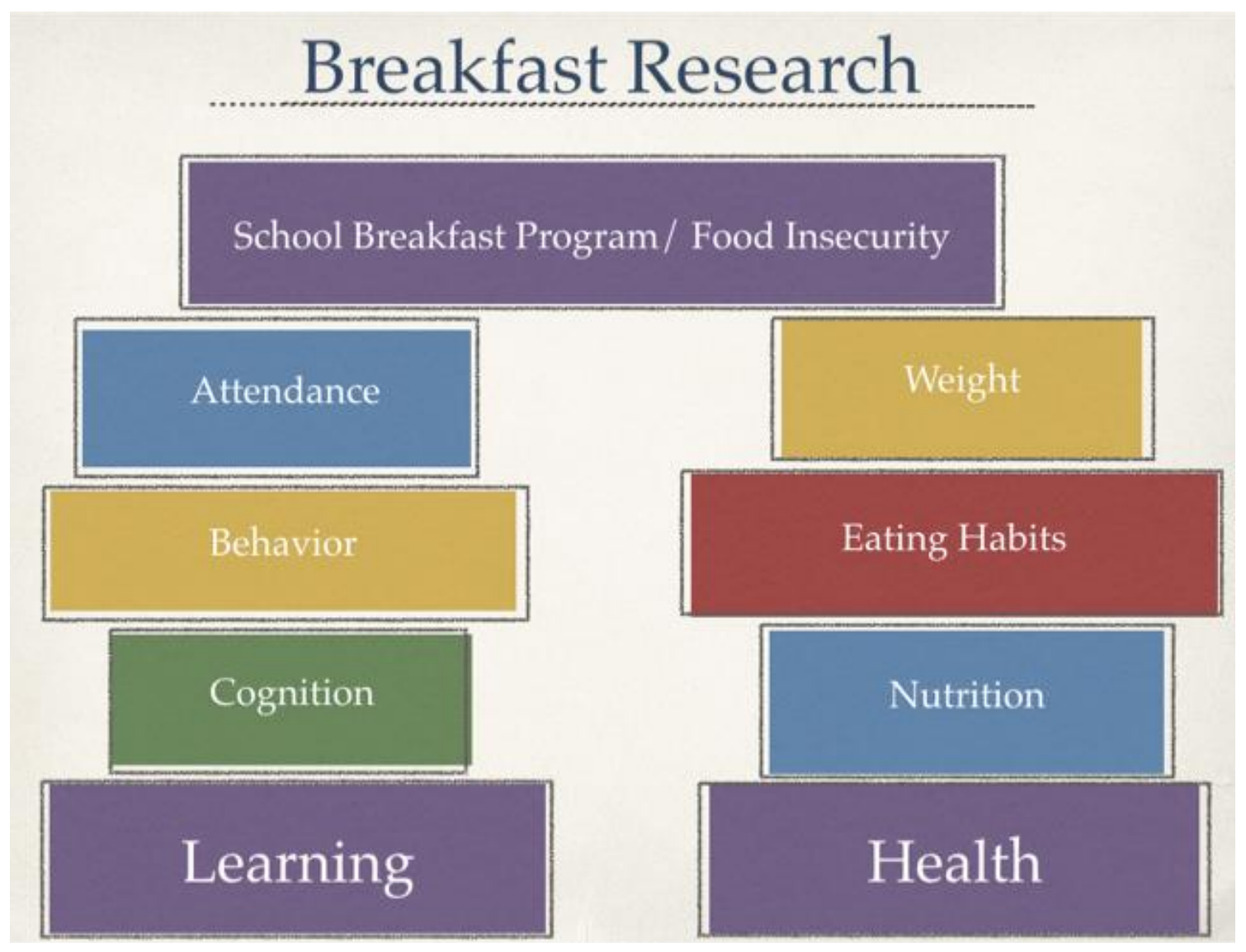

Figure 1. An illustration of the components of breakfast research that impacts educational and health outcomes.

As an adult, my first venture into the world of adolescent school meals was when I facilitated a youth action research project in a local high school. The purpose of the project was to understand, from the point-of-view of low-income adolescents, the factors in their environment that contribute to obesity. During the first 3 months of the project, the students worked to develop a research question that would reflect their community's struggle with factors related to poor health outcomes. I spent three hours a week with the students, arriving just as they returned from lunch. Week after week, I heard their complaints about how terrible the lunch served in the cafeteria was that day. "The pizza 
was rubbery, and everything is topped with an oily film." "We only have Chinese food, I bet the Thai and Vietnamese kids might like to have food from their country," and "The lettuce looks like it was put in the oven overnight." "Why do they want us to eat this crap?"

The students told me they often skipped the lunch altogether, and most of them said they never ate the breakfast. The students claimed that no one ate the school food, which I found surprising as the school served a high number of low-income students$85 \%$ of the student body qualified for free and reduced-price lunch — and the school provided universal breakfast. Additionally, this project occurred during the economic downturn of 2008-2009, and I expected that a large percentage of the students' families were struggling with food insecurity, as the families of two of the seven students I was working with were evicted from their homes during the course of the school year. By the end of the third month the students arrived at their research question: Why don't students eat school breakfast and lunch? When this topic was suggested, all of the students agreed that it was what we should focus on. For me, it felt like everything that I had been experiencing with the students over the last 3 months had been pulled together in the perfect research question. At this point, I was only familiar with the consequences that food insecurity and meal skipping had on weight-related issues like obesity and chronic disease. It was not until years later, when I began to research school meal participation, that I became aware of the academic impact.

There are significant variations in School Breakfast Program participation rates by age group, geographic region, race and ethnicity, and income (Bartfeld, 2010). Similar to 
breakfast skipping behavior, as students get older, participation in the School Breakfast Program declines (Neumark-Sztainer, French, Hannan, Story, \& Fulkerson, 2005). The high school student-researchers I worked with gained insight into why many of their classmates were not taking advantage of the School Breakfast Program; for example, their peers reported preferring to sleep-in an extra 15 minutes instead of getting to school early to eat (Young \& Thorne, 2009). There are multiple reasons cited in the literature for the decline in high school student participation in the School Breakfast Program, including those related to open campuses, social stigma, including the perception that school meals are for poor students, limited menu options, and foods sold on the school campus in direct competition with the federal meals program (Neumark-Sztainer et al., 2005). Additional research indicates that adolescents, especially females, often skip breakfast because of beliefs that it contributes to their weight gain (Reddan, Wahlstrom, \& Reicks, 2002). Finally, in 2016, researchers found that while there is a 50\% average daily participation rate for school lunch by free-and-reduced price eligible high school students, the average daily participation for breakfast for these students is only $15 \%$ (School Nutrition Association, 2016).

\section{Statement of the Research Problem}

Adolescent breakfast-skipping and low adolescent participation in the School Breakfast Program is well documented in the literature (Affenito, 2007; Bartfeld, 2010; Delva, O’Malley, \& Johnston, 2006; Devaney \& Fraker, 1989; Nicklas, O’Neil, \& Myers, 2004; Niemeier, Raynor, Lloyd-Richardson, Rogers, \& Wing, 2006; Rampersaud, 2009; Rampersaud, Pereira, Girard, Adams, \& Metzl, 2005; Siega-Riz, Carson, \& 
Popkin, 1998; Zapata, Bryant, McDermott, \& Hefelfinger, 2008). However, there are no studies to date that address why, even when the common reasons given by students for not participating in the School Breakfast Program are addressed, a meaningful percentage of students, including food insecure students, are still failing to eat school breakfast. In 2005, Jenkins and Horner identified gaps in the school breakfast literature research to include studies representing minority students and food preference for students with diverse cultural backgrounds. Consequently, research into these two topics is still in short supply. Finally, a very limited amount of qualitative research exists about adolescent eating behaviors, where students themselves describe their world and how their diet and food choices relate to influences in their home, school, and social-life, including media. While opponents may argue that it is not the role of the school to ensure that students eat breakfast, or that students may end up eating multiple breakfasts if school breakfast is available after the start of the school day, I contend that all students deserve to start the school day fed and ready to learn. School breakfast is so critically linked to food security, and therefore, learning and health, that I believe it is our social obligation to ensure that school breakfast is accessible and affordable for all students. To take the argument a step further, high school students, especially girls and lower income students, are at a particularly high risk for breakfast skipping. As adolescents, these students are experiencing a critical period of physical, emotional, and mental growth and development, and are also within, or quickly approaching, reproductive age. It follows, that their educational outcome, health, weight status, attitude, and perceptions about eating will directly impact the rest of their lives as well as the next generation. Therefore, 
the purpose of my study is to explore factors influencing participation in the School Breakfast Program for culturally diverse high school students within a school serving a predominately low-income population. I chose this specific population based on the research findings that participation in the School Breakfast Program decreases as students get older, with high school students having the lowest participation rates, and because the research shows that low-income, food insecure girls who eat breakfast at school are significantly more likely to maintain a healthy weight.

\section{Significance of the Study}

This study is significant because I conducted it through both an education and a public health lens. This was the first study, which I am aware of, to explore how the School Breakfast Program is viewed as an educational support in a college-prep high school serving predominantly low-income students. This study may provide insight into factors that influence the breakfast eating patterns of adolescent students coming from differing cultural and economic backgrounds, a gap that was noted in research literature. This study is significant as it is one of the first to explore the breakfast-eating attitudes and role-modeling behaviors of school staff, and the systems within the school that influence student breakfast eating behavior. Findings from this research may be used to inform school breakfast promotion, health education curriculum, and school policy that may increase knowledge about the importance of breakfast eating and participation in the School Breakfast Program. Furthermore, this study could have a direct influence on education and public health by influencing trends in breakfast eating behaviors and attitudes. Some of the findings revealed in the study, may be transferable to high schools 
and School Breakfast Programs beyond within and beyond the district and state where the case study was conducted.

\section{Presentation of Methods and Research Questions}

To understand the social and environmental factors that influence adolescent eating behaviors and School Breakfast Program participation, I conducted a case study within an urban high school in the Western United States that serves an ethnically diverse student population. At this school, all students have access to the School Breakfast Program and at least $60 \%$ of students are eligible for free or reduced-price meals.

An integrated composite framework that combines social cognitive theory and ecological systems theory was used as the theoretical framework to explore the factors that influence adolescent eating behavior. Social cognitive theory appears in the literature as the most common theoretical framework used to analyze attitudes and perceptions around school breakfast and eating behavior practices of adolescents (Bandura, 1989; Cooper, Bandelow, \& Nevill, 2011; Cooper, Bandelow, Nute, Morris, \& Nevill, 2012; Cusatis \& Shannon, 1996; Neumark-Sztainer, Story, Perry, \& Casey, 1999; Reddan et al., 2002). Social cognitive theory takes into account the environmental, behavioral, and social context that are fundamental for understanding attitudes and perceptions of students' food decisions. However, I have always been drawn to Bronfenbrenner's (1977, 1979) Ecological Systems Theory as well, and have found it useful to my work in public health. As a theoretical framework, Bronfenbrenner's model has often been applied to understand the complexity of influential factors in adolescents' lives—-taking into account inter- and intrapersonal relationships, social and environmental factors, and 
systems and policies. Therefore, I used an integrated composite framework that combines social cognitive theory and ecological systems theory, to understand the complexity of the social, behavioral, and environmental context of adolescents' lives and the influences that impact their decisions, specifically around eating school breakfast. This integrated model guided the explanation of factors that influence adolescent eating behavior.

The research design methodology was a qualitative study design used within a pragmatic conceptual framework (Howe, 2004). Both qualitative and quantitative data were gathered, and data collection methods included a staff survey, individual interviews with staff, student focus groups, and a Draw-A-High-School-Student-Breakfast Test (DAHSSBT).

The use of multiple research methods, and the combination of qualitative and quantitative data sources, strengthened validity through triangulation and provided insight from several different angles. Internal integrity was achieved by creating rapport, trust and credibility with the students and school staff involved in the study. Prior to the start of the study, the school principal sent an email to all staff making them aware that the study would be taking place, asking for their participation, and introducing me as "a friend of the school." The teacher who recruited the students for the focus groups must have used similar wording because the students treated me as a welcome and familiar adult. They were respectful yet seemed open and eager to share their thoughts. I was personally introduced to the staff that I interviewed by either the principal or vice principal. 
The research questions were at the center of my research design, and in this study, I focused on the following two research questions:

1. How do students at this college-prep high school for underserved students describe the factors - social, economic, physical - that influence their breakfast-eating behavior?

2. How do staff members at this college-prep high school for underserved students describe the systems and supports designed to promote breakfasteating?

The study took take place over a 10-week time period. The study included school staff and students. All staff members within the school were asked to participate in an online survey designed to provide data on their personal breakfast eating behaviors and attitudes, and on their perceptions of how breakfast eating is promoted in the school. Additionally, individual interviews were conducted with key members of the school staff, including teachers, coaches, administration, clerical and food service. Student participants included 14 high school students who were recruited to take part in two qualitative data gathering components of the study: focus groups and DAHSSBT. Two focus groups were conducted, each with seven student participants. The first focus group included only female students, while the second focus group included both male and female students. The rationale for conducting an all-female focus group was based on research literature that suggests weight-related issues are prevalent among female breakfast-skippers (Rampersaud, 2009; Reddan et al., 2002). It was my feeling that female students may feel more at ease discussing weight issues among other females than in a mixed-gender group. However, I was interested in having a mixed-gender group as a comparison to the female group, and to explore differences between the all-female and 
mixed-gender focus groups. All students participating in the focus groups were asked to complete a DAHSSBT, a drawing exercise provide another source of qualitative data, and modeled after the Draw-A-Scientist Test (Chambers, 1983). The data collected from the staff survey were coded using descriptive statistics, interviews, and student focus groups, and DAHSSBT were coded using descriptive statistics for the qualitative data, and In Vivo and pattern coding for the quantitative data. Then, thematic coding was used as a second cycle coding method and thematic networks were created. The thematic networks were used along with the theoretical framework as tools to analyze the data and to answer the research questions. Table 1 illustrates how the data collection methods align with the research questions.

Table 1

Research Question Alignment With Data Collection Methods

Research Questions

1. How do students at this college-prep high school for underserved students describe the factorssocial, economic, physical-that influence their breakfast-eating behavior?

2. How do staff at this college-prep high school for underserved students describe the systems and supports designed to promote breakfast eating? $\begin{array}{llll}\text { Staff } & \text { Staff } & \text { Student } & \text { DAHSSBT } \\ \text { Survey } & \text { Interviews } & \text { Focus } & \\ & & \text { Groups } & \end{array}$

X $\quad \mathrm{X}$

\section{Study Limitations}

The limitations of the study included recruitment of students for the focus groups, which was based on one teacher's selection of students. The study included only senior, 
junior, and sophomore students who had been at the high school in previous years and had the ability to compare between the previous and the current nutrition service director and staff. This study did not take into account the nutritional content or food quality of breakfast foods consumed outside of the school's breakfast program.

\section{Definition of Key Concepts}

In the following section, I define the key concepts used in my dissertation. These definitions, while possibly familiar to some readers, should help provide a deeper understanding of the dissertation subject matter.

Achievement Gap: The term achievement gap is generally understood to mean to the disparities in school performance, standardized test scores and graduation rates between minority, and recent immigrant, and nonminority students (Haycock, 2001; Ladson-Billings, 2006).

Adolescence: The term adolescence refers to the complex physical, developmental, and social period of transition in the human lifespan, and is usually associated with the adolescent years, roughly corresponding to the span between 10 and 19 years of age (Story, Neumark-Sztainer, \& French, 2002).

Breakfast Consumption: There is not consistency in the definition of the term breakfast consumption in the literature (Rampersaud, 2009). Therefore, the definition of breakfast eating used in this study is the first food and/or beverage consumed after sleep and that consists of at least two food groups.

Breakfast Skipping: In the breakfast literature, varying definitions of the term breakfast skipping are found. The definition for breakfast skipping that will divided into 
two categories: (a) a breakfast skipper will eat breakfast one or fewer times per week (Keski-Rahkonen, Kaprio, Rissanen, Virkkunen, \& Rose, 2003) ; (b) and an irregular breakfast eater will skip breakfast at least once per week (Sjöberg, Hallberg, Höglund, \& Hulthén, 2003).

Childhood Obesity: Defined as "abnormal or excessive fat accumulation that presents a risk to health" (World Health Organization, n.d., para. 1)., childhood obesity is one of the most serious public health challenges of the 21 st century, and the prevalence has increased at an alarming rate. Overweight and obese children are likely to stay obese into adulthood and more likely to develop noncommunicable diseases like diabetes and cardiovascular diseases at a younger age. Overweight and obesity, as well as their related diseases, are largely preventable (World Health Organization, n.d.).

Food Insecurity: Food Insecurity — as defined by the USDA—is a household-level economic and social condition of limited or uncertain access to adequate food. In contrast, hunger, a word often used interchangeably with food insecurity, is an individual-level physiological condition that may result from food insecurity. Food insecurity may also be characterized by reduced food intake resulting in disrupted eating patterns by some or all members of a household. According to the USDA, food insecurity is more likely among households with incomes near or below the Federal poverty line, households with children headed by single women or single men, and Black- and Hispanic-headed households (USDA Economic Research Service, 2017).

Health Disparities: The term health disparities is broadly defined as preventable differences in the burden of disease, injury, violence, or opportunities to achieve 
optimal health that are experienced by socially disadvantaged populations. Health disparities negatively affect groups of people who have systematically experienced greater social or economic obstacles to health (Centers for Disease Control and Prevention, 2008).

Healthy, Hunger-Free Kids Act of 2010: The term Healthy, Hunger-Free Kids Act refers to the 2010 legislation reauthorizing child nutrition federal school meal and child nutrition programs funding, and increases access to healthy food for lowincome children. The Healthy, Hunger-Free Kids Act allowed USDA the opportunity to make real reforms to the National School Lunch and School Breakfast Programs by improving the critical nutrition and hunger safety net for millions of children (USDA FNS, 2017b).

School Breakfast Program: The term School Breakfast Program refers to the U.S. federally assisted meal program operating in public and nonprofit private schools and residential childcare institutions. The School Breakfast Program is administered at the federal level by the Food and Nutrition Service. At the State level, the program is usually administered by state education agencies, which operate the program through agreements with local school food authorities. School districts and independent schools that choose to take part in the School Breakfast Program receive cash subsidies from the USDA for each meal they serve. In return, they must serve breakfasts that meet federal requirements, and they must offer free or reduced-price breakfasts to eligible children. The School Breakfast Program is available to all students at participating schools. School breakfasts must meet the meal pattern and nutrition standards based on the latest Dietary Guidelines 
for Americans; however, decisions about which specific foods to serve, and how the food is prepared, are made by local school food authorities (USDA FNS, 2017a).

Strategies such as providing breakfast free to all students and alternative meal service models that contrast with the traditional school breakfast delivery practice of providing breakfast in the cafeteria before school include: Universal Breakfast program; Provision 2; Community Eligibility Provision; Breakfast After the Bell; Breakfast in the Classroom; Grab-n-Go Breakfast; and, Second Chance Breakfast.

Breakfast After the Bell: Breakfast after the bell refers to an alternative service model that allows breakfast to be served after the school day begins, making it more accessible and a part of the regular school day. In the state of Oregon, legislation allows schools to count 15 minutes of instructional time for students to eat breakfast in the classroom. Schools generally use one or more of three options when offering breakfast after the bell: (a) Breakfast in the Classroom, (b) Grab-n-Go Breakfast, (c) and Second Chance Breakfast (Food Research and Action Center, 2018).

Breakfast in the Classroom: The term breakfast in the classroom refers to the alternative breakfast practice of meals delivered to the classroom and eaten in the classroom at the start of the school day. Often breakfast is brought to the classrooms from the cafeteria by students via insulated rolling bags, or served from carts in the hallways by school nutrition staff using mobile service carts. Breakfast consists of easy-to-eat and easy-to-clean items, such as breakfast sandwiches or burritos, low-fat muffins or cereals, plus milk and fruit or juice. Breakfast in the classroom typically takes 10-15 minutes to 
prepare, eat, and clean up. It can happen simultaneously with morning tasks such as attendance (Food Research and Action Center, 2018).

Grab-n-Go Breakfast: The term grab-n-go breakfast refers to the alternative breakfast practice that allows children (particularly older students) to grab the components of their breakfast quickly from carts or kiosks in the hallway or the cafeteria line to eat in their classroom or in common area (Food Research and Action Center, 2018).

Second Chance Breakfast: The term second chance breakfast refers to an alternative breakfast practice in which students are offered a second chance to eat breakfast after homeroom or first period (Grab-n-Go style). Research indicates that many middle and high school students may skip breakfast because they are not hungry first thing in the morning (Mullan et al., 2014; Reddan et al., 2002; Sweeney \& Horishita, 2005). Serving these students breakfast after first period may provide them the opportunity to get a nutritious start to the day (Food Research and Action Center, 2018).

Community Eligibility Provision: The term Community Eligibility Provision refers to a meal service option for schools and school districts in low-income areas. A key provision of the Healthy, Hunger-Free Kids Act of 2010, Community Eligibility Provision, allows the nation's highest poverty schools and districts to serve breakfast and lunch at no cost to all enrolled students without the burden of collecting household applications. Instead, schools that adopt Community Eligibility Provision are reimbursed using a formula based on the percentage of students participating in other specific means- 
tested programs, such as the Supplemental Nutrition Assistance Program and Temporary Assistance for Needy Families (Logan et al., 2014).

Provision 2: The term Provision 2 refers to a School Breakfast Program and National School Lunch Program option for schools to reduce the paperwork and simplify the logistics of operating school meals programs. Provision 2 enables schools and institutions to provide free meals without the burden of collecting applications and tracking and verifying school meal data every year. Provision 2 may be a good strategy for schools with a high percentage of low-income students (75\% or higher) (USDA FNS, 2002).

School Breakfast Participation: The term school breakfast participation is used to refer to the number of students who eat breakfast at school. Participation differs from eligibility, which refers to low-income students who are eligible to receive breakfast at a free or reduced-price, and is known by the acronym FRL, derived from free and reducedprice lunch (Bartfield, 2010).

Universal Breakfast: Universal School Breakfast can be broadly defined as any program that offers breakfast at no charge to all students, regardless of income status. On average, nationally only 47 children eat free or reduced-price school breakfast for every 100 who receive free or reduced-price school lunch. Studies show that Universal School Breakfast Programs significantly increase student participation in the School Breakfast Program (Bernstein, McLaughlin, Crepinsek, \& Daft, 2004). 


\section{CHAPTER 2: LITERATURE REVIEW}

In this chapter, I examine the existing literature relevant to the purpose of the study, which is to explore factors influencing participation in the School Breakfast Program for culturally diverse high school students within a school serving a predominately low-income population. In this literature review, I begin with a description of the theoretical framework, an integrated composite framework that combines social cognitive theory with ecological systems theory. In this chapter, I also include a review of the literature that has used this theory to understand adolescent eating behavior and the school food environment, why I chose to use it, and how it has been used in the previous research. In this chapter, I examine the literature within four topic areas: (a) breakfast and learning, (b) food insecurity (c) breakfast eating, and (d) breakfast skipping.

This literature review provides a synthesis of the literature on each of these topics raises questions and identifies existing gaps. The literature included in the review is a combination of peer-reviewed social science and natural science literature, as well as foundation-, nonprofit-, and government-funded documents that draw from peerreviewed research studies. Several of the studies used are systematic research reviews, but for the most part the research reviewed includes individual studies using a quantitative research design. I also examine and discuss the methodological literature, including limitations. 


\section{Theoretical Framework}

Theoretical frameworks are useful in providing insight into the factors that influence eating behaviors and food choice. Use of an appropriate theoretical framework can help explain and predict the proclivity of adolescent eating behaviors, the influences of external factors on food choice, and the impact of interventions on changing eating behaviors. Bandura's social cognitive theory (Bandura, 1998, 2004; Cooper et al., 2011; Cooper et al., 2012; Cusatis \& Shannon, 1996; Lorig et al., 2001; Lorig et al., 1999; Neumark-Sztainer et al.,1999; Reddan et al., 2002) and Bronfenbrenner's Ecological Systems Theory (Bronfenbrenner, 1977, 1979, 2009; Glanz, Rimer, \& Viswanath, 2008; Lindström \& Eriksson, 2006; Richard, Gauvin, \& Raine, 2011; Sallis et al., 2006) are two theories that frequently appear in health education and eating behaviors literature. In this paper, I borrow from Story et al. (2002) and use an integrated composite framework that

combines social cognitive theory and ecological systems theory to explain the factors that influence adolescent eating behavior (Story et al., 2002).

\section{Integrated Composite Framework}

The integrated composite framework combining social cognitive theory and ecological systems theory that I used for the theoretical framework in this study was developed and used by Story et al. (2002) in a study of the individual and environmental influences on adolescent eating behavior. I chose this particular conceptual model because it allowed me to examine eating behavior through multiple socioenvironmental and personal factors. Social cognitive theory can be described as in terms of a three-way dynamic interaction between environmental influences, personal factors, and behavior. 
Social cognitive theory provides an especially useful theoretical model for exploring the multiple influences that have an impact on food behavior of adolescents within a specific environment (Baranowski, Perry, \& Parcel, 2002). On the other hand, Bronfenbrenner's (1979) Ecological Systems Theory is equally important to this study. Bronfenbrenner's model provides an ecological perspective that considers the connections between the people and their environments through multiple levels of influence (Bronfenbrenner, 1979).

Integral to the composite framework, and to each individual theoretical frameworks - social cognitive theory and ecological systems theory - is the theory of reciprocal determinism, meaning that individual behavior both influences and is influenced by personal factors and the social environment (Glanz, Rimer, \& Lewis, 2002; McLeroy, Bibeau, Steckler, \& Glanz, 1988). Reciprocal determinism is a fundamental aspect to the integrated model applied to this study in terms of understanding how both cognitive processes and the social environment influence attitudes and beliefs and influence behavior, especially in a school environment that has made attempts to make school breakfast accessible to all students. An example of reciprocal determinism can be found in a study that compared the perceptions of breakfast between students in schools that served universal school breakfast and those that did not (Reddan et al., 2002). In this study, the environmental factors were changed to allow free access to the program for all students, not just for those who could not afford to pay. This social change, making breakfast equally free to all students made breakfast more accessible to all students in the school and resulted in an increase of students served across income groups. In doing so, 
even more students are likely to participate in the School Breakfast Program, as stigma about the program being for poor children is lessened. Ultimately, students coming from food insecure homes will access a safe, socially welcoming, and nutritionally nurturing food environment.

Because there has been only one previous study to date, that I am aware of, using this combined theoretical model, I have included a review of research similar to this study that have used either social cognitive theory or ecological systems theory as the theoretical frame.

Social cognitive theory. Social cognitive theory is based on the premise that human behavior is the product of the dynamic exchange between personal, behavioral and environmental influences (Bandura, 1977). Social cognitive theory is supported by a plethora of research by Albert Bandura, Professor Emeritus at Stanford University, known as the originator of social cognitive theory. Formerly known as social learning theory, social cognitive theory bridges behaviorism and cognitive psychology. As shown in Figure 2, Bandura's social cognitive model demonstrates the three dynamic and reciprocating factors that he believes are responsible for how people acquire and maintain certain behavioral patterns: environment (external to the individual); personal factors (cognitive, biological, etc.); and behavior. In this model, behavior is not simply the result of the environment and the individual, just as the environment is not simply the result of the person and behavior (Glanz et al., 2002). 


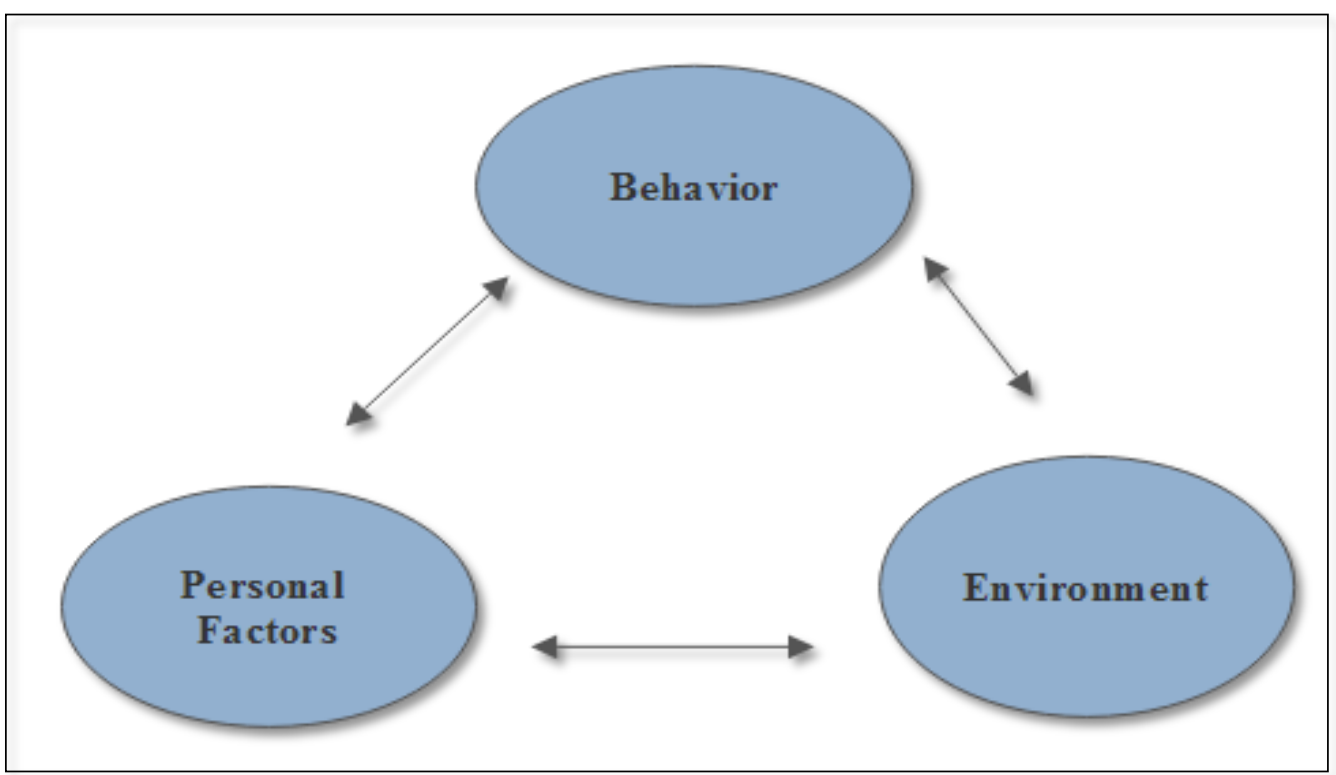

Figure 2. Bandura's Social Cognitive Theory Model. Source: Bandura (1977). This figure illustrates the dynamic interplay between behavior, environment, and personal factors that reflect how people acquire and maintain certain behavioral patterns.

Social cognitive theory is effectively used in the health behavior literature to predict health behaviors and incite behavior change (Bandura, 1986; Bandura, 1997; McAuley, Jerome, Elavsky, Marquez, \& Ramsey, 2003; Saksvig et al., 2005; Sallis, Calfas, Alcaraz, Gehrman, \& Johnson, 1999). Social cognitive theory is often used to explain eating behavior, and has been used to understand the food choices and breakfast behavior of adolescents (Mirzaei, Ghofranipour, Ghazanfari, \& Ahmadi Vasmehjini, 2016; Neumark-Sztainer et al., 1999; Reddan et al., 2002).

Core constructs of this framework include self-efficacy, outcome expectations, self-regulation, and perceived impediments and facilitators of behavior (Bandura, 2004). In this study, self-efficacy (an individual's belief to change his or her behavior), and environmental influences that serve to impede and facilitate behavior of students and 
staff, were explored. In a recent study of the breakfast eating behavior of elementary school students, Mirzaei et al. (2016) found that social cognitive theory was an effective theoretical framework for predicting the breakfast eating behavior in children.

Ecological systems theory. Bronfenbrenner first introduced the ecological paradigm in the 1970s (Gauvain \& Cole, 2004). The ecological systems frameworks conceptualize the connection between the individuals and the levels of influence of their environments. In Bronfenbrenner's model, environmental influences are separated into four different levels: microsytems, mesosystems, exosystems, and macrosystems. This model is often depicted as a series of concentric circle with the individual at the center, or in a three-dimensional sense, a set of nested spheres, with each sphere representing a different level of influence (see Figure 3).

The level most proximal to the individual—-the microsystem—represents the intrapersonal relationships of the individual with family, peers, and teachers. The microsystem is where the most direct one-on-one influence often occurs. Moving out from the center, the mesosystem is the next level. The mesosystem represents the interrelationship among the various places where the individual is involved in daily activities such as school, work, church, and home. The exosystem, the next layer, refers to community norms and values including indirect influences such as marketing and media. Finally the outermost, macrosystem level, refers to the social structure created through the interrelationship of culturally-held beliefs, economic systems and political values (Bronfenbrenner, 1977). The four spheres of influence in Bronfenbrenner's model can be used to demonstrate the influence that each system has on eating behaviors (Story, 
Kaphingst, Robinson-O’Brien, \& Glanz, 2008). The ecological systems theory model allows the reader to situate an individual high school student within a social and ecological context to understand the multiple levels of influence from the microlevel systems to large political, economic and cultural forces at the macro level. Table 2 illustrates breakfast-eating influences of high school students using Bronfenbrenner's (1979) Ecological Systems Theory model.

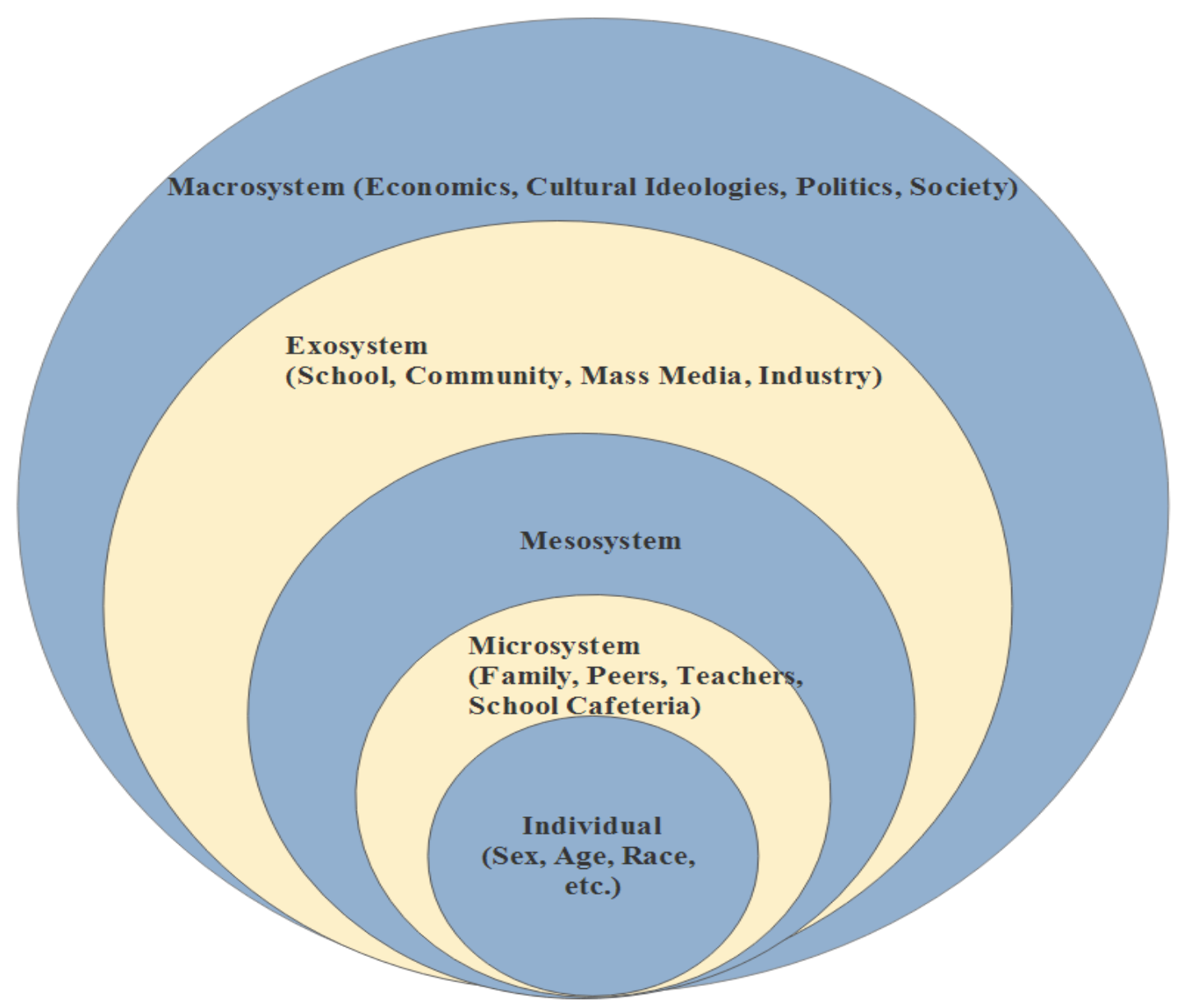

Figure 3. Bronfenbrenner's Ecological Systems Theory model. Source: Bronfenbrenner (1979). This figure illustrates the multiple levels of influence on an individual's attitudes and behaviors. 
Table 2

Conceptual Applications of Bronfenbrenner's Ecological Systems Theory Model on Breakfast-Eating Influences of High School Students

\begin{tabular}{|c|c|c|}
\hline $\begin{array}{l}\text { Level of } \\
\text { Influence }\end{array}$ & Description & Examples of Influential Activities \\
\hline Individual & $\begin{array}{l}\text { Unchanging qualities and } \\
\text { characteristics of the } \\
\text { individual }\end{array}$ & $\begin{array}{l}\text { Gender, age, genetic make-up, position in family, } \\
\text { economic-status, knowledge, geographic location (e.g. } \\
\text { rural, suburban, urban, etc.), food preferences (e.g. taste, } \\
\text { association, or tightly-held belief system), self-efficacy, } \\
\text { body image }\end{array}$ \\
\hline Microsystem & $\begin{array}{l}\text { Most proximal contexts } \\
\text { where the individual } \\
\text { engages directly with } \\
\text { others }\end{array}$ & $\begin{array}{l}\text { Family food security, family meals frequency, peer } \\
\text { influence, role modeling, nutrition education, and } \\
\text { adolescent rebellion }\end{array}$ \\
\hline Mesosystem & $\begin{array}{l}\text { Linkages among } \\
\text { mircrosystems }\end{array}$ & $\begin{array}{l}\text { Availability of food where adolescents spend their time, } \\
\text { such as family food purchases, acceptability of school } \\
\text { food, fast and convenience food accessibility }\end{array}$ \\
\hline Exosystem & $\begin{array}{l}\text { Factors within the larger } \\
\text { social system in which } \\
\text { the individual exists }\end{array}$ & $\begin{array}{l}\text { How food is produced and distributed, media and food } \\
\text { and beverage marketing, built environment (e.g. zoning, } \\
\text { school nutrition standards, policies and practices that } \\
\text { influence which foods are accessible, affordable and } \\
\text { desirable) }\end{array}$ \\
\hline Macrosystem & $\begin{array}{l}\text { Cultural and societal } \\
\text { forces }\end{array}$ & $\begin{array}{l}\text { Culturally-based beliefs, economic and political systems } \\
\text { (e.g. Farm bill, Federal Trade Commission and other } \\
\text { federal policies governing food availability, price, and } \\
\text { advertising) }\end{array}$ \\
\hline
\end{tabular}

Source: Bronfenbrenner (1979).

\section{Summary of the Theoretical Framework Literature}

Developed and used by Story et al. (2002), I have found that the integrated composite framework combining social cognitive theory and ecological systems theory was used in only one previous study to date. However, it was effectively used in the previous study and to explore the individual and environmental influences on adolescent eating behavior, which is exactly what I wanted to examine in my study. The integrated 
composite framework contributed important aspects of both social cognitive theoryespecially (a) outcome expectations, and (b) and environmental influences that serve to impede and facilitate behavior — and ecological systems theory — using the four spheres of influence to demonstrate the impact that each system has on eating behaviors.

Although many of the health behavior and nutrition studies using social cognitive theory were interested in behavior change, in this study I was most interested in understanding behavior. I was drawn to social cognitive theory by the interplay of behavior, environment, and personal factors. I feel this model provides a very good lens in which to view my study.

I am much more familiar with Bronfenbrenner's $(1977,1979)$ Ecological Systems Theory as I have used it throughout my career in public health. I feel that this model provided the other half of the lens I needed to explore fully the systems, policies, and various levels of influence on students' breakfast eating behavior.

\section{Review of the Research Literature}

In this literature review, I provide a brief overview of the research literature on the methodology used in my study, and then examine the specific content literature within four topic areas: (a) breakfast and learning, (b) food insecurity, (c) breakfast eating, and (d) breakfast skipping. The first section, breakfast and learning, includes two subsections, one on the effects of breakfast on cognition, and the other includes research on breakfast and behavior. The next section focuses on the educational and health significance of food insecurity, while the third section, labeled breakfast eating, covers the research literature on diet quality, and participation in the School Breakfast Program. 
The last section, breakfast skipping, is divided into adolescent eating behaviors and breakfast skipping. Figure 4 provides and overview of the student breakfast literature review and how these topics are interrelated.

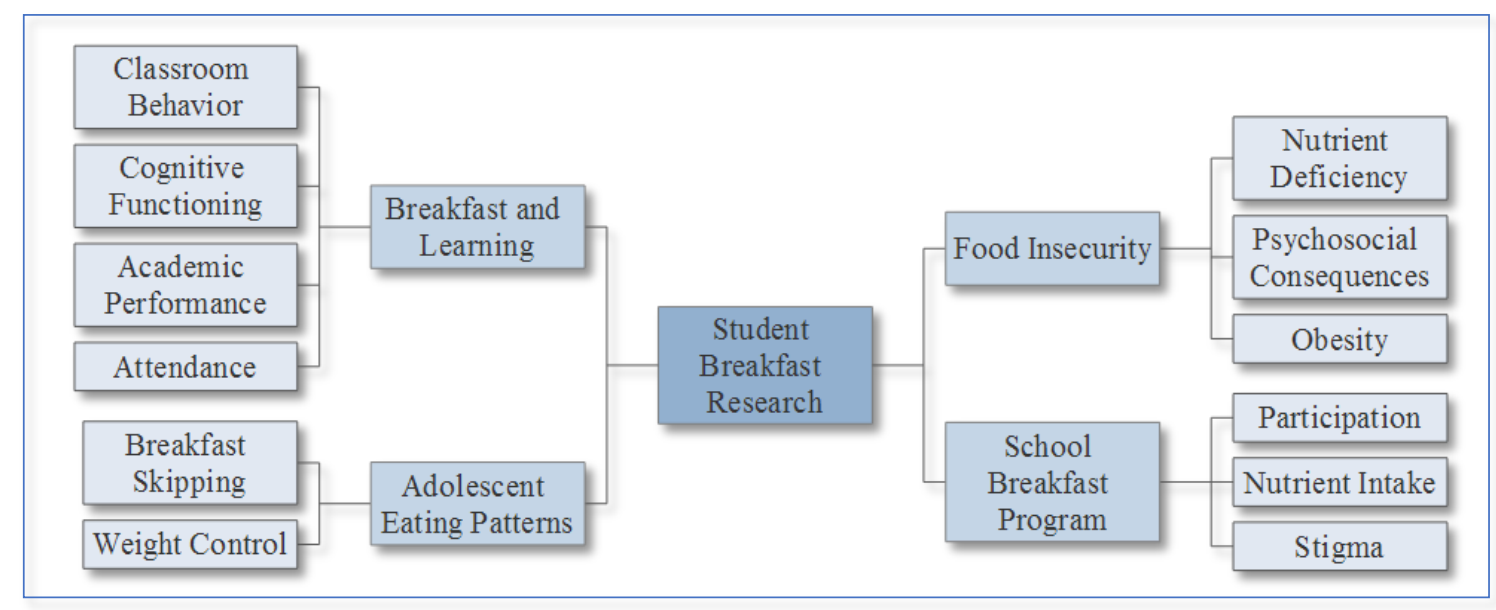

Figure 4. Overview of student breakfast research components. This figure illustrates the student breakfast research reviewed in this chapter.

\section{Methodology}

The majority of the research literature reviewed is exclusively quantitative or qualitative studies: however, Spruance, Harrison, Brady, Woolford, and LeBlanc (2018) used a mixed-methods design to understand school breakfast participation by exploring parent attitudes. Although not common in the school breakfast research literature, case studies have been used, although most have been done on a larger scale using a district or a state as the case study (Askelson, Golembiewski, Bobst, Delger, \& Scheidel, 2017; Boschloo et al., 2012; Rainville \& Carr, 2008). Several studies, similar to my study, successfully used focus groups as a data collection method for gaining information on adolescent and school staff attitudes pertaining to nutrition and school meal programs 
(Cullen, Eagan, Baranowski, Owens, \& de Moor, 2000; Haesly, Nanney, Coulter, Fong, \& Pratt, 2014; Livingood et al., 2017; Neumark-Sztainer, 2006). Finally, the use of a thematic approach to analyze and interpret the research findings is supported by several studies exploring breakfast consumption and perceptions of the School Breakfast Program (Askelson et al., 2017; Bailey-Davis et al., 2013; Spruance et al., 2018; Stevenson, Doherty, Barnett, Muldoon, \& Trew, 2007).

\section{Breakfast and Learning}

This section will provide a review of the research literature on breakfast and learning, and is divided into two distinct subsections: (a) the influence of breakfast on cognitive of ability, and (b) the impact of breakfast on behavior. In this section, and within the entire literature review, there are continuous references to studies on breakfast eaten at home or on the way to school, and studies that examine the School Breakfast Program. In this paper, I use "breakfast" to refer to food eaten anywhere and anytime in the morning, and I refer to the School Breakfast Program, or use the term "school breakfast" to refer only to breakfast served at school as part of the School Breakfast Program. In the case of the research literature, studies of school breakfast look at schoolwide or individual student participation in the School Breakfast Program (Murphy, 2007).

The effects of breakfast on cognitive functioning. Four large studies reviewing the literature on breakfast and learning occurred between 2005 and 2013. Although many of the same studies were included in the various reviews, the reviewers employed different methodologies, and each review varied slightly in the scope of the issues being reviewed. The effect of breakfast on cognition and academic improvement was 
considered in each of the four reviews (Adolphus et al., 2013; Hoyland et al., 2009; Murphy, 2007; Taras, 2005). Although some of the individual studies' findings provided mixed results, overall, the reviews indicate that breakfast eating has a positive outcome on cognition and educational achievement. Some of the most comprehensive and complex evidence on breakfast and cognitive impact come from evaluations of universal school meals in the United States and Breakfast Clubs in England, which like the United States provide breakfast to all students, but typically meet other needs like childcare, tutoring, and social services (Murphy, 2007). Standardized cognitive tests were used in the English evaluations, but not the evaluations of U.S. Universal Breakfast studies (Murphy, 2007). After a three-month trial, the English studies found that students who had been randomly assigned to Breakfast Clubs scored better on standardized cognitive tests than those in the control group who's schools did not have breakfast clubs available (Reitan, 1992). During relatively the same time period, large school breakfast trials were conducted in Baltimore, Maryland and the state of Minnesota. Both trials concluded that test scores, and other educational outcomes, improved more in schools that provided universal School Breakfast Programs than in control schools; however, these studies were not conclusive as the influence of confounding variables could not be ruled out (Murphy et al., 2000; Peterson et al., 2004). The authors of the studies discussed the methodological complications of using test data, but noted that the overall results of standardized test scores were positive for the students in schools serving universal school breakfast as compared to the control schools. Similarly the overwhelming response from 
school administrators and teachers surveyed was that they believed that the program had a positive academic impact (Murphy, 2007; Murphy \& Pagano, 2001).

A 2005 review of 18 peer-reviewed articles (Taras, 2005), published after 1980 and related to child and adolescent nutrition and its potential effect on school performance, was one of the first to look at the evidence on breakfast eating and participation in the School Breakfast Program with cognitive functioning and academic performance. Taras (2005) concluded students with iron deficiency anemia are at a disadvantage academically; School Breakfast Programs seem to improve school attendance and decrease tardiness; offering a healthy breakfast is an effective measure to improve academic performance and cognitive functioning among undernourished populations; and that food insufficiency is a serious problem affecting children's ability to learn but that its relevance in U.S. populations needs to be better understood.

In a systematic review of the nutrition research literature, Hoyland et al. (2009) examined 45 studies related to the effect of breakfast on the cognitive effect of children and adolescents. Twenty-eight of these studies focused on the acute effects of breakfast or no breakfast on cognitive performance, which were further broken down into studies on well-nourished children $(n=21)$ and children in differing nutritional status $(n=7)$ (Hoyland et al., 2009). Few good quality studies examining the cognitive performance of school-age children were identified in the review, and the majority of the studies reviewed were sponsored in-whole or in-part by industry invested in children's breakfast eating like cereal companies. Hoyland et al. concluded that, overall, the findings from short-term studies on breakfast and cognition and longer-term School Breakfast Program 
suggest that breakfast consumption has generally positive effects on cognitive performance in comparison with eating no breakfast. They also noted that the breakfast effects are more apparent in nutritionally vulnerable students. However, they also concluded that the beneficial effects of the School Breakfast Program may be more likely an effect of better attendance and reduced absenteeism.

In another literature review, Adolphus et al. (2013) examined breakfast on behavior and academic performance in children and adolescents using articles published between 1950 and 2013. This review included 36 studies, spanned a 60+ year timeframe, and included 4 years of articles that had not been previously part of any other systematic review. Evidence from this review indicated that School Breakfast Programs and habitual breakfast eating have a positive influence on students' academic performance with the clearest effects on mathematics in undernourished children (Adolphus et al., 2013). Adolphus et al. concluded that positive changes in cognitive functioning might be due to nutritional improvements through fortification of breakfast products, especially iron and iodine, which have been implicated in improving cognitive function. Similar to Hoyland's earlier conclusion, Adolphus et al. suggested that behavioral changes, like improved attendance, are partially responsible for the improvements seen in test scores and academic performance.

Although the mechanism regarding breakfast and cognition is not well understood, it may be a simple explanation, such as students who are not preoccupied with hunger are much better able to listen to their teacher and concentrate on their schoolwork (Hoyland et al., 2009). Furthermore, increasing breakfast consumption was 
noted as one of seven strategic priorities that schools can take to address the achievement gap based on relevance to educational outcomes (Basch, 2011a).

The effects of breakfast on behavior. Many of the reviews that examined cognitive functioning also examined the effects of breakfast on psychosocial functioning. For the purpose of this literature review, studies that fall into this category are referred to as behavior and include mental health, peer relations, behavior at school, and attendance.

As mentioned in reference to decreased tardiness and absenteeism, the effect of cognitive and behavioral functioning are not independent, and changes in one area may be reflected by changes in in the other, and influence overall academic performance. Most of the findings on breakfast and behavior come from studies of the School Breakfast Program and the reviews that both Adolphus et al. (2013) and Hoyland et al. (2009) called out as the least scientifically rigorous of the studies reviewed. In a study of 40 Maryland schools, school suspensions decreased significantly after implementing Universal Breakfast (Murphy \& Pagano, 2001). Similar to what was previously noted in the review of breakfast and cognition literature, improved attendance, due to decreases in both absenteeism and tardiness, has been suggested as a factor in the improved academic performance attributed to School Breakfast Programs (Adolphus et al., 2013; Hoyland et al., 2009; Pollitt \& Mathews, 1998; Rampersaud et al., 2005; Taras, 2005).

Of the 19 studies reviewed by Adolphus et al. (2013) on breakfast and behavior, 11 studies demonstrated a positive effect, mainly for on-task behavior in the classroom that was similar for all children, regardless of socioeconomic status or income, although no effect was found for students with pre-existing behavior problems like Attention 
Deficit Hyperactivity Disorder (Adolphus et al., 2013). Adolphus et al. concluded that the on-task behavior related to eating breakfast might indicate that children who eat breakfast are more able to concentrate and therefore stay on task.

An exploration into the research literature on breakfast exposes a major limitation in determining accuracy of studies and comparing the breakfast studies within this review and within the systematic reviews published in the literature. There is no consistency between studies in the way that breakfast is defined, and there are multiple ways data are collected based on the definition used for breakfast and breakfast skipping behavior. Rampersaud (2009) pointed out that in some studies breakfast consumption is assessed using a 24-hour recall, or a 1-day dietary survey, while other studies defined breakfast consumption on a frequency basis such as a specific number of days per week. In addition, the majority of studies that looked at academic outcomes are cross-sectional and adjusting for cofounders is critical. Social economic status is a potential cofounder and is associated with student eating behavior, academic performance, and cognitive ability. Some of the studies failed to adjust for social economic status or used various proxy measures that may be inadequate (Adolphus et al., 2013).

\section{The Educational and Health Impact of Food Insecurity}

The literature clearly demonstrated the adverse educational and health outcomes of food insecurity in childhood and adolescence. As a reminder, food insecurity is defined as is a household-level economic and social condition of limited or uncertain access to adequate food, and may also be characterized by reduced food intake resulting in disrupted eating patterns by some or all members of a household (USDA Economic 
Research Service, 2017). In the United States, the same demographic populations often experience both poverty and food insecurity; however, this is not always the case. Individuals experiencing food insecurity are not always poor, and poor individuals are not always food insecure (Nord, Andrews, \& Carlson, 2005).

Students struggling with food insecurity demonstrate academic struggles ranging from poor academic performance, social delays, grade repetition, and need for special education services (Alaimo et al., 2001; Dunifon \& Kowaleski-Jones, 2003; Jyoti, Frongillo, \& Jones, 2005; Kleinman et al., 1998; Olson, 1999; Winicki \& Jemison, 2003). Additional research documents an increase in behavioral problems such as anxiety, fighting with other children, being in trouble at school, and suicide attempts (Olson, 1999; Slack, Holl, McDaniel, Yoo, \& Bolger, 2004; Slopen, Fitzmaurice, Williams, \& Gilman, 2010).

Jyoti et al. (2005) indicated that the educational and social impact of food insecurity might be more apparent in females. This study suggested that the negative effects of food insecurity on reading and math scores were found to be more severe for girls than for boys. Furthermore, they found that children who transitioned from food insecurity to food security demonstrated improved social skills, with greater gains for girls than boys; and that among girls only, there were smaller increases in reading scores for those who were persistently food insecure than for those who were persistently food secure (Jyoti et al., 2005).

A review of the research literature on food insecurity revealed far fewer studies exist on the effects of adolescent food insecurity as opposed to those focused on younger 
children or the number of studies that combine younger children with adolescents. Alaimo et al. (2001) documented the psychosocial consequences of adolescent food insecurity reporting that food insecure teens are three times more likely to have been suspended, twice as likely to have mental health counseling, twice as likely to have difficulty getting along with others, and four times as likely to have no friends. In a second study, Alaimo, Olson, and Frongillo (2002) suggested that food insecure adolescents and have higher rates of dysthymia (chronic depression) and suicidal thoughts. A study of adolescents in rural communities indicates that poorer health status, lower grades, and less exercise is associated with food insecurity, when food insecure and food secure rural adolescents are compared (Shanafelt, Hearst, Wang, \& Nanney, 2016). A large qualitative study by Slopen et al. (2010) described the externalizing disorders (problem behavior) and internalizing disorders (anxiety) associated with food insecurity in youth. Slopen et al. conducted interviews with 2,810 youth between the ages of 4 and 14 years at baseline, and 5 and 16 years at follow-up, concluding that persistent food insecurity is associated with internalizing and externalizing problems, even after adjusting for poverty and other potential confounders. They suggested that food insecurity may be a potential risk factor for child mental wellbeing, and, if causal, may be an important factor in mental health prevention.

A recent qualitative study conducted for Feeding America (2014) indicated that adolescent food insecurity is widespread; yet, the stigma around food insecurity is so shameful that adolescents actively try to hide it. Consequently, many adolescents refuse to accept food or assistance in public settings or from people outside of a trusted circle of 
friends and family. The study suggested that food-insecure adolescents strategize about how to dull their hunger and make food last longer for the whole family. The study described strategies used by adolescents, like staying longer at friends or relatives' houses to eat, and saving their school lunch for the weekend. Findings from focus groups and interviews, indicated that adolescents in food-insecure families routinely take on the role of going hungry so younger siblings can eat, or finding ways to bring in food and money, and at times engaging in risky-behaviors such as shoplifting, drug-selling, and prostitution (Popkin, Scott, \& Galvez, 2016).

From a nutritional point of view, the research literature suggests that food insecurity increases the risk of deficiency of key nutrients (Adams, Grummer-Strawn, \& Chavez, 2003; Casey, Szeto, Lensing, Bogle, \& Weber, 2001; Lee \& Frongillo, 2001; Rose, Habicht, \& Devaney, 1998), which is of critical concern since multi-micronutrients are associated with children's cognitive development (Best, Miller, \& Naglieri, 2011; Leung, Wiens, \& Kaplan, 2011). Limited food access increases the risk of anemia with iron deficiency (Skalicky et al., 2006), and iron deficiencies can remain well into adolescence, suggesting chronic anemia in children raised in food-insecure households (Eicher-Miller, Mason, Weaver, McCabe, \& Boushey, 2009). Food insecurity has been shown to increase the prevalence of diets higher in fat and sugar, and decrease physical activity (Bronte-Tinkew, Zaslow, Capps, Horowitz, \& McNamara, 2007; Fram, Ritchie, Rosen, \& Frongillo, 2015; Jyoti et al., 2005; Shanafelt et al., 2016). Food insecurity is associated with worse overall health status, including more stomachaches, headaches, and colds; more hospitalizations, and reduced physical functioning (Alaimo et al., 2001; 
Bronte-Tinkew et al., 2007; Casey et al., 2001; J. T. Cook et al., 2006; Gundersen \& Garasky, 2012). The link between food insecurity and obesity, often referred to as the "hunger-obesity paradox" (Scheier, 2005), is a popular concept in food security advocacy and the research literature. However, the results from studies on food insecurity and obesity are mixed. While some studies have found a positive association between food insecurity and obesity (Alaimo et al., 2001; Eisenmann, Gunderson, Lohman, Garasky, \& Stewart, 2011; Olson, 1999; Townsend, Peerson, Love, Achterberg, \& Murphy, 2001), other studies, including several longitudinal studies, showed no relationship (Bhargava, Jolliffe, \& Howard, 2008; Gundersen, Garasky \& Lohman, 2009; Gundersen, Lohman, Eisenmann, Garasky, \& Stewart, 2008; Lyons, Park, \& Nelson, 2008). However, review of the research literature indicates that adolescent and adult females who experience food insecurity may be more likely to be obese compared to females with adequate household resources for food (Casey et al., 2006; Jyoti et al., 2005); yet, there is little evidence from longitudinal studies that food insecurity promotes increased weight gain over time (Larson \& Story, 2011).

Three potential mechanisms are acknowledged in the literature to account for the connection between food insecurity and negative academic and health outcomes. The first is the impact of the deficiency of micro-nutrients necessary for healthy growth and development, especially during critical periods in the life-span such as adolescence, pregnancy, and especially early in life (Casey et al., 2001). The second possible mechanism is the effect of maternal stress or depression. Food insecure mothers are more likely to experience depression and anxiety, as compared to food secure mothers, which 
can adversely affect parenting practices (Beydoun \& Wang, 2010; Bronte-Tinkew et al., 2007; Whitaker, Phillips, \& Orzol, 2006). The third proposed mechanism is exposure to a home environment disrupted by the unrelenting nature of hunger and food insecurity. Following the theory of this suggested mechanism, if money is tight for food, it is likely that the budget for other necessities like housing, energy, clothing, transportation, and childcare is also limited, and household turmoil and personal stress are high.

Young people raised in tumultuous or unstable households have a higher risk of decreased physical and psychological health (Brooks-Gunn, Johnson, \& Leventhal, 2010; Evans, Gonnella, Marcynyszyn, Gentile, \& Salpekar, 2005). Research also indicated that early environments that include uncertainty, neglect, and threat lead to greater levels of cortisol, an adrenal hormone activated by stress, and increased risk of chronic disease (Shonkoff \& Levitt, 2010).

From my work in the field, I propose two additional potential mechanisms to the list. The first is stigma and shame that children and adolescents and their family members experience as a result of food insecurity (Fram, Frongillo, Fishbein, \& Burke, 2014; Popkin et al., 2016). This would include the desire to eat what other students have ready access to, while pretending to fit in. The other mechanism, I believe is at play, is the limited access to healthy and affordable food, including fruits and vegetables that commonly plague those living in low-income communities known as "food deserts" (Turrell, Hewitt, Patterson, Oldenburg, \& Gould, 2002). This includes access to fullservice grocery stores, as well as constant exposure to low-cost, aggressively marketed, 
calorie dense foods high in sugar, fat and salt, providing high palatability (Drewnowski \& Specter, 2004).

In summarizing the research literature on food insecurity, it appears that the health and psychosocial factors associated with food insecurity can clearly have an extreme influence on academic performance and the ability for a child or adolescent to attend, succeed, and graduate from school. Although there are relatively few research studies specific to adolescent food insecurity, those that exist are poignant and indicate the need for further research to understand the factors and mechanisms involved. The research literature that exists warrants efforts, like the School Breakfast Program, to prevent and alleviate child and adolescent food insecurity. Furthermore, a clearer understanding of the weight-related research is important because overweight females tend to believe that skipping breakfast is a useful strategy for weight loss (Hearst, Shanafelt, Wang, Leduc, \& Nanney, 2016; Rampersaud, 2009; Rampersaud et al., 2005; Reddan et al., 2002), when in fact it is the opposite, and could further increase weight gain leading to obesity and obesity-related health issues (Cohen, Evers, Manske, Bercovitz, \& Edward, 2003), that can have a lifelong impact on the individual's health as well as well as on the health of her children (Balen \& Anderson, 2007; Boney, Verma, Tucker, \& Vohr, 2005; Drake \& Reynolds, 2010; Kushner, Lawrence, \& Kumar, 2013; Must et al., 1999).

\section{Breakfast Eating and the School Breakfast Program}

In this section of the literature review, I explore the studies that included student breakfast eating both at home and at school. This section includes studies on diet quality 
of breakfast, participation in the School Breakfast Program, and the stigma that may be inherent in participating in federal food security programs.

Diet quality. The research literature on nutrient composition and breakfast quality of children and adolescents in the United States is dated. The most recent comprehensive research is based on a systematic review of four National Health and Nutrition Examination Surveys conducted in 1971-1974, 1976-1980, 1988-1994, and 1999-2000. During this 30-year period of time, mean energy changed little among children ages 1 to 19, except for an increase among adolescent females. The factors attributed to increases in energy intake include increases in the percentage of the population eating away from home (particularly at fast-food restaurants), larger portion sizes of foods and beverages, increased consumption of sweetened beverages, changes in snacking habits, and improved dietary methodology (Briefel \& Johnson, 2004). A cross-sectional analysis study of 711 ninth-grade students, used 24-hour dietary recall as the method to assess their breakfast consumption patterns concluded that important nutritional contribution to total daily intake. Nicklas, Reger, Myers, and O’Neil (2000) found that compared with adolescents who ate breakfast, adolescents who skipped breakfast consumed a higher percentage of energy intake from fats and a lower percentage of energy intake from carbohydrates. Individuals who skipped breakfast also had lower intakes of most vitamins and minerals compared with those who consumed breakfast.

Additionally, the research literature suggests that children and adolescents who eat breakfast are more likely to meet their nutrient needs and have overall healthier diets. Some nutrients, especially vitamin A, vitamin $\mathrm{C}$, riboflavin, calcium, zinc, and iron are 
associated with breakfast consumption (Nicklas et al., 2004; Rampersaud et al., 2005; P. Williams, 2007). Ready-to-eat cereals, milk, eggs, bread, fruit and fruit juices are breakfast foods are common breakfast items consumed by youth (A. M. Siega-Riz, Popkin, \& Carson, 1998; Sweeney \& Horishita, 2005). Children and adolescents who consume ready-to-eat cereal are more likely to meet nutrient requirements for calcium and fiber and have lower blood cholesterol than those not consuming ready to eat cereal (Barton et al., 2005; Song, Chun, Obayashi, Cho, \& Chung, 2005).

School meal programs, including the School Breakfast Program, follow strict meal pattern guidance and nutrition standards that align with the Dietary Guidelines for Americans, and promotes fruits, vegetables, whole grains, low-fat milk; reduced levels of sodium, saturated and trans fat in meals; and meets the needs of school children within their calorie requirements (USDA FNS, 2016). Studies of the School Breakfast Program have demonstrated improved nutritional intake among participants than nonparticipants, as well as a positive effect on overall breakfast eating and dietary intake (Bhattacharya, Currie, \& Haider, 2006; Devaney \& Stuart, 1998; Gleason \& Suitor, 2001). Furthermore, the link between eating school breakfast, and maintaining a healthy weight, is documented in the research literature, participation in the School Breakfast Program, and not the National School Lunch Program, is associated with a lower body mass index (Gleason \& Dodd, 2009). Furthermore, girls from food-insecure families who eat school breakfast, are less likely to be obese compared to their counterparts who do not eat school breakfast (Jones et al., 2003). Taken together, these research findings make an extremely 
strong case in favor of ensuring that all students have access to a healthy, affordable breakfast.

School breakfast participation. The USDA’s School Breakfast Program began as a pilot program in 1966, and during the $2015-2016$ school year, $92.2 \%$ of schools that served the National School Lunch Program, also served breakfast (Food Research and Action Center, 2018). In 2007, less than half of low-income students participated in the School Breakfast Program (Food Research and Action Center, 2018). Since 2007, and the great recession, School breakfast participation has increased among low-income students by 50 percent which is attributed to changes to the program, including direct certification-requiring that all students participating in Supplemental Nutrition Assistance Program are "directly certified" for free school meals_ and the community eligibility provision - the ability of high poverty schools to offer free breakfast and lunch to all students and not collect, process or verify school meal applications or keep track of meals by fee category (Food Research and Action Center, 2018).

Participation in the School Breakfast Program is much less common than participation in the National School Lunch Program, even among children with access to both programs (Bartfeld, 2010). In 2016, average daily participation for the National School Lunch Program was 61\%, while average daily participation for the School Breakfast Program was 26\%. This disparity is even greater when only high school participation rates are considered. The average daily participation rate for the National School Lunch Program for high school students in 2016 was 50\% and the daily average participation for the School Breakfast Program was 15\% (School Nutrition Association, 
n.d.). Poverty has been the strongest predictor of School Breakfast Program participation (Bartfeld, 2010; Murphy, 2007). Participation rates are highest for Black, Hispanic, and rural students (Gleason \& Suitor, 2001). Furthermore, students are more likely to eat breakfast in the morning if they have access to the School Breakfast Program, but participation is almost entirely limited to a subset of the students who eat lunch at school (Bartfeld, 2010).

A study for the Economic Research Service indicated that increasing the convenience of the School Breakfast Program leads to greater participation, specifically serving breakfast in the classroom rather than the cafeteria, and adjusting the time and duration of the breakfast period (Bartfeld, 2010). Moreover, the same study suggests that access to the School Breakfast Program may improve family food security among families at the margin of food insecurity by freeing up resources to feed others in the household, while increasing the likelihood that school children from low-income families eat breakfast in the morning.

A qualitative study exploring food insecurity at school found that secrecy, stigma, and hiding were themes that ran through parent, child, and adolescent data. Both parents and youth reported embarrassment at letting people outside the family know about their hardships. The study indicated that school is a place where students who do not want to be seen as food insecure avoid interactions that would identify their food challenges (Fram et al., 2014). Stigma related to school meals has been documented in other research literature on school meal participation, suggesting that some students who knew they could access food-related help at school, avoided doing so for fear of being seen or 
labeled (Marples, 1995; Poppendieck, 2010). Stigma is a strong determinant, especially for older children who are more aware of social pressure and peer judgment (McLoyd et al., 2009). Making breakfast free for all students appears to increase breakfast participation for all students across the income spectrum, including those already eligible for free meals, suggesting reduction in stigma, rather than price, may be the mechanism responsible for increasing school breakfast participation (Leos-Urbel, Schwartz, Weinstein, \& Corcoran, 2013).

\section{Adolescent Eating Patterns and Breakfast Skipping}

The majority of the breakfast literature examining the academic and behavioral aspects of breakfast, and participation in the School Breakfast Program, has been conducted on younger (elementary) school-age students (Adolphus et al., 2013). However, the research on breakfast skipping behavior has been focused mostly on the adolescent population. Therefore, I believe it is important to begin this section with a focus on the significance of adolescent nutrition, as well as a description of attitudes and dietary behaviors of adolescents during this critical period of life.

Adolescent eating patterns. The period of adolescence is a time of rapid physical, psychosocial, and cognitive change (Neinstein \& Kaufman, 1996; Spear, 2002). Nutritional intake during adolescence is important for growth, long-term health promotion, and the development of lifelong eating behaviors (Story \& Alton, 1996; Story \& Neumark-Sztainer, 1996). Total nutrient needs are higher during adolescence than at any other time in the lifecycle, and nutrient intake and deficiencies during this period may have long-term health implications (Kelder, Perry, Klepp, \& Lytle, 1994; Lipsky 
et al., 2015; Sandler et al., 1985). However, adolescence is recognized as a time when individuals are establishing personal independence and beginning to make many of their own decisions, which may include food (Stevenson et al., 2007). Moreover, adolescent lifestyles, influenced by a desire to fit perceived social norms, combined with a lack of a sense of urgency about long-term effects of nutrition, may contribute to less than optimal eating practices (Story \& Resnick, 1986).

Adolescents have knowledge regarding healthy foods and eating practices, but find it difficult to eat a healthy diet due to time constraints, access to healthy food, and general lack of concern regarding healthy eating recommendations (Croll, NeumarkSztainer, \& Story, 2001). A study found that teens are more likely than younger students to eat breakfast alone (Mullan et al., 2014). Adolescents report that they equate eating unhealthy foods with their peers and eating healthy food with their families (Croll et al., 2001).

Breakfast skipping. Research indicated that the number of children and adolescents who skip breakfast has markedly increased over time (Nicklas, Morales et al., 2004; Siega-Riz et al., 1998). One of the strongest trends in the overall breakfast literature is the decline in breakfast eating as children get older (Affenito et al., 2005; Delva et al., 2006; Devaney \& Stuart, 1998; Nicklas, Morales et al., 2004; Niemeier et al., 2006; Rampersaud et al., 2005; Siega-Riz et al., 1998). Breakfast skipping differs from food insecurity as it occurs across all income groups, and school breakfast may help bridge the relationship between income and breakfast skipping (Bartfeld, 2010). 
Research indicated that breakfast skipping is higher in single parent and low income families, and students who live in urban environments tend to skip breakfast more often than those living in rural environments (Gross, Bronner, Welch, Dewberry-Moore, \& Paige, 2004). The research on minority students has been mixed, possibly because of the multiple socioeconomic, and demographic factors involved with this category. In the literature, researchers reported that sometimes, but not always, minority students have higher rates of breakfast skipping than their white peers (Affenito et al., 2005; Dwyer, 1995; Nicklas, O’Neil, \& Berenson, 1998; Stang, Kong, Story, Eisenberg, \& NeumarkSztainer, 2007; Zapata et al., 2008).

The reasons commonly reported by children and adolescents for skipping breakfast include not having enough time in the morning to eat (Mullan et al., 2014; Reddan et al., 2002; Sweeney \& Horishita, 2005), not hungry or not feeling like eating (Mullan et al., 2014; Reddan et al., 2002; Sweeney \& Horishita, 2005), or would rather sleep (Neumark-Sztainer et al., 1999).

Siega-Riz et al. (1998) found that adolescent females had the highest decline and the lowest rates of breakfast eating. These findings have been supported by more recent research (Berkey, Rockett, Gillman, Field, \& Colditz, 2003; Timlin, Pereira, Story, \& Neumark-Sztainer, 2008; Zapata et al., 2008). Rampersaud et al. (2005) have conducted two thorough reviews of the literature on adolescent breakfast eating habits, nutritional intake, and weight. They found that adolescents, particularly female adolescents, who were engaging in weight loss behavior or who had negative perceptions of their body weight frequently reported skipping breakfast (Hearst et al., 2016; Rampersaud, 2009; 
Rampersaud et al., 2005; Reddan et al., 2002). However, breakfast skipping was not an effective weight loss strategy (Cohen et al., 2003), and on the contrary, meal skipping often led to greater caloric intake later in the day, preventing weight lost and even contributing to weight gain. Simply adding breakfast into the daily routine of obese adult breakfast skippers, reduced both dietary fat intake and impulsive eating (Schlundt, Hill, Sbrocco, Pope-Cordle, \& Sharp, 1992).

Adolescents who skip breakfast tend to eat more snacks between meals, have lower micronutrient. and higher sugar intakes than those who eat breakfast on a regular basis (Sjöberg et al., 2003). A research study, Reddan et al. (2002), exploring students' perceived benefits and barriers to eating school breakfast, found that students in schools with universal school breakfast were less likely to wish they were thinner, to go on a diet, or skip breakfast because it might make them fat, as compared to students in schools without universal breakfast; furthermore, the students with access to universal breakfast were also more likely to believe that eating breakfast would give them energy and help pay attention. Similarly, in a study of rural adolescents, students who reported barriers to eating school breakfast three or more days a week, were less likely to report associated benefits — academic, social, or health status — as compared to students who skipped breakfast 0-2 days per week (Hearst et al., 2016).

As with the breakfast eating literature, the breakfast skipping research is difficult to compare and measure. For example, if using a one-day survey breakfast skipping may be defined as not having breakfast on that particular day, which may not reflect regular breakfast skipping habits; however, if breakfast frequency data is used, breakfast 
skipping may be defined as skipping breakfast on one or more days during a week or a specific time period. In other studies, breakfast skipping may be captured in more qualitative terms like seldom, sometimes, often, and typically (Rampersaud, 2009).

Regardless of the difficulty in capturing the data, the literature strongly suggests that adolescents have higher rates of breakfast skipping than younger children, that urban, and low-income students have a higher prevalence than other youth, with females at the highest risk for breakfast skipping because of because of weight-related beliefs (SiegaRiz et al., 1998). This literature review reflects the importance of decreasing physical and social barriers to the School Breakfast Program, but also the need for increasing efforts to educate students, staff, and parents about the benefits of breakfast to learning and overall health including nutrition and weight. Furthermore, the studies on universal breakfast and perception are promising, and may be a useful strategy in changing social norms around the perception of school breakfast and breakfast-eating behavior in general. More studies are needed to examine how changes in the school environment, such as providing universal school meals and breakfast in the classroom, impact perceptions, attitudes, and behaviors of adolescents.

\section{Summary of Research Literature}

While reviewing the literature, a few issues made comparing findings from studies difficult. The majority of the literature on breakfast eating and the School Breakfast Program, combined elementary and secondary student data, make it difficult to find specific information for adolescents or high school students. Additionally, there is not consistency in the definition, or assessment of frequency, for breakfast consumption 
or breakfast-skipping in the research literature. This results in difficulty comparing the studies' findings. Furthermore, many of the studies in the literature review did not account for nutrient quality of the breakfast consumed. Although my study did not focus on nutrient quality of breakfast eaten outside of the School Breakfast Program, the lack of information on nutrient quality in many of the studies was surprising. I was able to find an abundance of studies on the various breakfast-related topics covered in this study, although there were some gaps in the literature and some of the most thorough studies were over a decade old. However, judging by the number of studies that have been published over the last few years, research on breakfast eating seems to be a rising area of interest.

In the literature review, I established a link between food insecurity and critical health and psychosocial factors that impact a student's ability to succeed in school. The studies reviewed indicate that access to, and participation in, the School Breakfast Program may be an important factor in addressing food insecurity for vulnerable students, and improve classroom learning by improving attendance and concentration. The research literature on adolescent food insecurity and breakfast eating is sparse; however, the findings from existing studies indicate that adolescent students, especially those from low income and urban settings, and especially females, have a high prevalence of skipping breakfast, especially as compared to younger children. Furthermore, despite wide availability, the majority of school age youth, especially high school students, do not participate in the school Breakfast Program. The literature review suggests that the School Breakfast Program can make a meaningful contribution to 
students' health and academic achievement. The literature review also suggests that improving access to the school breakfast can increase participation rates for students across income levels, and decrease stigma for low-income students. However, the literature indicates that adolescents are skipping breakfast at much higher rates than younger students are, and have significantly lower participation in the School Breakfast Program. I conducted this study because it was clear from the literature review that more research was, and still is, needed to understand how best to increase breakfast eating and participation in the School Breakfast Program for all students, especially adolescents. 


\section{CHAPTER 3: METHODS}

In the last chapter, I identified existing research gaps and suggested research questions relevant to the purpose of the study, which is to explore factors influencing participation in the School Breakfast Program for culturally diverse high school students within a school serving a predominately low-income population. In this chapter, I describe the study — a case study — that took place at a high school in the western United States. Using an interactive research design model (Maxwell, 2012) this chapter revisits the purpose of the study and situates it within the appropriate research methodology (qualitative) and conceptual framework (pragmatic). In this chapter, I describe the data collection methods, both qualitative and quantitative, that strengthened the validity of the study, and provided a deeper understanding of the motivators and barriers to participation in the School Breakfast Program. I also describe the study's participants (students and staff); procedures, instruments and measures; the role of the researcher; and data analysis procedures. This section also includes a description of the research tools. ${ }^{1}$

The purpose of the study was to examine the social and environmental context influencing the beliefs, attitudes and behaviors of students and staff that influence breakfast eating and school breakfast participation in a college-prep high school serving a predominantly low-income student population. To guide the research, I used the following research questions:

\footnotetext{
1 Research instruments are found in Appendices B-D.
} 
1. How do students at this college-prep high school for underserved students describe the factors - social, economic, physical - that influence their breakfast-eating behavior?

2. How do staff members at this college-prep high school for underserved students describe the systems and supports designed to promote breakfasteating?

\section{Research Design}

The research design, or plan to conduct research, involves the intersection of philosophy, strategies of inquiry, and specific methods (Creswell, 2009). In this study, I used an interactive research design model that consists of the goals or purpose of the research; the conceptual framework or paradigm; research questions, methods; and validity (Maxwell, 2012). For this study, the research methodology was qualitative research. As the researcher, I chose to use qualitative research because it supports stakeholders' engagement and participation through the principles of inclusion and dialogue, and emphasizes understanding research participants on their own terms.

\section{Conceptual Framework}

A pragmatic approach was used as the conceptual framework (research paradigm) in this study. The pragmatic approach was essential in this study to answer the research questions thoroughly. For the qualitative researcher, pragmatism opens the door to multiple methods, different world-views, different assumptions and different forms of data collection and analysis (Creswell, 2009). Research paradigms tend to be differentiated by how researchers make claims about what knowledge is (ontology), how researchers obtain knowledge (epistemology), what values go into it (auxiology), how we write about it (rhetoric), and the process for studying it (methodology) (Creswell, Plano 
Clark, Guttman, \& Hanson, 2003). Within the pragmatic paradigm, knowledge is gained through the practical approach of action and reflection. The strength of the pragmatic approach to social science research methodology is its emphasis on the connection between the epistemological concerns about the nature of knowledge that we produce, and technical concerns about the methods that we use to generate the knowledge (Morgan, 2007). American pragmatists include John Dewey, William S. Pierce, and William James, all who advocated for the philosophical belief that knowledge to be viewed as both constructed and based on the physical world (Johnson \& Onwuegbuzie, 2004).

The methodology of this qualitative study, allowing various forms of data collection to be used to best answer the research question(s), is concordant with the pragmatic paradigm, where the focus is on the problem in its social and historical context, rather than on the method deployed (Creswell, Hanson, Clark, Plano, \& Morales, 2007). The logic of pragmatic inquiry includes the use of inductive (discovery of patterns), and deductive (testing of theories and hypotheses) reasoning — essentially, moving back and forth between induction and deduction - first converting observations into theories, and then assessing those theories through action-uncovering and relying on the best of a set of explanations for understanding one's results (Johnson \& Onwuegbuzie, 2004; Morgan, 2007). Pragmatism also addresses how our assumptions and actions are influenced by the ethics, values, politics and epistemologies we bring to the research (Morgan, 2007), which is helpful in understanding researcher bias present in the study. Furthermore, Morgan (2014) argued that pragmatism can serve as a philosophical framework for social 
science research regardless whether the research uses qualitative, quantitative, or mixed methods. Either way, use of a pragmatic framework was a logical choice for this qualitative research study.

\section{Research Questions}

Research questions are the component that links most directly to all other components within a study; research questions are the heart of the research design (Maxwell, 2012). Because I adopted Maxwell's interactive research design model for my study, my research questions were intended to be the heart of the study. A realist approach was applied to the research questions and included both process- and variancetheory components. The realist approach assumes that data gathered about feelings, beliefs, and attitudes - this unobserved-phenomena — is real data, and can be used like verifiable data to develop and test ideas about the existence of nature of the phenomena studied (Campbell, 1998; T. D. Cook \& Campbell, 1979; Maxwell, 1992, 2012). Critics of the realist approach argued that the increased reliance on inference, incumbent in realist questions, could easily lead to researcher bias, and the risk of potential validity threats such as participants' distortion of the actual effects on them (Maxwell, 2012). I contend that a realist approach to the research questions was a good fit for this study, and as the researcher, I was cautious of the risks of using this method.

\section{Research Methods}

The majority of existing research associated with the School Breakfast Program has been collected through the use of quantitative research methods like large surveys and data sets (Adolphus et al., 2013; Bartfeld, 2010; Murphy, 2007; Rampersaud, 2009) 
A handful of social science research has applied qualitative methods such as focus groups and ethnography to document attitudes and perspectives around embedded topics like food insecurity, parent and teacher attitudes, and the social and environmental nutrition environment in the school setting (Haesly et al., 2014; Hearst et al., 2016; Huang \& Vaughn, 2015; Lambert, Raidl, Carr, Safaii, \& Tidwell, 2007; Reddan et al., 2002). Research using qualitative methods tends to help connect the dots, or fill in the spaces, left by quantitative studies. Because I would like this study to be as complete as possible, I proposed to use a variety of research methods that are both quantitative and qualitative in nature. Using both quantitative and qualitative data collection methods is useful in gaining information from various data sources to understand different aspects of the phenomena studied (Greene, 2008), and as a check on one another to be sure they support the same conclusion (Fielding \& Fielding, 1986). In this qualitative study design, the qualitative data gathering tools outnumbered the quantitative, and the analysis utilizes a qualitative approach. The qualitative data collection methods included two open-ended survey questions, focus groups, individual semi-structured interviews, and a DAHSSBT. The sole quantitative data collection method used in the study was a staff survey sent to all school staff members.

\section{Case Study}

The research was carried out as a case study. The term case study refers to the intensive study of a case, but the meaning of "case" can vary broadly in different disciplines (Glesne, 2015). The defining principle of a case however, is that it is a bounded, integrated system with working parts (Stake, 1995). Using a school as a case 
agrees with the definition. The bounds of this case study are those within the school community—students, and school staff. Schram (2006) reflected, "Whether you consider a case study as a way of conceptualizing human social behavior or merely as a way of encapsulating it, its strategic value lies in its ability to draw attention to what can be learned from the single case" (p. 107).

This case study was situated within an urban college preparatory high school that serves economically and socially disadvantaged youth located in the western United States. The school is known for providing a rigorous curriculum and a high-quality education. The student population is racially and ethnically diverse and primarily lowincome. Many of the school's students will be the first in their family to attend college; for some students, they are the first in their family to attend high school.

The school has a population of roughly 50 staff and 300 students in grades nine through 12. The school provides Title 1 services in reading and math and participates in federal child nutrition programs, including the School Breakfast Program and National School Lunch Program.

The physical structure of the school is important to the study. The school is a selfcontained building with two levels. The main entry and the majority of classrooms is on street level, and the school gym, cafeteria, and several classrooms are on the lower level — accessible from the back parking lot. In the morning, the school's main door remains locked until after the morning bell; however, the lower level door, near the cafeteria is unlocked several hours before school begins, so unless a student arrives at school late, after the bell, the student must enter through the lower level door and pass 
through the cafeteria. According to school staff, the students who are dropped off early at school tend to congregate in the school cafeteria, studying or talking with friends. The school breakfast service begins at 45 minutes before the start of school, and students can get breakfast until about five minutes before first period begins. However, a prepackaged "grab-n-go" breakfast is available for those arriving just before, or after, the bell signaling first period rings at 8:00 a.m.

Through interviews with staff, I learned that during the year in which the data for this study was collected, the school's food and nutrition program went through two major transitions. I am including the information because it is relevant to the findings from the study. The first transition began during the summer before the school year began when the nutrition director, who had worked in the school for 5 years, gave notice that she would not be returning. The nutrition director had been responsible for planning the menus, food purchasing, compliance with federal program regulations and nutrition standards, and reporting to the state education agency. The duties of the position were divided and distributed among existing staff who had little understanding of the federal meal program and no direct food service experience. During the first few weeks of the school year, available staff provided cold meals like cereal and sandwiches and packaged food. Several weeks into the school year a kitchen manager and two part-time kitchen staff were hired to prepare the food, but the nutrition director duties remained assigned to a staff with little knowledge or interest in the responsibilities of the school meal program. The second transition occurred following a state administrative review of the meal program. The administrative duties, like program compliance and reporting, were 
transferred to another staff position, and the kitchen manager was given the menu planning and food ordering duties. This second transition is important because it shifted the staff responsible for the program and brought more attention to the school meal program.

\section{Participants}

The participants in the study were associated with the bounded case study school. Participants were the school staff including teachers, administrators, coaches, food service, and clerical positions, and high school students in grades 10-12.

\section{Students}

Student participants were critical to this study in understanding the social and environmental factors that influence eating breakfast and participating in the School Breakfast Program. All the student participants were students at the case-study school. Student participants were male and female high school students, ranging in age from 1518 years, in grades 10-12. The school included freshman students as well; however, none of those recruited attended the focus group discussions. Fourteen students participated in one of two focus groups and completed a DAHSSBT. Because the focus groups took place during the lunch hour, students brought lunch from the cafeteria and ate while participating. Based on the discussion, the majority of the student participants received free school meals, although at least one participant was expected to pay full priceindicating a higher family economic status than the other students.

Student participants provided perspectives about their breakfast eating behavior and attitudes toward the School Breakfast Program. The students also contributed 
important insight and strengthened my understanding of the social and relational influences that affect breakfast eating behavior.

\section{School Staff}

The staff within the high school setting included a variety of positions of both certified and classified staff. Certified staff must hold a certification or license to be employed in their position and this includes positions such as teachers, counselors, and nurses. On the other hand, classified staff positions do not require certification and include most support personnel, such as clerical, transportation, custodial and food service staff. Data were gathered from both certified and classified staff within the case study school: the school administrator and teaching staff, as well as support staff like secretarial and the school nutrition staff, were included in the study. Their attitudes toward breakfast eating, and school nutrition programs can have a profound effect on their behavior, remarks, and role-modeling (Haesly et al., 2014; Lambert et al., 2007). The two collection methods used with school staff were (a) an anonymous email survey and (b) semi-structured interviews with selected staff members.

\section{Procedures, Instruments, and Measures}

The process of data collection occurred over a two-month period. Data collection methods included a survey of staff; interviews with key staff — administrators, food and nutrition service staff, clerical staff, teachers, and coaches; two student focus groups; and a DAHSSBT with focus group participants. 


\section{Communication}

Prior to data collection, I met with the school principal and vice principal and discussed the format of the study and the number of students and staff, as well as the role of staff, ideal for the study. The principal then sent an email to all staff informing them that the research project would be taking place over the next few months at their school, and that they would be asked to complete a survey and may also be contacted by the researcher to request an interview. The principal also asked one of the teachers on staff to recruit students for the focus groups. Communications with participants included emails sent to staff to set up interview times, including email correspondence with the teacher recruiting students to set up a time and place for the focus groups. Following completion of write-up, I sent a thank you note to the principal and included a short list of suggestions for increasing school breakfast participation at their school.

\section{Gaining Access}

To obtain the case study school site, requests went to school nutrition directors and principals in high schools that fit the demographic and school breakfast characteristics described. Once a school administrator confirmed interest in the study, I completed the Institutional Review Board process through Portland State University. I provided a research summary and letter for the school principal, which Glesne (2015) referenced as the lay summary, to the school and district administrator (p. 58). The summary included: (a) Who I am; (b) What I'm doing and why; (c) What I will do with the results; (d) How the study site and participants were selected; (e) Any possible risks, as well as benefits to the participants; (f) The promise of confidentiality ad anonymity to 
participants and site; (g) How often I would like to observe and meet for interviews and focus groups; (h) How long I expect each session to last; (i) Requests to record observations and words (by notes or audio, or video recording).

\section{Staff Survey}

All school staff, including administration, were asked to complete an on-line survey. A limited number of research studies have been conducted on school administration and staff attitudes about the School Breakfast Program (Haesly et al., 2014; Lambert et al., 2007). Interviews with selected staff members were conducted to provide qualitative insight into the quantitative survey data.

The staff survey was written with the research questions in mind, and included questions designed to understand the participants' perceptions and behaviors linked to nutrition, breakfast eating/skipping, weight maintenance, and food security (see

Appendix B). The survey was created using Qualtrics, a software survey instrument with the capability of gathering both quantitative and qualitative data. The survey included 14 questions, and all but two of the answers provided quantitative data. The majority of these questions used a Likert-type scale to judge importance. The remaining two questions were open-ended and provided qualitative results.

The school principal sent all employees an email with an introduction to the survey, information that the survey was part of a doctoral research project, and a link to the survey. Roughly $32 \%$ of the school staff completed the survey. The survey results were anonymous and no identifying data were collected, with the exception of one attribute question (demographic information) asking whether the participant was male, 
female, or non-binary. Consent for the survey was included within the survey introduction, and the participant was required to consent before moving forward with the survey. The questions covered topics related to personal breakfast eating beliefs, and habits, and what the participant perceived about the student breakfast eating behaviors. Qualtrics collected the survey data and provided statistical information for the quantitative information.

I analyzed the quantitative survey data using descriptive statistics. Then, I coded and analyzed the qualitative data along with the data findings from the staff interviews. I discuss the findings from these analyses in Chapter 4.

\section{Staff Interviews}

Interviews with selected staff members were conducted to provide qualitative insight into the quantitative survey data. The principal and vice principal introduced key staff members to the researcher in-person and through email. The researcher then followed-up and scheduled the interview appointments by email or phone. Semistructured interview questions (see Appendix C) were created and approved by the Institutional Review Board. Five 30-minute semi-structured interviews were conducted with six participants. During one interview, two staff members were present. Those interviewed included administrative staff, a food service staff, teachers, a coach and clerical positions. The interviews all took place at the school during the school day. The same script and questions were used for all interviews, and all of the interviews were 2030 minutes in length. The interview questions focused on the participant's role in the school; their knowledge of the School Breakfast Program and the link between breakfast 
eating and learning; their own breakfast-eating attitudes and behaviors; and the breakfast eating attitudes and behaviors of the students in the school. All interviewees signed a consent form prior to being interviewed. The interviews were audio-recorded and transcripts from the recordings were coded and analyzed using In Vivo and pattern coding as primary coding methods, both descriptive coding methods that allowed me to label sections of data. As a secondary coding method, I used thematic coding analysis to group the previous data categories by theme. Coding occurs at two levels-identifying information about the data and interpretive constructs related to analysis, (Merriam, 1998).

Following each interview, I gave the participant(s) a thank you note and small gift card purchased with my own funds. All hard copies of the transcribed interviews were placed in a manila envelope, labeled with the appropriate interview convention, and placed in a locked filing cabinet drawer in the office of the researcher. A complete list of the interview questions can be found in Appendix B.

\section{Student Focus Groups}

Fourteen students were recruited for focus group interviews. The students were recruited directly by one of the teachers at the school. The teacher recruited students who she felt would be willing to share their experiences in a group setting. Each focus group was conducted with seven students. The first focus group was made up of all female students and included five seniors and two sophomores. The second focus group was mixed gender and included three males and four female students who were a combination of junior and sophomore students. Both focus groups - the female only and mixed-gender groups- 
were conducted using the same format, script, and questions. Research indicates that female adolescents who had negative perceptions of their body weight or engaged in weight loss behavior frequently reported skipping breakfast, (Hearst et al., 2016; Rampersaud, 2009; Rampersaud et al., 2005; Reddan et al., 2002). Therefore, my motive for conducting female-only focus group was my belief that the female students may have been more likely to delve into issues such as their perceptions of breakfast skipping and body weight in an all-female focus group. The focus groups were held on the school campus in one of the empty classrooms during the lunch hour. The students ate lunch while participating in the focus group discussion. Each focus group lasted approximately 45 minutes and included the DAHSSBT.

When the students first gathered for the focus group, students chose a pseudonym to protect their anonymity. The students printed their chosen pseudonym on their name tags, and these names were used during the focus group discussion. Before beginning the focus group questions, the students participated in a 10-minute DAHSSBT, described in the next section.

From past experience, I was aware that the success of focus groups relies on the facilitator's ability to moderate and ensure that each participant is able to share his or her experience without being put down or silenced by other participants within the group, and similarly that one participant does not dominate the conversation or monopolize the time. I explained ground rules to all focus group participants which included, but was not limited to, confidentiality, respecting each other's opinions, and trying not to talk over each other. The focus group questions (see Appendix D) were designed to create 
conversation around breakfast eating patterns — why or why not students eat breakfastand why or not they participate in the School Breakfast Program. Although the focus group questions did not ask directly about weight issues and breakfast skipping, the students' issues with food insecurity or stigma influencing school breakfast eating behavior, my thought was that information on these topics might be gleaned from the conversation.

With the parents' and students' consent, audio-recordings were made of the focus group conversations, and later transcribed. At the end of the focus group, I gave students a thank you note for their participation and a small incentive of $\$ 15$ from my personal funds.

The focus groups were audio-recorded and transcripts from the recordings were coded and analyzed. The coding process for this qualitative data was the same as what was used for the staff interviews and for the answers to the open-ended survey questions: first in vivo coding was used, then, pattern coding, and finally, thematic coding leading to thematic networks.

\section{DAHSSBT}

During the first 10 minutes of each focus group session, the students completed a DAHSSBT, an additional qualitative data collection method. The students were asked to draw their impression of a high school student's breakfast. Students were told they could draw what they typically ate for breakfast or what they believed the typical high school student's breakfast might look like; one of the student's DAHSSBT is provided as an example in Figure 5. DAHSSBT is adapted from the Draw-A-Scientist Test. The Draw- 
A-Scientist Test is an open-ended test designed to investigate children's perception of a scientist (Chambers, 1983).

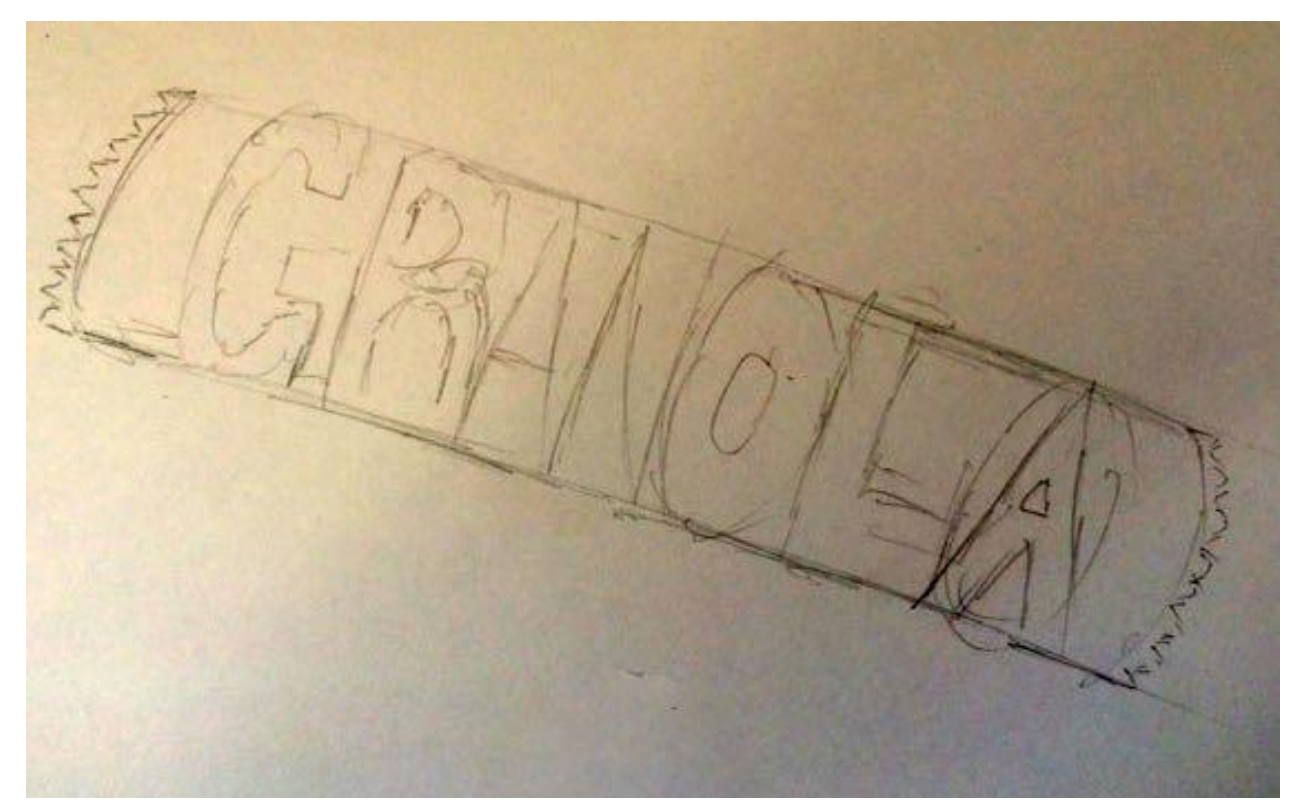

Figure 5. An example of a student's DAHSSBT, a drawing of a granola bar.

In the first focus group — the female only group — the students completed their drawings, labeled the drawing with their self-selected pseudonym, and handed it in to the researcher. During the second focus group, the students described their drawings and explained the contents of the picture to the researcher and group of other students. The students then also labeled their drawing with their pseudonym, and handed them to the researcher. The collected drawings were analyzed later. Analysis of DAHSSBT can provide additional insight into social, environmental, and cultural factors influencing the student's perception and attitudes toward breakfast eating, and possibly the School Breakfast Program. However, according to Chambers (1983), a drawing test is probably more useful in identifying than in measuring attitudes. 
Pattern coding was used to analyze the DAHSSBT pictures. I determined the pattern codes by commonalities between the students' drawings and themes that had emerged through the literature review and within the previous data analysis from the student focus group discussion and staff survey and interviews.

\section{Timeline}

The data collection occurred at the school over a 10-week timeframe as described in Table 3. This 10-week period occurred the last 10 weeks of the school year, in fact the final focus group was on the last day of school for the freshman, sophomores, and junior students.

Table 3

Data Collection Timeframe

\begin{tabular}{|l|l|}
\hline Weeks & Activities \\
\hline Week 1 & $\begin{array}{l}\text { Met with food service director and school principal - explained project. Toured school. } \\
\text { Provided description of study for principal to use to communicate to students and staff } \\
\text { members. }\end{array}$ \\
\hline Weeks 2-3 & $\begin{array}{l}\text { Provided staff survey link and description to school principal. Provided student focus } \\
\text { group request to staff tasked with recruiting students for focus groups. Set up dates and } \\
\text { times for interviews with school staff. }\end{array}$ \\
\hline Weeks 4-5 & $\begin{array}{l}\text { Provided focus group consent forms and information for parents/guardians. Finalized } \\
\text { times for staff interviews. Closed surveys. }\end{array}$ \\
\hline Weeks 6-7 & Compiled and coded staff survey data. Begin staff interviews. \\
\hline Weeks 8-9 & $\begin{array}{l}\text { Conducted female student focus Continued interviews with administrators and school } \\
\text { staff. }\end{array}$ \\
\hline Week 10 & Conducted mixed-gender focus group. Completed interviews with school staff. \\
\hline
\end{tabular}




\section{Role of the Researcher}

This study strongly connects to my work in education and to my work in public health. It also continues to dig deeper into the question about why food insecure students are not taking advantage of the School Breakfast Program in greater numbers, the same question that students that I worked with years ago in the Youth Action Research Project explored. Therefore, my role as a researcher was to work to identify my own expectations, beliefs and self-bias. My intent, as a thoughtful researcher, was to become anticipatory, a learner, analytic, reassuring, and grateful, as suggested in Becoming Qualitative Researchers: An Introduction (Glesne, 2015). Instilling validity through ethics and self-awareness is critical to my role as a researcher. Validity does not imply the existence of any objective truth to which an account can be compared. It refers to the correctness or credibility of a description, conclusion, explanation, interpretation or similar account (Maxwell, 2012, p. 122). The validity of this study was strengthened through the triangulation of data collection methods and my own awareness of my role as the researcher and how my expectations and mere presence could affect self-bias and comprehension. Triangulation is the use of several means to examine the same phenomenon, can occur within or between methods, and may be used for several purposes (Vogt, Gardner, \& Haeffele, 2012, p. 111). Triangulation allows for the findings from one research method to confirm the findings of another research method used within the study. Triangulation was built into the research design of this study to confer validity, and strengthen the research. 
As the researcher, I did my best to minimize both researcher bias and reactivity. Researcher bias includes how my own values, expectations and beliefs impact the study design, how I conducted the research, and the conclusions of the study. To reduce researcher bias, I attempted to identify and acknowledge my own perceptions. Once the study concluded, I continued to be vigilant of researcher bias I brought to the study, and this was addressed in the final write-up under limitations of the study. Although there is no way to completely eliminate reactivity - the influence of the researcher on the setting or the individuals studied, I tried to be aware and understand in which ways my presence might be influencing what was done or said. This was especially relevant as I conducted focus group and individual interviews.

\section{Data Analysis Procedures}

I used descriptive statistics, In vivo and pattern coding, and thematic networks as my main analytic methods. "Data analysis involves organizing what you have seen, heard, and read so you can figure out what you have learned and make sense of what you have experienced" (Glesne, 2015, p. 183).

Statistical data and analysis for quantitative survey data were done using Qualtrics, the online survey software tool. Qualtrics made it possible for the data to be easily displayed in a variety of visual formats. Creating bar graphs and pie charts with the data presents the data visually and may enhance the reader's understanding of the data. Similarly, creating visual displays with quantitative data can be helpful in considering the relationship of the data in different ways and possibly seeing patterns that were not evident from the start. 
Once I gathered the qualitative data, the analysis started using in vivo coding, and then looking for commonalities, using pattern coding. I underlined words and wrote notes in the margins, as the patterns and ideas evolved. I then used thematic coding as a second cycle coding method to categorize the various patterns or themes and extract meaning. Thematic coding helped draw distinctions between significant ideas and themes that appeared. A theme is an extended phrase or sentence that identifies what a unit of data is about or what it means (Saldaña, 2015, p. 199). “A theme may be identified at the manifest level (directly observational in the information) or at the latent level underlying the phenomenon" (Boyatzis, 1998, p. vii). At its manifest level, a theme functions to organize repeating ideas (Auerback \& Silverstein, 2003). “An important aspect of thematic analysis is segregating data into categories by codes or labels" (Glesne, 2015, p. 184). Following Glesne's (2015) advice, I used my colored highlighters to indicate patterns within the in vivo coding. Analysis of DAHSSBT was conducted using a more interpretive approach specifically, descriptive coding and sub-coding and pattern coding. I have found that DAHSSBT tells its own story, and often what one person notices in a picture has more to do with their personal beliefs and world-view. Put together with the other collected data, DAHSSBT provides a rich visualization.

I created themes using the results from the descriptive statistics and pattern coding. These themes were then arranged into thematic networks. The thematic networks serve as a tool in analysis, and is not the analysis itself, (Attride-Stirling, 2001). Figure 6 reflects the various data collection methods and the analysis process sequence. 


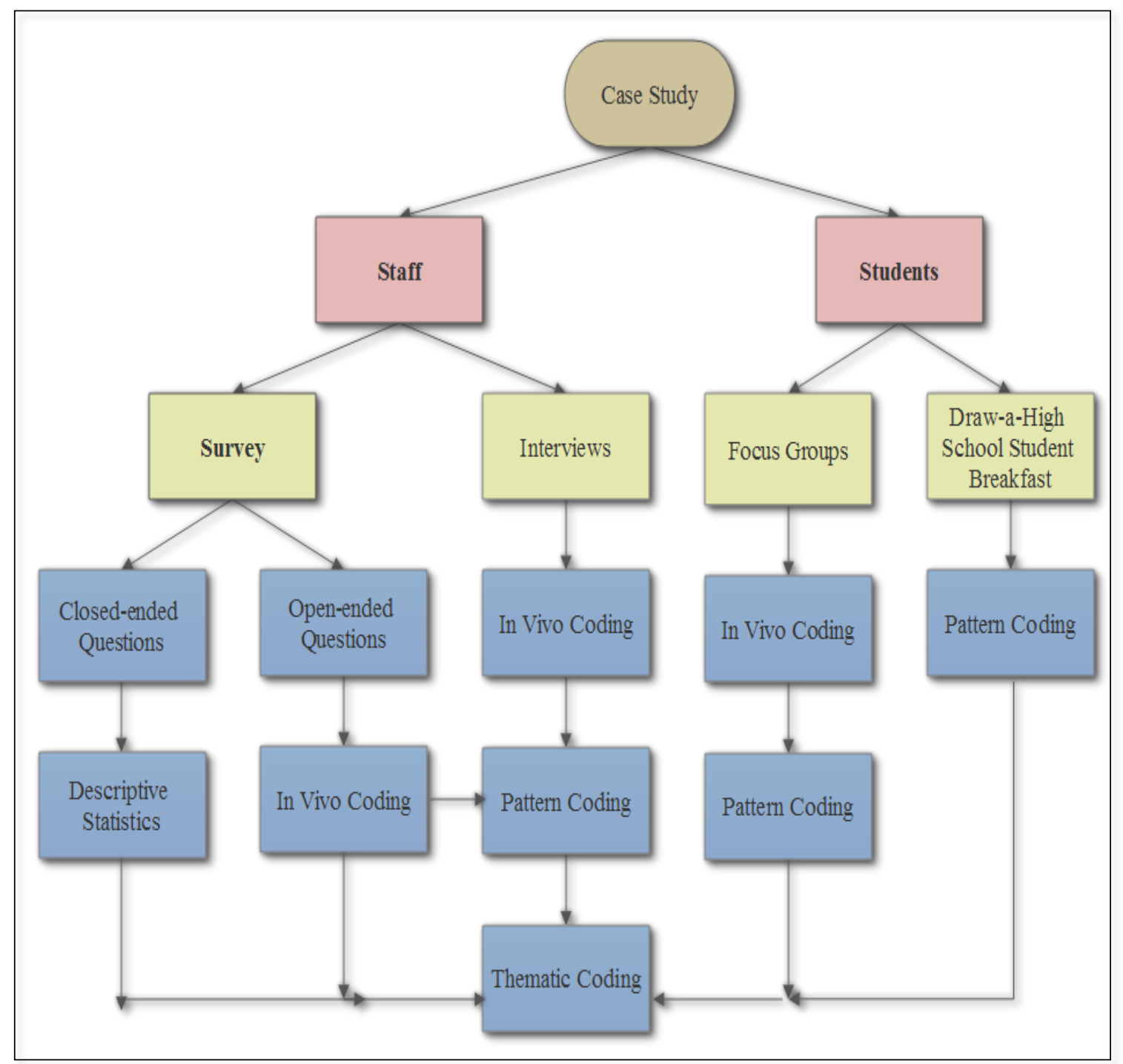

Figure 6. Organization of data analysis.

\section{Summary of Methods}

I proposed a qualitative research design using a pragmatic conceptual framework for this study. The research occurred during a 10-week timeframe at a high school in the western U.S., which was the focus of a case study designed to answer the research questions proposed in the study. The research questions used a realist approach, and the 
use of several different data collection methods to examine the social context — attitudes, beliefs, and behaviors - around breakfast eating and the School Breakfast Program. Triangulation was built into the research design to broaden the understanding of the social context and to increase confidence in the results of the study. The data collection methods of the bounded case study included a surveys of the school staff; student focus groups, including a mixed gender and a single-sex, female group; individual interviews with school administration and staff; and DAHSSBT. Data analysis included descriptive statistics for the quantitative data, and in vivo and pattern coding first stage coding methods, and thematic coding as a second stage data coding tool. Communications with the school and district administration began several months before the study and will conclude once the dissertation is final and the summary is shared. 


\section{CHAPTER 4: RESULTS/ANALYSIS}

In Chapter 3, I described the qualitative research design, the conceptual framework, and data collection methods. In Chapter 3, I also included my role as a researcher conducting this study that explores the factors influencing participation in the School Breakfast Program in a college-prep high school for underserved students. I conducted a case study, using the actual school environment and immediate school community—school staff and students - to bound, or encapsulate, the parameters of the study. A case study is a bounded system (Creswell et al., 2007). It is through the perspective of the participants within this bounded case study that I sought to answer the following research questions:

1. How do students at a college-prep high school for underserved students describe the factors - social, economic, physical — that influence their breakfast-eating behavior?

2. How do staff at a college-prep high school for underserved students describe the systems and supports designed to promote breakfast eating?

The process of triangulation, using two different participant groups and several different collection methods, should act to improve the validity of my results (Maxwell, 2012, p. 128).

In this chapter, I present data results and findings from the quantitative and qualitative data analysis. The chapter is organized into three major sections: (a) analysis of the data and presentation of results, (b) interpretation of findings, and (c) limitations of the study. In the first section, analysis of the data and presentation of the results is organized by analytical method. I begin by describing the quantitative data results and then the qualitative data 
analysis and findings. In this first section, I explain the data coding and initial analysis process used for each data collection method, including a description of the thematic networks- the final analysis tool. In second section, interpretation of findings, I address the research questions and the context of the case study. In the third section, I discuss the limitations of the study design, data gathering methods, analysis, and my own biases as a researcher.

\section{Analysis of the Data and Presentation of the Results}

This section is organized by coding method: (a) descriptive statistics, (b) in vivo coding, (c) pattern coding, and (d) thematic networks. Figure 6 illustrates analytic coding that was used with the various data collection methods. This section includes a brief description of the data collection tools, the analysis process used with each data collection method, the analysis process used to synthesize the data into thematic networks used to analyze the data further.

\section{Descriptive Statistics}

I used descriptive statistics to analyze the quantitative questions asked in the staff survey. The on-line survey included 15 questions, and all but two of the answers provided quantitative data. The survey was designed to understand the staff's perceptions and behaviors linked to nutrition, breakfast eating/skipping, weight maintenance, and food security (see Appendix A). All of the school staff were invited to complete the survey. Responses indicate that roughly $32 \%$ of the staff $(N=17)$ completed the survey and all respondents completed all of the quantitative questions.

One of the quantitative survey questions was a demographic question asking if the respondent was male or female, and another asked about where the respondent typically 
ate breakfast and choices were given. These two questions are addressed in the results section. The remaining 11 questions were asked using a Likert-scale survey, and for these questions, the mean and standard deviation have been calculated, and ordered by highest to lowest mean, see Table 4.

The mean represents the center of the distribution data. The standard deviation describes how spread out the data are from the mean. Therefore, a higher standard deviation value reveals a higher spread of the data, which means there was not as much consistency in the responses across the group. I have described the answers to the questions and provided graphs for some of the questions to enhance understanding and decrease boredom.

The first question listed in the Table 4, (Q7) "I think the School Breakfast Program is an important resource for our students," has the highest mean and the smallest standard deviation. This indicates that there was high agreement on this question, and all but one of the respondents agreed or strongly agreed that the School Breakfast Program was an important resource for their students. Similarly, the next question on the table, (Q3) "Eating breakfast helps me perform better at work," had high agreement although slightly more variability in the spread of the data. The third question, however, (Q4) "I eat breakfast because it is important for my health," had much more variability in the answers. While many respondents felt very strongly that eating breakfast mattered, those who felt otherwise brought down the mean. 
Table 4

Descriptive Statistics for Staff Survey

\begin{tabular}{|l|c|c|}
\hline Survey Question & Mean (scale 1-5) & Standard Deviation \\
\hline $\begin{array}{l}\text { Q7 I think the school breakfast program is an important } \\
\text { resource for students. }\end{array}$ & 4.65 & 0.59 \\
\hline Q3 Eating breakfast helps me perform better at work. & 4.35 & 0.76 \\
\hline Q4 I eat breakfast because it is important for my health. & 4.12 & 0.96 \\
\hline $\begin{array}{l}\text { Q6 I notice that the students who eat breakfast are more } \\
\text { alert in class. }\end{array}$ & 3.82 & 0.86 \\
\hline $\begin{array}{l}\text { Q9 I encourage students to take part in the School Breakfast } \\
\text { Program. }\end{array}$ & 3.71 & 0.75 \\
\hline Q8 I am very familiar with our School Breakfast Program. & 3.35 & 1.03 \\
\hline $\begin{array}{l}\text { Q11 The school encourages students to take part in the } \\
\text { School Breakfast Program. }\end{array}$ & 3.29 & 0.81 \\
\hline $\begin{array}{l}\text { Q11 The school encourages students to take part in the } \\
\text { School Breakfast Program. }\end{array}$ & 3.24 & 1.13 \\
\hline $\begin{array}{l}\text { Q11 The school encourages students to take part in the } \\
\text { School Breakfast Program. }\end{array}$ & 3.12 & 0.71 \\
\hline $\begin{array}{l}\text { Q10 The school promotes the importance of eating } \\
\text { breakfast. }\end{array}$ & 2.82 & 1.51 \\
\hline $\begin{array}{l}\text { Q1 On a typical school/work day, how often do you eat } \\
\text { breakfast? }\end{array}$ & 1.94 & \\
\hline
\end{tabular}

The next questions on Table 4, (Q5) "Eating breakfast helps me control my weight" (see Figure 7) and (Q6) "I notice that the students who eat breakfast are more alert in class," had some variation in answers although the majority of respondents chose the middle selection, neither agree nor disagree. 


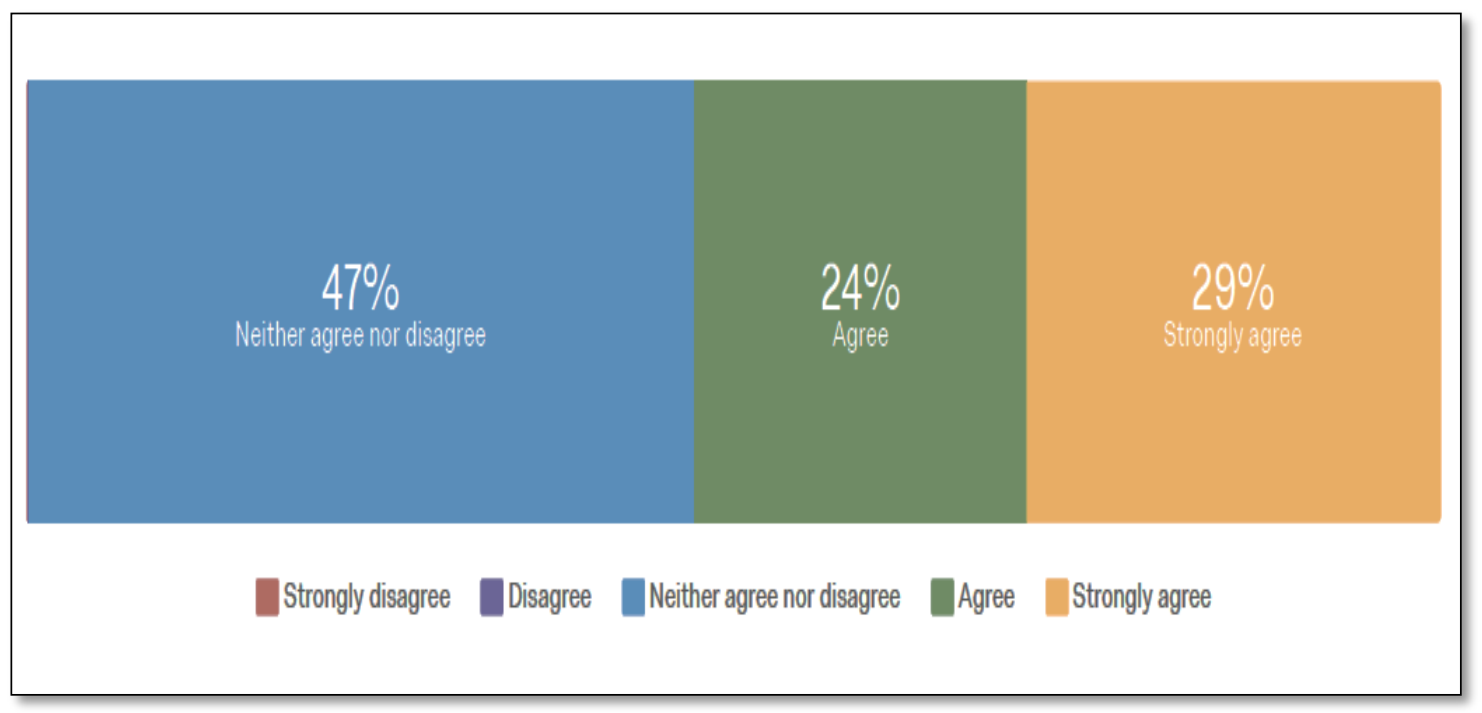

Figure 7. Q5, Eating breakfast helps me control my weight.

(Q9), "I encourage students to take part in the School Breakfast Program," had wide variability with at least one respondent selecting each answer category. However the majority of answers selected fell into the neither agree nor disagree category, or the agree category. Figure 8 illustrates the wide variability in the response to (Q8), "I am very familiar with our School Breakfast Program."

(Q11), "The school encourages students to take part in the School Breakfast Program," was closely split between respondents who chose disagree, neither agree nor disagree, and agree. (Q 12), "In my role within the school, I promote the importance of eating breakfast," is shown in Figure 9. It is important to remember that all staff positions were asked to complete the survey. 


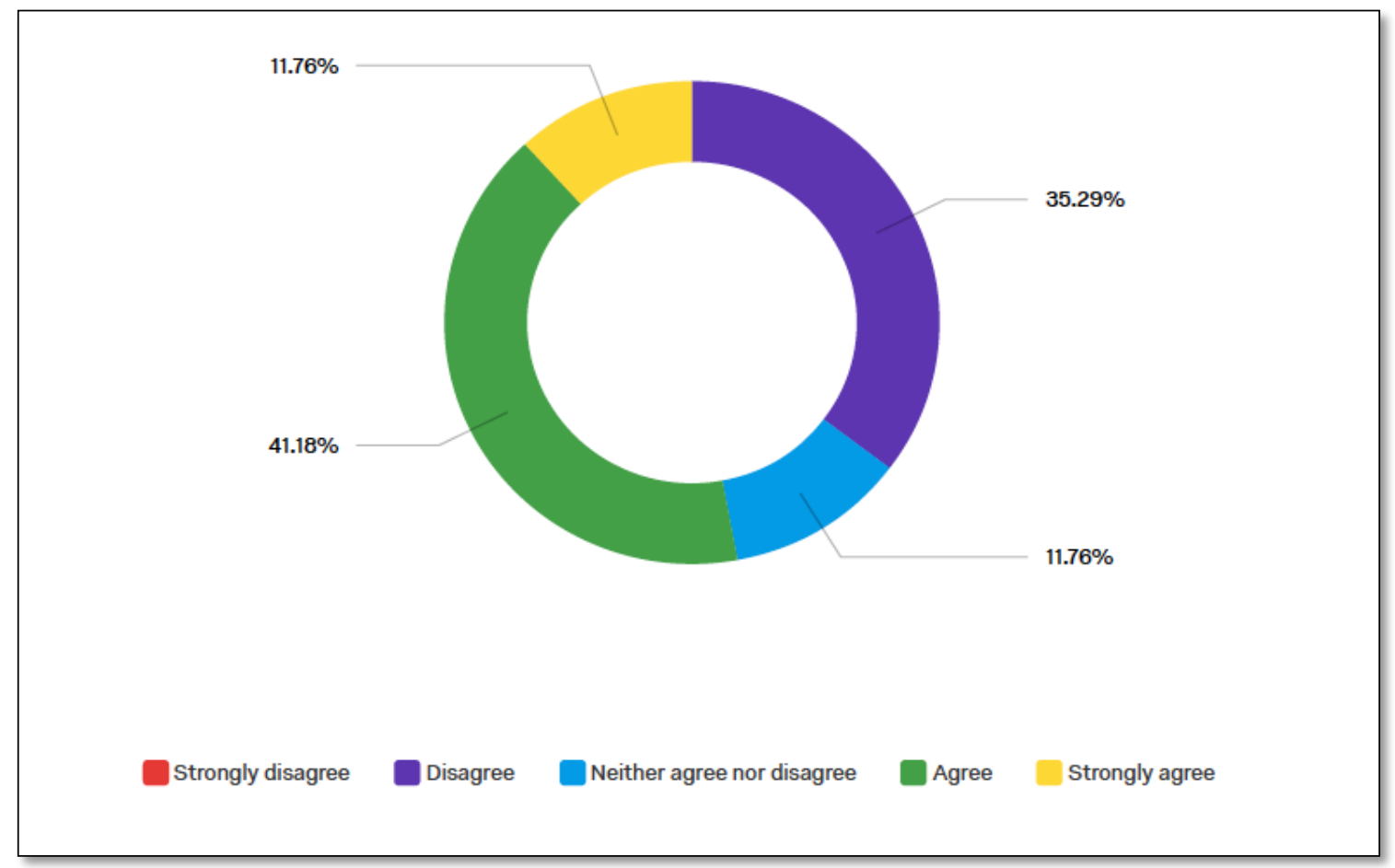

Figure 8. Q8, I am very familiar with our School Breakfast Program.

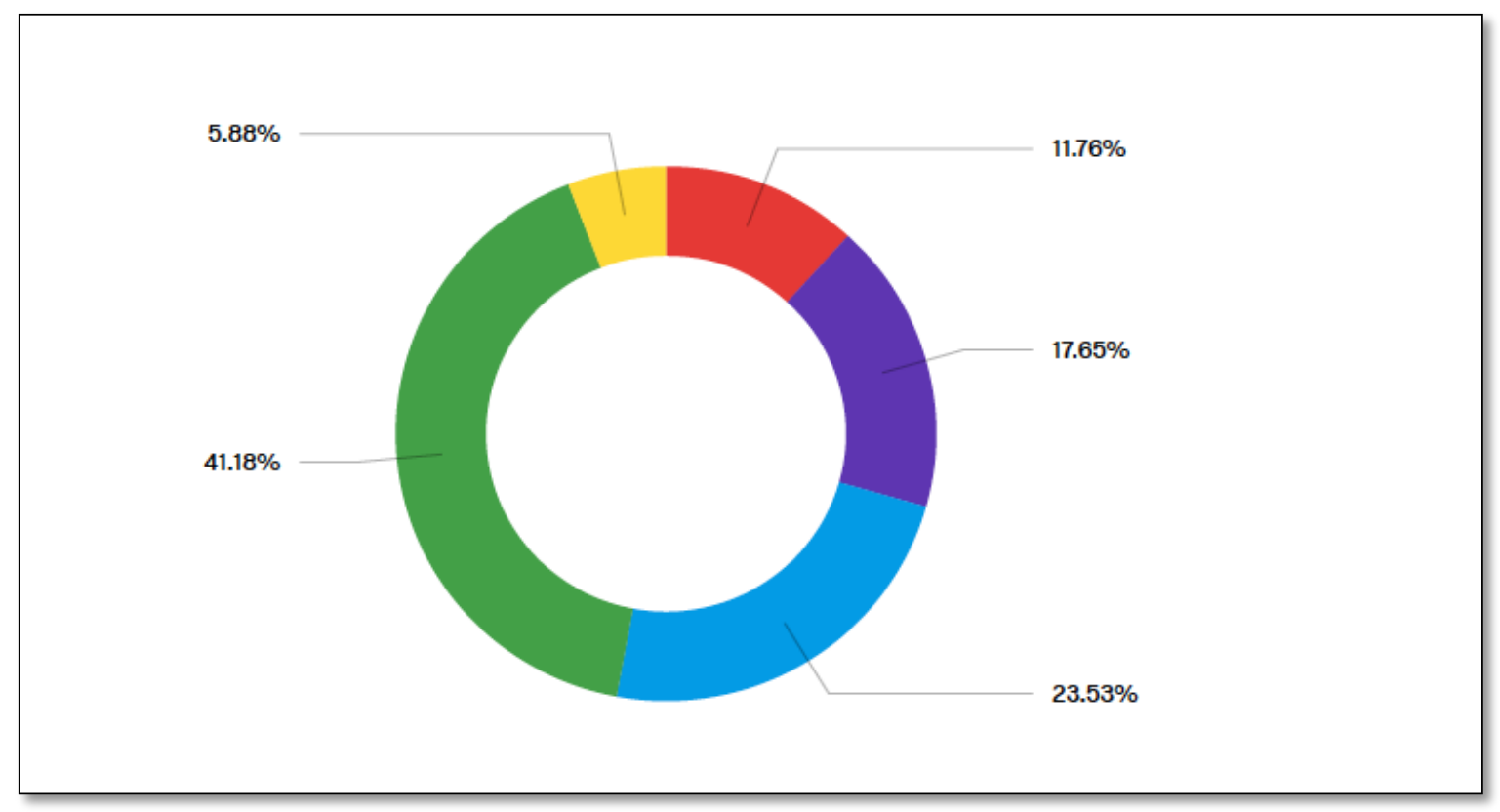

Strongly disagree Disagree $\quad$ Neither agree nor disagree $\quad$ Agree

Figure 9. Q9, In my role within the school, I promote the importance of eating breakfast. 
In (Q10), "The school promotes the importance of eating breakfast," the second to the last question on Table 4, the responses were centered on the middle question with some variability as seen in Figure 10.

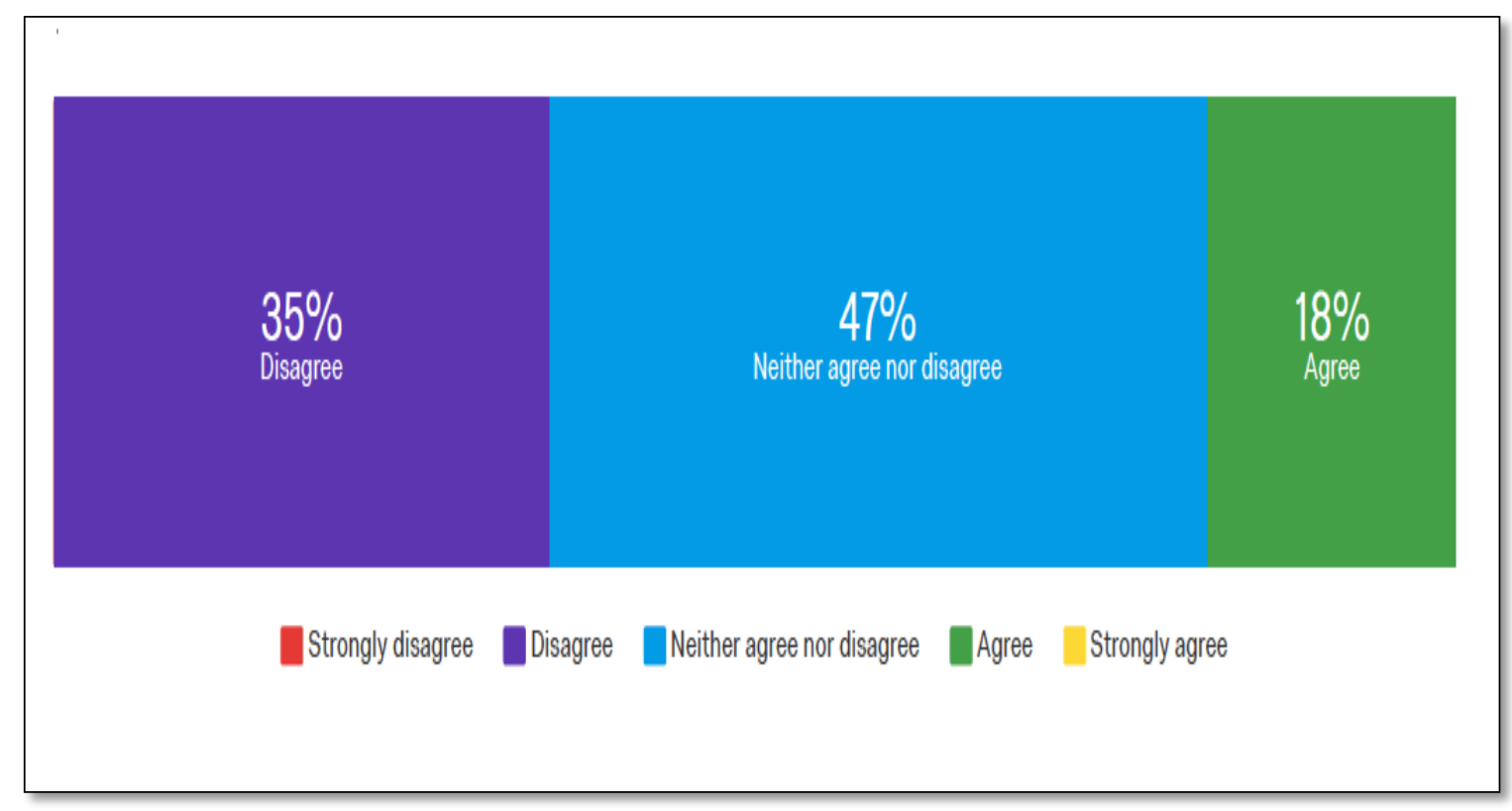

Figure 10. Q10, The school promotes the importance of eating breakfast.

The last question in Table 4, (Q1) “On a typical school/work day, how often do you eat breakfast?" had the lowest mean and the highest standard deviation or greatest spread of the data. In this case, it was not because most of the staff were skipping breakfast, although some were, it was because the question was asked on the scale of the answer 1 corresponding to every day and 5 corresponding with never.

The final two quantitative questions include a question about whether the respondent was male or female, and one about where the respondent typically eats breakfast on a school/work day. The answer to the former question, "What is 
your gender?" is $35.29 \%(n=6)$ respondents were male, and $64.71 \%(n=11)$ of respondents were female. The latter question, “On a typical school/work day I eat breakfast," is illustrated in Figure 11.

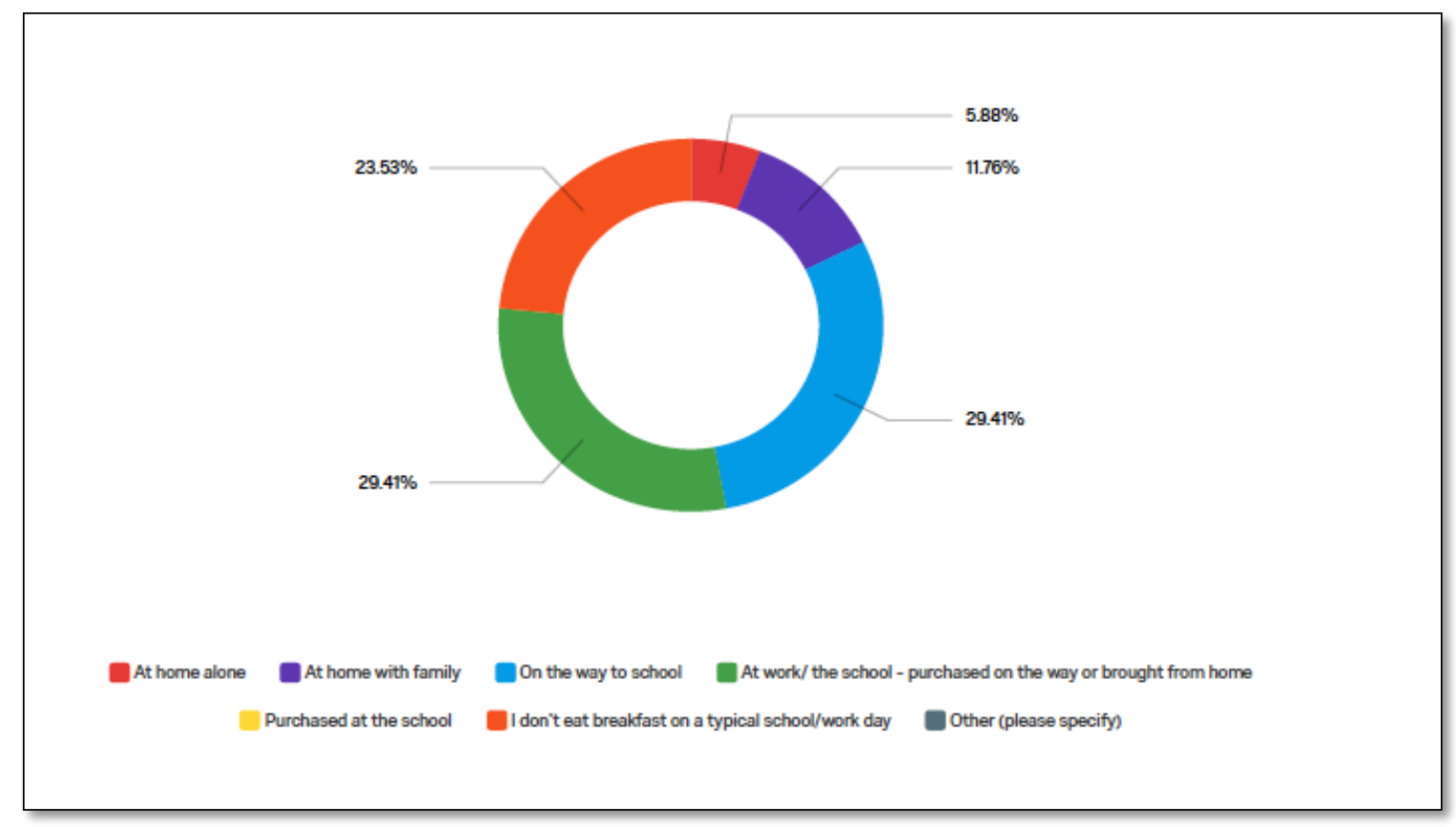

Figure 11. On a typical school/work day, I eat breakfast.

\section{In Vivo Coding}

In Vivo coding is a first cycle coding method that, according to Saldaña (2015), is appropriate for virtually all qualitative studies, and especially for those with beginning researchers who are learning how to code data. Furthermore, Saldaña noted that In Vivo coding is especially useful when capturing the voice of youth (Saldana, 2015). In Vivo coding was used as an initial coding method for the qualitative questions in the staff survey, the staff interviews, and the student focus groups. The coding was accomplished by going through the 
narrative answers of the survey and the interviews and focus group transcripts and pulling out sentences and phrases that I believed captured the meaning of what the individual was conveying.

\section{Pattern Coding}

Pattern coding is a second cycle coding method used to categorize coded data as an initial analytic strategy (Saldaña, 2015). In this study, pattern coding was used to categorize the In Vivo coding of the qualitative answers in the staff survey together with the In Vivo coding of the staff interviews. Another set of pattern coding was created to categorize the In Vivo coding from the two focus group transcripts, and then separate patterns were developed through the analysis of the DAHSSBT.

\section{Pattern coding for staff survey open-ended questions and staff}

interviews. The results of the In Vivo coding from the staff interviews, and from the open-ended questions on the staff survey, were analyzed together. These codes were then categorized by the patterns that I identified within the In Vivo coded data. The data were then organized into 12 patterns. These patterns were then given the following labels: (a) aware "our students" need food, (b) communication issues about school meal menus, (c) confusion about the School Breakfast Program, (d) feeding students snacks during the day, (e) improved learning (f) inconsistencies in allowing students to eat breakfast in the classroom,

(g) kids complain, (h) knowledge of school breakfast requirements, (i) nostalgia for former nutrition director, (j) relationships between kitchen staff and students, 
(k) time to eat in the morning, (1) transitions with nutrition director and kitchen

staff. Table 5 includes the pattern codes and a sample of the In Vivo coding

within each pattern code.

Table 5

Pattern Codes and In Vivo Coding Analysis for School Staff Data

\begin{tabular}{|c|c|c|c|c|}
\hline \multicolumn{5}{|c|}{ Coding Analysis } \\
\hline Pattern & $\begin{array}{l}\text { In Vivo } \\
\text { Example } 1\end{array}$ & $\begin{array}{l}\text { In Vivo } \\
\text { Example } 2\end{array}$ & $\begin{array}{l}\text { In Vivo } \\
\text { Example } 3\end{array}$ & $\begin{array}{l}\text { In Vivo } \\
\text { Example } 4\end{array}$ \\
\hline $\begin{array}{l}\text { Aware "our } \\
\text { students" need } \\
\text { food. }\end{array}$ & $\begin{array}{l}\text { "We are always } \\
\text { very much aware } \\
\text { of kids who need } \\
\text { food during the } \\
\text { day. It is always on } \\
\text { our mind." }\end{array}$ & $\begin{array}{l}\text { "We've had } \\
\text { students who at } \\
\text { home may not have } \\
\text { eaten properly or at } \\
\text { all, and we're } \\
\text { asking them to do } \\
\text { homework and } \\
\text { we've had students } \\
\text { come in and say, 'I } \\
\text { didn't do the } \\
\text { homework because } \\
\text { I didn't have } \\
\text { anything to eat, and } \\
\text { I was hungry and } \\
\text { tired."' }\end{array}$ & $\begin{array}{l}\text { "The culture here is } \\
\text { 'oh our kids are from } \\
\text { lower socio- } \\
\text { economics, under } \\
\text { represented- we } \\
\text { need to feed them."' }\end{array}$ & $\begin{array}{l}\text { "Students, in } \\
\text { particular our } \\
\text { students, it seems } \\
\text { as if they're not } \\
\text { eating as much at } \\
\text { home, whether it's } \\
\text { due to time and } \\
\text { they have to hurry } \\
\text { and get out of the } \\
\text { house." }\end{array}$ \\
\hline $\begin{array}{l}\text { No promotion } \\
\text { of menu or } \\
\text { meals. }\end{array}$ & $\begin{array}{l}\text { "One of the issues } \\
\text { is that I can't find } \\
\text { the menu." }\end{array}$ & $\begin{array}{l}\text { "You know } \\
\text { sometimes I would } \\
\text { like to eat lunch } \\
\text { here, and I would } \\
\text { wonder what's } \\
\text { being offered and it } \\
\text { would just be a } \\
\text { surprise." }\end{array}$ & $\begin{array}{l}\text { "I would even say } \\
\text { communications } \\
\text { outside of the } \\
\text { school, so families } \\
\text { know why - if } \\
\text { they're paying for } \\
\text { something why } \\
\text { aren't they getting } \\
\text { something that } \\
\text { they're expected to } \\
\text { get." }\end{array}$ & $\begin{array}{l}\text { "It would be nice to } \\
\text { know what is being } \\
\text { served so you can } \\
\text { pick and choose - } \\
\text { for those who have } \\
\text { options. Some of } \\
\text { them just eat here } \\
\text { every day, so it } \\
\text { doesn't matter for } \\
\text { them." }\end{array}$ \\
\hline $\begin{array}{l}\text { Confusion } \\
\text { about the } \\
\text { School } \\
\text { Breakfast } \\
\text { Program. }\end{array}$ & $\begin{array}{l}\text { "I have a vague } \\
\text { idea of what } \\
\text { they're served. } \\
\text { They're some cold } \\
\text { and hot breakfast } \\
\text { choices." }\end{array}$ & $\begin{array}{l}\text { "I'm still a little } \\
\text { confused about } \\
\text { what's allowed and } \\
\text { what's not allowed. } \\
\text { We had coffee } \\
\text { cake a few times." }\end{array}$ & $\begin{array}{l}\text { We've had } \\
\text { compliance issues, } \\
\text { and I think that a lot } \\
\text { of this is because } \\
\text { people who are } \\
\text { supervising or in } \\
\text { charge don't have } \\
\text { all the information." }\end{array}$ & $\begin{array}{l}\text { "I don't know what } \\
\text { the percentages are } \\
\text { of the students who } \\
\text { show up for } \\
\text { breakfast." }\end{array}$ \\
\hline
\end{tabular}


Table 5 (continued)

\begin{tabular}{|c|c|c|c|c|}
\hline \multicolumn{5}{|c|}{ Coding Analysis } \\
\hline Pattern & $\begin{array}{l}\text { In Vivo } \\
\text { Example } 1\end{array}$ & $\begin{array}{l}\text { In Vivo } \\
\text { Example } 2\end{array}$ & $\begin{array}{l}\text { In Vivo } \\
\text { Example } 3\end{array}$ & $\begin{array}{l}\text { In Vivo } \\
\text { Example } 4\end{array}$ \\
\hline $\begin{array}{l}\text { Feeding } \\
\text { students } \\
\text { during the } \\
\text { day (aka } \\
\text { granola bars). }\end{array}$ & $\begin{array}{l}\text { "They're not eating } \\
\text { breakfast, but we } \\
\text { also have some } \\
\text { snacks throughout } \\
\text { the day, granola } \\
\text { bars kind of thing } \\
\text { and our kids are } \\
\text { coming in } \\
\text { constantly getting } \\
\text { granola bars as } \\
\text { well, so that might } \\
\text { be a substitute for } \\
\text { them of not eating } \\
\text { the breakfast." }\end{array}$ & $\begin{array}{l}\text { "I usually have } \\
\text { snacks in this } \\
\text { office, even if it is } \\
\text { just fruit, up in the } \\
\text { admin office there } \\
\text { is always granola } \\
\text { bars" }\end{array}$ & $\begin{array}{l}\text { "Students come by } \\
\text { different offices, and } \\
\text { say, 'Hey, do you } \\
\text { got anything to } \\
\text { eat?"' }\end{array}$ & $\begin{array}{l}\text { "We have these } \\
\text { granola bars, and if } \\
\text { you were here in } \\
\text { between classes, } \\
\text { because they only } \\
\text { give them out in } \\
\text { between classes, } \\
\text { not during class } \\
\text { time, you would } \\
\text { just see a steady } \\
\text { stream of kids } \\
\text { coming through." }\end{array}$ \\
\hline $\begin{array}{l}\text { Improved } \\
\text { learning. }\end{array}$ & $\begin{array}{l}\text { "The more that you } \\
\text { are not thinking } \\
\text { about being hungry } \\
\text { you can perform } \\
\text { better." }\end{array}$ & $\begin{array}{l}\text { "We've all seen } \\
\text { research, and it's } \\
\text { proven that when a } \\
\text { kid is properly fed, } \\
\text { or just has } \\
\text { something in their } \\
\text { body, and they're } \\
\text { not hungry they're } \\
\text { able to concentrate } \\
\text { more." }\end{array}$ & $\begin{array}{l}\text { "Just being able to } \\
\text { focus, and as I } \\
\text { narrow it down to } \\
\text { our school, the } \\
\text { content that we are } \\
\text { providing our } \\
\text { students is pretty } \\
\text { deep considering } \\
\text { what they're used to } \\
\text { and so there has to } \\
\text { be some focus." }\end{array}$ & $\begin{array}{l}\text { "They are } \\
\text { distracted when } \\
\text { they're hungry." }\end{array}$ \\
\hline $\begin{array}{l}\text { Inconsistenci } \\
\text { es in allowing } \\
\text { students to } \\
\text { eat breakfast } \\
\text { in the } \\
\text { classroom. }\end{array}$ & $\begin{array}{l}\text { "They're not } \\
\text { allowed to eat (in } \\
\text { class), but teachers } \\
\text { have made the } \\
\text { accommodations } \\
\text { for students to eat } \\
\text { breakfast in the } \\
\text { classroom." }\end{array}$ & $\begin{array}{l}\text { "It's dependent on } \\
\text { the teacher." }\end{array}$ & $\begin{array}{l}\text { "There are teachers } \\
\text { who will allow the } \\
\text { kids to eat breakfast } \\
\text { in the classroom and } \\
\text { only breakfast." }\end{array}$ & $\begin{array}{l}\text { "It varies, the } \\
\text { science teachers, } \\
\text { no, but that makes } \\
\text { sense." }\end{array}$ \\
\hline $\begin{array}{l}\text { Kids } \\
\text { complain. }\end{array}$ & $\begin{array}{l}\text { "Kids are picky } \\
\text { eaters and they like } \\
\text { to complain, so you } \\
\text { can take that with a } \\
\text { grain of salt." }\end{array}$ & $\begin{array}{l}\text { "But they also } \\
\text { complain because } \\
\text { our cook used to } \\
\text { make cookies, and } \\
\text { now she can't. So } \\
\text { they complain } \\
\text { about that too." }\end{array}$ & $\begin{array}{l}\text { "See it's hard } \\
\text { because some kids } \\
\text { just like to complain } \\
\text { more than others, so } \\
\text { it is hard to gauge." }\end{array}$ & $\begin{array}{l}\text { "When we had our } \\
\text { old kitchen staff } \\
\text { who had been here } \\
\text { for years, the kids } \\
\text { complained about } \\
\text { that too." }\end{array}$ \\
\hline
\end{tabular}


Table 5 (continued)

\begin{tabular}{|c|c|c|c|c|}
\hline \multicolumn{5}{|c|}{ Coding Analysis } \\
\hline Pattern & $\begin{array}{l}\text { In Vivo } \\
\text { Example } 1\end{array}$ & $\begin{array}{l}\text { In Vivo } \\
\text { Example } 2\end{array}$ & $\begin{array}{l}\text { In Vivo } \\
\text { Example } 3\end{array}$ & $\begin{array}{l}\text { In Vivo } \\
\text { Example } 4\end{array}$ \\
\hline $\begin{array}{l}\text { Knowledge } \\
\text { of School } \\
\text { Breakfast } \\
\text { Requirements } \\
\text {. }\end{array}$ & $\begin{array}{l}\text { "When Michelle } \\
\text { Obama made all } \\
\text { her changes, we } \\
\text { had to make a lot } \\
\text { of changes so we } \\
\text { have nothing white. } \\
\text { So all of our grains } \\
\text { are whole grain, } \\
\text { whole grain bread, } \\
\text { pasta, stuff like } \\
\text { that." }\end{array}$ & $\begin{array}{l}\text { "I think the food is } \\
\text { not always what } \\
\text { the kids want, and I } \\
\text { would imagine } \\
\text { that's a small piece } \\
\text { of the plan or of the } \\
\text { program, more so } \\
\text { given them what } \\
\text { they need." }\end{array}$ & $\begin{array}{l}\text { "I had some } \\
\text { questions, but is } \\
\text { coffee cake, I mean } \\
\text { it's a grain, but it } \\
\text { didn't appear to be a } \\
\text { whole grain?" }\end{array}$ & $\begin{array}{l}\text { "I think that we are } \\
\text { hoping now, now } \\
\text { that we have done } \\
\text { this process that it } \\
\text { is going to } \\
\text { improve, not only } \\
\text { financially but also } \\
\text { in the nutrition as } \\
\text { well." }\end{array}$ \\
\hline $\begin{array}{l}\text { Nostalgia for } \\
\text { former } \\
\text { Nutrition } \\
\text { Director. }\end{array}$ & $\begin{array}{l}\text { "Our former head } \\
\text { of the cafeteria was } \\
\text { a woman much } \\
\text { beloved by } \\
\text { students. She was } \\
\text { sweet, affectionate } \\
\text { and motherly with } \\
\text { them. Her care } \\
\text { showed up in her } \\
\text { preparation of the } \\
\text { food and treatment } \\
\text { of students." }\end{array}$ & $\begin{array}{l}\text { "Everything was } \\
\text { from scratch." }\end{array}$ & $\begin{array}{l}\text { "She was amazing } \\
\text { she came here at } \\
\text { like 5:00 in the } \\
\text { morning and started } \\
\text { making spaghetti } \\
\text { sauce." }\end{array}$ & $\begin{array}{l}\text { "She was like our } \\
\text { Grandma." }\end{array}$ \\
\hline $\begin{array}{l}\text { Relationships } \\
\text { between } \\
\text { kitchen staff } \\
\text { and students }\end{array}$ & $\begin{array}{l}\text { "I would say it's } \\
\text { more the } \\
\text { relationships } \\
\text { between the } \\
\text { kitchen staff and } \\
\text { the students." I } \\
\text { don't think they're } \\
\text { as positive as they } \\
\text { were before. }\end{array}$ & $\begin{array}{l}\text { "I was encouraged } \\
\text { because the new } \\
\text { kitchen manager } \\
\text { went on a week- } \\
\text { long retreat with } \\
\text { some of our } \\
\text { students as a } \\
\text { chaperone." }\end{array}$ & $\begin{array}{l}\text { "The people who } \\
\text { prepare and serve } \\
\text { the students matter } \\
\text { and affect students } \\
\text { eating habits." }\end{array}$ & $\begin{array}{l}\text { "Our new cafeteria } \\
\text { staff, as reported } \\
\text { by students, are } \\
\text { short tempered and } \\
\text { don't build } \\
\text { relationship with } \\
\text { the kids." }\end{array}$ \\
\hline Time & $\begin{array}{l}\text { "I hear it, I didn't } \\
\text { eat anything this } \\
\text { morning, I didn't } \\
\text { have time." }\end{array}$ & $\begin{array}{l}\text { "Whether it's due } \\
\text { to time and they } \\
\text { have to hurry and } \\
\text { get out of the } \\
\text { house, getting } \\
\text { breakfast here may } \\
\text { help them with } \\
\text { their time } \\
\text { management in the } \\
\text { morning." }\end{array}$ & $\begin{array}{l}\text { "Because they were } \\
\text { late, they didn't } \\
\text { make it to school on } \\
\text { time, so they } \\
\text { couldn't eat, they } \\
\text { lost that chance." }\end{array}$ & $\begin{array}{l}\text { "I have many } \\
\text { students tell me } \\
\text { that they don't eat } \\
\text { breakfast, usually } \\
\text { because of a lack } \\
\text { of time." }\end{array}$ \\
\hline Transition & $\begin{array}{l}\text { "We had a cook } \\
\text { who was here for a } \\
\text { long time and she } \\
\text { left. So we had a } \\
\text { new cook this } \\
\text { year." }\end{array}$ & $\begin{array}{l}\text { "We kind of took a } \\
\text { while this year to } \\
\text { get into a groove, } \\
\text { of not using frozen } \\
\text { food as much but } \\
\text { cooking instead." }\end{array}$ & $\begin{array}{l}\text { "Now it seems to be } \\
\text { up, as far as more } \\
\text { homemade meals } \\
\text { and not so much } \\
\text { frozen meals." }\end{array}$ & $\begin{array}{l}\text { "You know it has } \\
\text { been really difficult } \\
\text { this year." }\end{array}$ \\
\hline
\end{tabular}


Pattern coding for student focus groups. The In Vivo coding of the student focus group data were coded into patterns using the same process that was done with the staff data. There were some striking similarities in the patterns that emerged between the staff and student data. There were nine clear categories that the student focus group In Vivo coded data fit into. These coded patterns were labeled and include: (a) "disgusting food," (b) how time factors in to eating breakfast, (c) learning/focus, (d) negative attitude toward current nutrition staff, (e) nostalgia for past nutrition director, (f) Obama Lunch Plan, (g) poor communication about the menu and food and nutrition, (h) status/identity based on food served/not cared about through food, (i) suggestions for school breakfast. Table 6 describes the student focus group pattern codes and examples of the In Vivo coded data within the patterns.

Table 6

Pattern Codes and In Vivo Coding Analysis for Student Data

\begin{tabular}{|l|l|l|l|l|}
\hline \multicolumn{2}{|c|}{ Coding Analysis } \\
\hline Pattern & $\begin{array}{l}\text { In Vivo } \\
\text { Example 1 }\end{array}$ & $\begin{array}{l}\text { In Vivo } \\
\text { Example 2 }\end{array}$ & $\begin{array}{l}\text { In Vivo } \\
\text { Example 3 }\end{array}$ & $\begin{array}{l}\text { In Vivo } \\
\text { Example 4 }\end{array}$ \\
\hline $\begin{array}{l}\text { "Disgusting } \\
\text { food." }\end{array}$ & $\begin{array}{l}\text { "The food just feels } \\
\text { like it has just been } \\
\text { sitting out for a } \\
\text { long time." }\end{array}$ & $\begin{array}{l}\text { "They had chunky } \\
\text { milk. The fact that } \\
\text { that happened is } \\
\text { not cool. That } \\
\text { means they are not } \\
\text { checking or } \\
\text { caring." }\end{array}$ & $\begin{array}{l}\text { "And the frozen } \\
\text { stuff is not like } \\
\text { it is frozen for like } \\
\text { 2 months." }\end{array}$ & $\begin{array}{l}\text { "I don't think they } \\
\text { wash their fruits } \\
\text { and vegetables and } \\
\text { that is nasty. Like, } \\
\text { you can taste the } \\
\text { chemicals on the } \\
\text { vegetables." }\end{array}$ \\
\hline
\end{tabular}


Table 6 (continued)

\begin{tabular}{|c|c|c|c|c|}
\hline \multicolumn{5}{|c|}{ Coding Analysis } \\
\hline Pattern & $\begin{array}{l}\text { In Vivo } \\
\text { Example 1 }\end{array}$ & $\begin{array}{l}\text { In Vivo } \\
\text { Example } 2\end{array}$ & $\begin{array}{l}\text { In Vivo } \\
\text { Example } 3\end{array}$ & $\begin{array}{l}\text { In Vivo } \\
\text { Example } 4\end{array}$ \\
\hline $\begin{array}{l}\text { How time } \\
\text { factors in to } \\
\text { breakfast } \\
\text { eating. }\end{array}$ & $\begin{array}{l}\text { "Some days if you } \\
\text { come later, there is } \\
\text { no option for you } \\
\text { to go down there } \\
\text { (to get breakfast)." }\end{array}$ & $\begin{array}{l}\text { "If I am late and I } \\
\text { know that I am } \\
\text { going to be like, } \\
\text { 'Oh, it is too late' } \\
\text { then, I will make } \\
\text { myself a nice } \\
\text { wholesome } \\
\text { breakfast at home, } \\
\text { but if I am at } \\
\text { school on time, I } \\
\text { never eat } \\
\text { breakfast." }\end{array}$ & $\begin{array}{l}\text { (If you want a } \\
\text { vegetarian meal) } \\
\text { "You have to sign } \\
\text { up every day. If you } \\
\text { are already late, than } \\
\text { how are you going } \\
\text { to come in and sign } \\
\text { up?" }\end{array}$ & $\begin{array}{l}\text { "You have to be } \\
\text { early or they stop } \\
\text { serving it." }\end{array}$ \\
\hline $\begin{array}{l}\text { Learning/Foc } \\
\text { us. }\end{array}$ & $\begin{array}{l}\text { "For me it is just } \\
\text { going to be the } \\
\text { same. I don't } \\
\text { know, you study } \\
\text { the same, you are } \\
\text { not going to forget } \\
\text { them just because } \\
\text { you didn't eat } \\
\text { breakfast." }\end{array}$ & $\begin{array}{l}\text { "Some days, if I } \\
\text { don't eat food, all I } \\
\text { can think about is } \\
\text { how I do need food } \\
\text { and when lunch is } \\
\text { coming." }\end{array}$ & $\begin{array}{l}\text { "It helps me focus } \\
\text { when I eat breakfast. } \\
\text { But, when I don't } \\
\text { eat breakfast, I am } \\
\text { somewhere else." }\end{array}$ & $\begin{array}{l}\text { "Some of it I think } \\
\text { is mental, too, } \\
\text { because we have } \\
\text { all heard you } \\
\text { should eat } \\
\text { breakfast before } \\
\text { you take a test and } \\
\text { we are mentally } \\
\text { thinking, "Oh, I am } \\
\text { going to do better } \\
\text { because I ate } \\
\text { breakfast today." }\end{array}$ \\
\hline $\begin{array}{l}\text { Negative } \\
\text { attitude } \\
\text { towards } \\
\text { current } \\
\text { nutrition } \\
\text { staff. }\end{array}$ & $\begin{array}{l}\text { "Yeah, in the } \\
\text { morning, it ruins } \\
\text { your mood." }\end{array}$ & $\begin{array}{l}\text { "I am talking also } \\
\text { about their attitude } \\
\text { because it makes } \\
\text { you not want to } \\
\text { eat." }\end{array}$ & $\begin{array}{l}\text { "And like, you are } \\
\text { scared to ask for } \\
\text { extras or ... if you } \\
\text { want extras. Like, } \\
\text { 'No!'-Or scared to } \\
\text { ask for something } \\
\text { different. " }\end{array}$ & $\begin{array}{l}\text { "The lunch ladies } \\
\text { are really rude to } \\
\text { me and I really } \\
\text { don't appreciate } \\
\text { it." }\end{array}$ \\
\hline $\begin{array}{l}\text { Nostalgia for } \\
\text { past Nutrition } \\
\text { Service } \\
\text { Director. }\end{array}$ & $\begin{array}{l}\text { "In the past it was } \\
\text { better . . . They } \\
\text { used to give us } \\
\text { toast, which I } \\
\text { loved-And } \\
\text { bagels. Toast and } \\
\text { bagels were good." }\end{array}$ & $\begin{array}{l}\text { "I don't like that } \\
\text { even though they } \\
\text { do certain healthy } \\
\text { stuff, the healthy } \\
\text { parts of it is not } \\
\text { good." }\end{array}$ & $\begin{array}{l}\text { "But that coffee } \\
\text { cake, though? That } \\
\text { was busted ..." }\end{array}$ & $\begin{array}{l}\text { "... wheat bread } \\
\text { and stuff, it does } \\
\text { not taste good!" }\end{array}$ \\
\hline
\end{tabular}


Table 6 (continued)

\begin{tabular}{|c|c|c|c|c|}
\hline \multicolumn{5}{|c|}{ Coding Analysis } \\
\hline Pattern & $\begin{array}{l}\text { In Vivo } \\
\text { Example } 1\end{array}$ & $\begin{array}{l}\text { In Vivo } \\
\text { Example } 2\end{array}$ & $\begin{array}{l}\text { In Vivo } \\
\text { Example } 3\end{array}$ & $\begin{array}{l}\text { In Vivo } \\
\text { Example } 4\end{array}$ \\
\hline $\begin{array}{l}\text { Poor } \\
\text { Communica- } \\
\text { tion about the } \\
\text { menu and } \\
\text { food and } \\
\text { nutrition. }\end{array}$ & $\begin{array}{l}\text { "People always ask } \\
\text { what it is." }\end{array}$ & $\begin{array}{l}\text { "It is just on our } \\
\text { chalkboard (in the } \\
\text { cafeteria), so, we } \\
\text { can't even prepare } \\
\text {. . Like, if we } \\
\text { wanted to bring } \\
\text { lunch." }\end{array}$ & $\begin{array}{l}\text { "Most schools will } \\
\text { like do an } \\
\text { announcement at a } \\
\text { meal .. . they don't } \\
\text { even do that here } \\
\text { anymore." }\end{array}$ & $\begin{array}{l}\text { "Most schools have } \\
\text { a lot more } \\
\text { awareness around } \\
\text { the food that we } \\
\text { are eating, but our } \\
\text { school doesn't do } \\
\text { anything like, } \\
\text { "Here is our } \\
\text { healthy meal of the } \\
\text { day." }\end{array}$ \\
\hline $\begin{array}{l}\text { Status/ } \\
\text { identity based } \\
\text { on food } \\
\text { served/Not } \\
\text { cared about } \\
\text { through food. }\end{array}$ & $\begin{array}{l}\text { "They have these } \\
\text { old ghetto donated } \\
\text { oranges and like } \\
\text { donated apples ... } \\
\text { the fruit at } \\
\text { breakfast is really } \\
\text { suspect and they } \\
\text { force you to grab it, } \\
\text { but I know I am } \\
\text { just going to } \\
\text { compost it." }\end{array}$ & $\begin{array}{l}\text { "I feel like } \\
\text { sometimes the food } \\
\text { that we are } \\
\text { provided with } \\
\text { might be bad and } \\
\text { sometimes they } \\
\text { say, 'Well, this is } \\
\text { what we got."' }\end{array}$ & $\begin{array}{l}\text { "I think we need } \\
\text { more investment } \\
\text { and the lunch people } \\
\text { need to be invested } \\
\text { in their job and their } \\
\text { importance in our } \\
\text { education." }\end{array}$ & $\begin{array}{l}\text { "Also, they keep } \\
\text { leftovers and they } \\
\text { have us eat } \\
\text { leftovers." }\end{array}$ \\
\hline $\begin{array}{l}\text { Suggestions } \\
\text { for School } \\
\text { Breakfast. }\end{array}$ & $\begin{array}{l}\text { "They have had } \\
\text { grapes and } \\
\text { watermelon (at } \\
\text { lunch), but, at } \\
\text { breakfast, they } \\
\text { don't have that. } \\
\text { Why can't they } \\
\text { have grapes every } \\
\text { morning for } \\
\text { breakfast?" }\end{array}$ & $\begin{array}{l}\text { "I used to be a } \\
\text { vegetarian early in } \\
\text { the year and you } \\
\text { have to sing up } \\
\text { every single day } \\
\text { (for a vegetarian } \\
\text { meal) which is } \\
\text { dumb. And if you } \\
\text { didn't sign up, you } \\
\text { wouldn't get food. } \\
\text { It is like, if you are } \\
\text { going to do that } \\
\text { (for vegetarians) } \\
\text { then have } \\
\text { everybody sign up } \\
\text { for food. And they } \\
\text { (could) do that like } \\
\text { maybe by month or } \\
\text { by three months." }\end{array}$ & $\begin{array}{l}\text { "I think there should } \\
\text { be a lot more } \\
\text { holistic options, like } \\
\text { things that we } \\
\text { actually want to eat } \\
\text { maybe, like take } \\
\text { into consideration } \\
\text { that." }\end{array}$ & $\begin{array}{l}\text { "They should give } \\
\text { a survey for all of } \\
\text { us." }\end{array}$ \\
\hline
\end{tabular}

Pattern coding for DAHSSBT. Pattern coding was also used to code the DAHSSBT drawings. The DAHSSBT was conducted and the drawings analyzed 
to provide additional insight into the social, environmental, and cultural factors influencing the student's perception of breakfast. In the case of DAHSSBT, pattern coding was used as a first cycle coding method. Drawing from the research literature and the patterns that had emerged from the focus group analysis, images within the drawing were identified and coded; these images were coded into nine separate patterns: (a) grab-n-go, (b) drink, (c) fruit, (d) hot breakfast, (e) nothing, (f) plate, (g) preparation, (h) school breakfast, (g) table. Table 7 includes definitions of the pattern codes used to analyze the DAHSSBT drawings.

Table 7

DAHSSBT Pattern Codes and Pattern Definitions

\begin{tabular}{|l|l|}
\hline Pattern Code & Definitions \\
\hline Drink & An image of a cup, glass or mug \\
\hline Fruit & An image of a piece or several pieces of fruit - or a resemblance to fruit. \\
\hline Grab-n-Go & $\begin{array}{l}\text { An image of a food item that is individually wrapped like a granola bar, or easy to } \\
\text { grab and eat while walking like a bagel or piece of fruit. }\end{array}$ \\
\hline Hot Breakfast & Images that resemble a hot breakfast such as eggs and sausage, pancakes and bacon. \\
\hline Nothing & An image indicating that no breakfast is eaten. \\
\hline Plate & The drawing contains an image of a plate. \\
\hline Preparation & $\begin{array}{l}\text { The type of food included in the drawing requires some degree of preparation and } \\
\text { multiple ingredients (e.g., bowl of cereal, egg sandwich). }\end{array}$ \\
\hline School Breakfast & The drawing indicates that the food item(s) are part of the school breakfast program. \\
\hline Table & The drawing contains the image of a table. \\
\hline Variety & The drawing contains images of foods from three or more food groups. \\
\hline
\end{tabular}


Figures 12-14 are examples of the analyzed DAHSSBT drawings: Figure 12 shows a plate on a table containing air and water molecules illustrating that high school students often eat nothing in the morning; Figure 13 is a drawing of an egg sandwich and a glass of milk, an example of a grab-n-go meal to eat on the run; and Figure 14 is a comparison of good and bad days for breakfast, the student's description showing a good day when time for breakfast was not an issue.

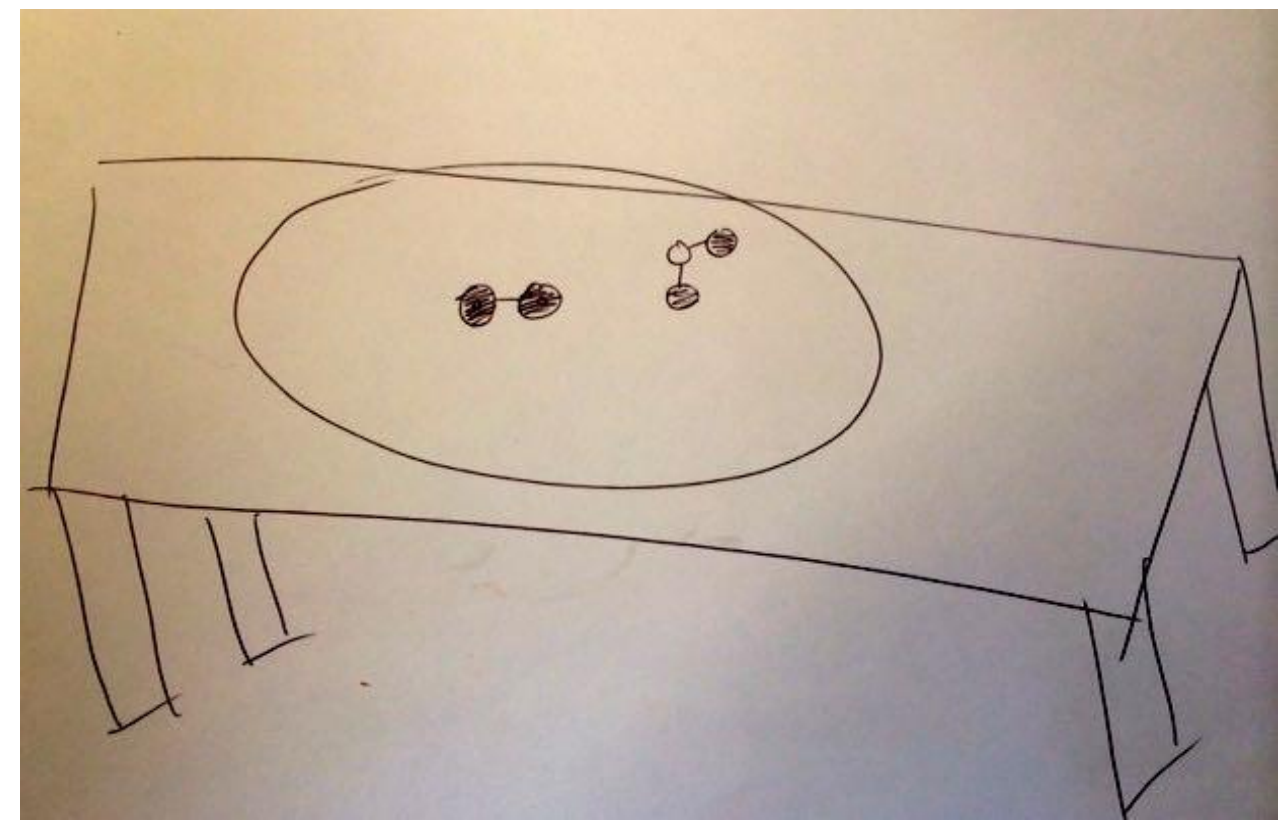

Figure 12. DAHSSBT drawing of water and air molecules. Pattern codes for this drawing include nothing, plate, and table. 


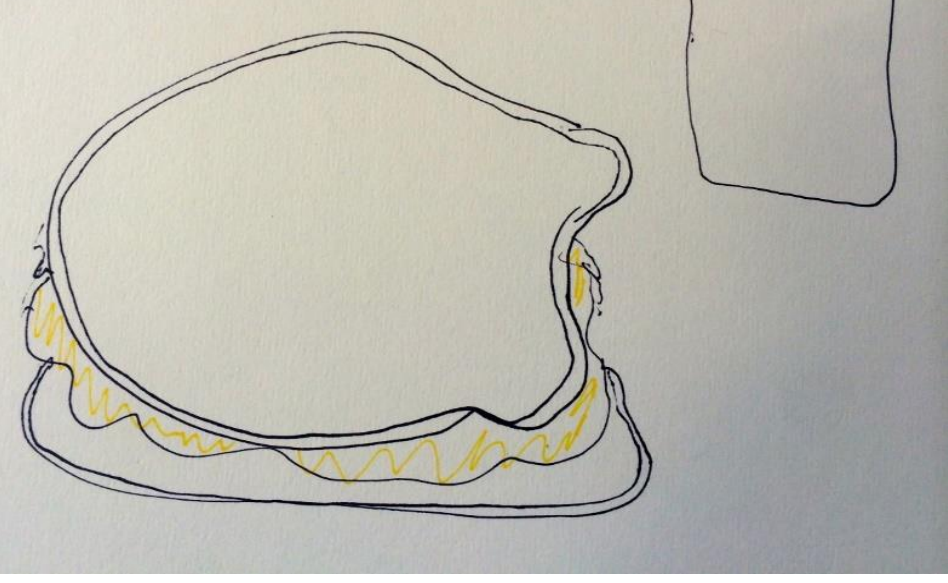

Figure 13. DAHSSBT drawing of an egg sandwich and milk. Pattern codes for this drawing include grab-n-go; drink; preparation; and variety.

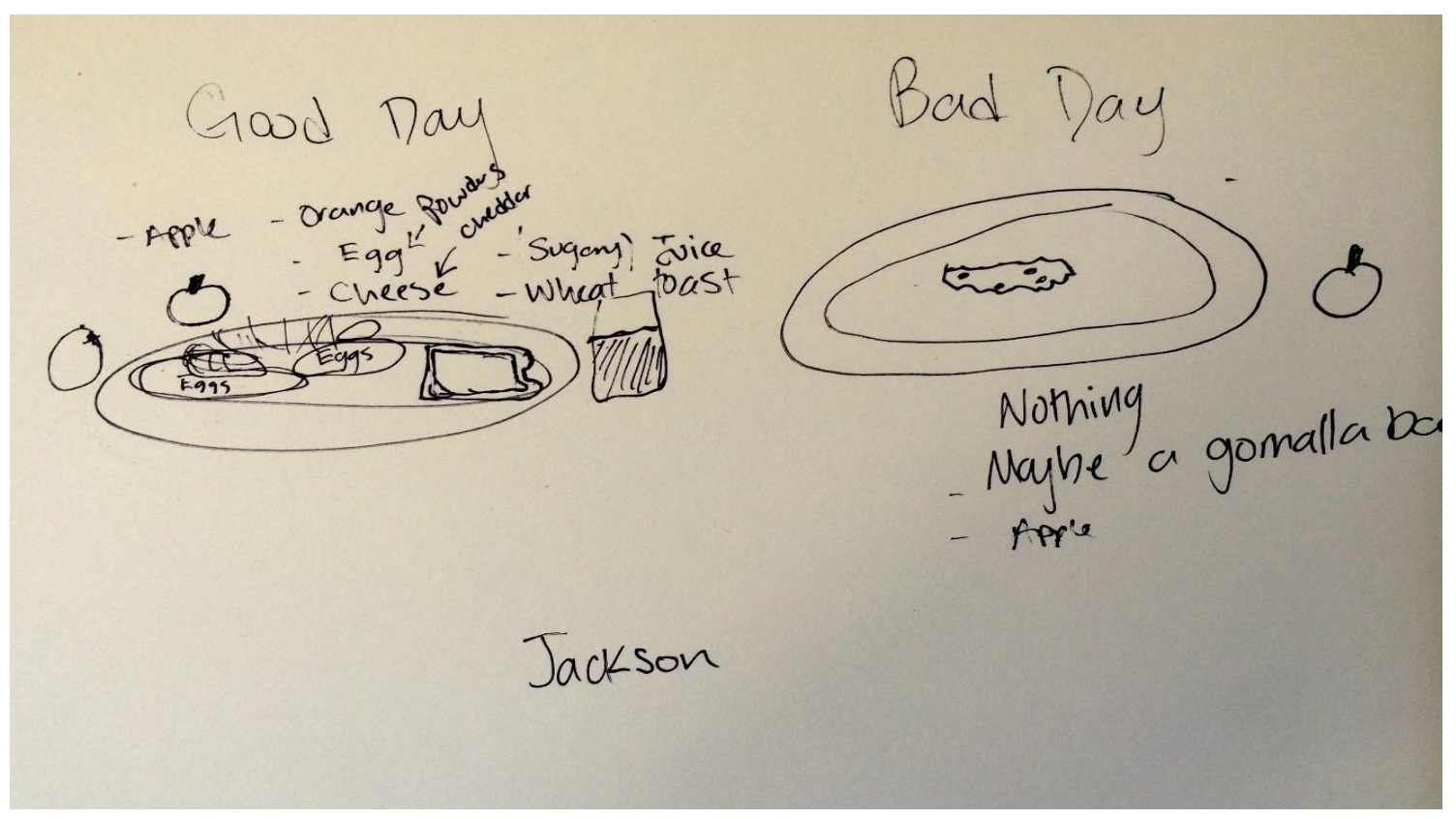

Figure 14. DAHSSBT drawing of good and bad days for breakfast. Good day pattern codes include drink, and fruit. Bad day pattern codes include nothing, plate, preparation, and variety. 
Table 8 provides a summary of the analysis of the DAHSSBT pattern coding. The items that appeared the most frequently in the drawings were drinks, plates, preparation, variety, and fruit. These patterns suggest that students value these breakfast items and think of them as part of a typical high school student's breakfast.

Table 8

DAHSSBT Analysis Organization

\begin{tabular}{|c|c|c|c|c|c|c|c|c|c|c|c|c|c|}
\hline & \multicolumn{13}{|c|}{ DAHSSBT Analysis Organization } \\
\hline $\begin{array}{l}\text { Pattern } \\
\text { Code }\end{array}$ & 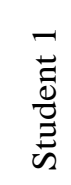 & 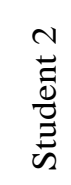 & 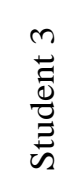 & $\underset{\stackrel{\nabla}{\vec{D}}}{\stackrel{+}{\vec{D}}}$ & 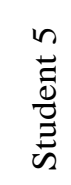 & $\begin{array}{l}0 \\
\stackrel{0}{0} \\
\underset{0}{0} \\
\underset{n}{\tilde{D}}\end{array}$ & 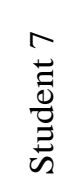 & 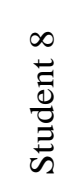 & 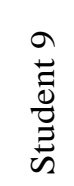 & $\begin{array}{l}O \\
\tilde{E} \\
\tilde{\theta} \\
\tilde{E} \\
\dot{v}\end{array}$ & 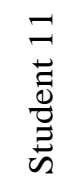 & 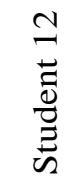 & 丞 \\
\hline Grab-n-Go & $\mathrm{X}$ & & & & $\mathrm{X}$ & & $\mathrm{X}$ & & & & & & 3 \\
\hline Drink & & & $\mathrm{X}$ & $\mathrm{X}$ & & $\mathrm{X}$ & $\mathrm{X}$ & $\mathrm{X}$ & $\mathrm{X}$ & & $\mathrm{X}$ & $\mathrm{X}$ & 8 \\
\hline Fruit & & & $\mathrm{X}$ & $\mathrm{X}$ & & & $\mathrm{X}$ & $\mathrm{X}$ & & $\mathrm{X}$ & & $\mathrm{X}$ & 6 \\
\hline $\begin{array}{l}\text { Full (Hot) } \\
\text { Breakfast }\end{array}$ & & & $\mathrm{X}$ & $\mathrm{X}$ & & & $\mathrm{X}$ & & & & $\mathrm{X}$ & $\mathrm{X}$ & 5 \\
\hline Nothing & & $\mathrm{X}$ & & & & & $\mathrm{X}$ & & & & & & 2 \\
\hline Plate & & $\mathrm{X}$ & $\mathrm{X}$ & $\mathrm{X}$ & & $\mathrm{X}$ & $\mathrm{X}$ & & $\mathrm{X}$ & & & $\mathrm{X}$ & 7 \\
\hline Preparation & & & & $\mathrm{X}$ & & $\mathrm{X}$ & $\mathrm{X}$ & & $\mathrm{X}$ & $\mathrm{X}$ & $\mathrm{X}$ & $\mathrm{X}$ & 7 \\
\hline $\begin{array}{l}\text { School } \\
\text { Breakfast }\end{array}$ & & & $\mathrm{X}$ & & & & & $X$ & & & & & 2 \\
\hline Table & & $\mathrm{X}$ & & & & $\mathrm{X}$ & & & & $\mathrm{X}$ & & & 3 \\
\hline Variety & & & $X$ & $X$ & & & $X$ & $X$ & $X$ & & $X$ & $X$ & 7 \\
\hline
\end{tabular}

Thematic Networks

The next step in the analysis process was the development of thematic networks. This process, based on the work by Attride-Stirling (2001), proposes that the thematic 
networks technique is a powerful and highly sensitive tool for the systematization and presentation of qualitative analysis. I organized the pattern codes into eight minor (organizing) themes and labeled them to reflect the outcome of the analysis of the pattern codes that comprised them. Using these minor organizing themes, and working through the analysis process, I developed four overarching themes that are the basis for the thematic network. The four overarching themes include: (a) communication, (b) relationships, (c) transitions, and (d) value. Creating the thematic networks helped me systematize the data and conceptualize the patterns that emerged through the In Vivo coding.

\section{Communication}

The two minor organizing themes that make up the overarching communication theme include communication about food and nutrition and student communication. The organizing theme food and nutrition was comprised of three pattern codes: (a) communication issues about school meal menus, (b) poor communication about the menu and food and nutrition, and (c) inconsistencies in allowing students to eat breakfast in the classroom. Kids complain and student suggestions for school breakfast are the two pattern codes that comprise the student communication organizing theme. Table 9

illustrates the sequence of pattern coding to the overarching communication theme, and Figure 15 shows the communication strand of the thematic network. 
Table 9

\section{Sequence of Pattern Coding to Communication Overarching Theme}

\begin{tabular}{|l|l|l|}
\hline Overarching Theme & Minor Theme & Pattern Code \\
\hline \multirow{4}{*}{ Communication } & \multirow{2}{*}{$\begin{array}{l}\text { Communication about } \\
\text { Food and Nutrition }\end{array}$} & $\begin{array}{l}\text { Communication issues about school meal menu } \\
\text { nutrition }\end{array}$ \\
\cline { 3 - 3 } & $\begin{array}{l}\text { Inconsistencies in allowing students to eat breakfast in } \\
\text { the classroom }\end{array}$ \\
\cline { 2 - 3 } & $\begin{array}{l}\text { Student } \\
\text { Communication }\end{array}$ & Kids complain \\
\cline { 3 - 3 } & Student suggestions for school breakfast \\
\hline
\end{tabular}

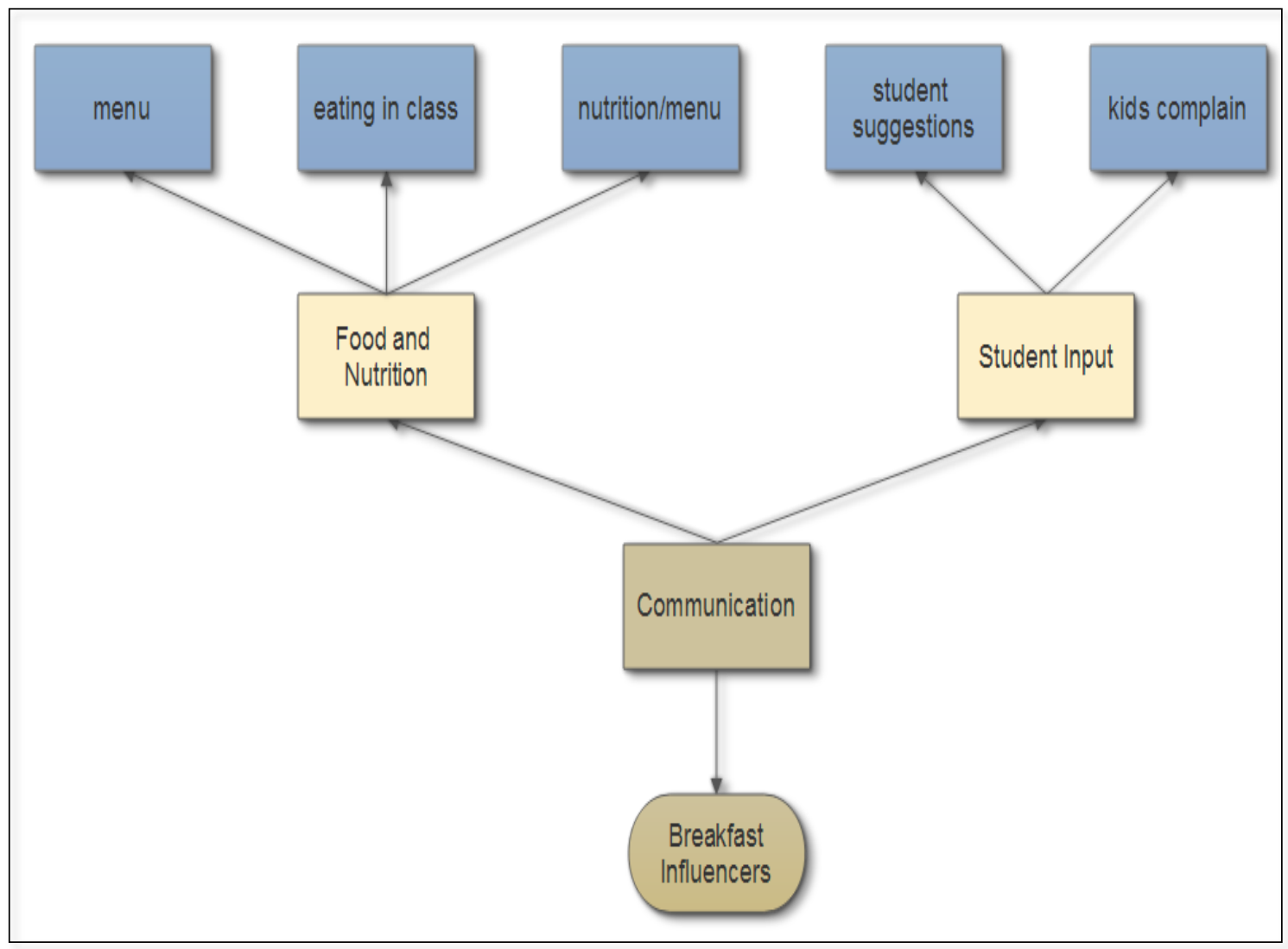

Figure 15. Communication strand of the thematic network. 


\section{Relationships}

The organizing theme, relationships, is comprised of two organizing themes:

current kitchen staff and students; and relational identity. The pattern themes that are included within the organizing theme of current kitchen staff and students include negative attitude toward current nutrition staff and the relationship between kitchen staff and students. The relational identity minor organizing theme is made up of three pattern codes: (a) disgusting food, (b) feeding students snacks during the day, and (c) status/identity based on food served/not cared about through food. Table 10 illustrates the sequence of pattern coding to the overarching relationships theme, and Figure 16 illustrates the relationships strand of the thematic network.

Table 10

Sequence of Pattern Coding to Relationships Overarching Theme

\begin{tabular}{|l|l|l|}
\hline Overarching Theme & Minor Theme & Pattern Code \\
\hline \multirow{3}{*}{ Relationships } & $\begin{array}{l}\text { Current kitchen staff } \\
\text { and students }\end{array}$ & Negative attitude toward current nutrition staff \\
\cline { 2 - 3 } & \multirow{2}{*}{ Relational Identity } & Relationship between kitchen staff and students \\
\cline { 2 - 3 } & & Aware “our students" need food \\
\cline { 2 - 3 } & & Feed students snacks during the day \\
\cline { 2 - 3 } & $\begin{array}{l}\text { Status/identity based on food served/not cared about } \\
\text { through food }\end{array}$ \\
\hline
\end{tabular}




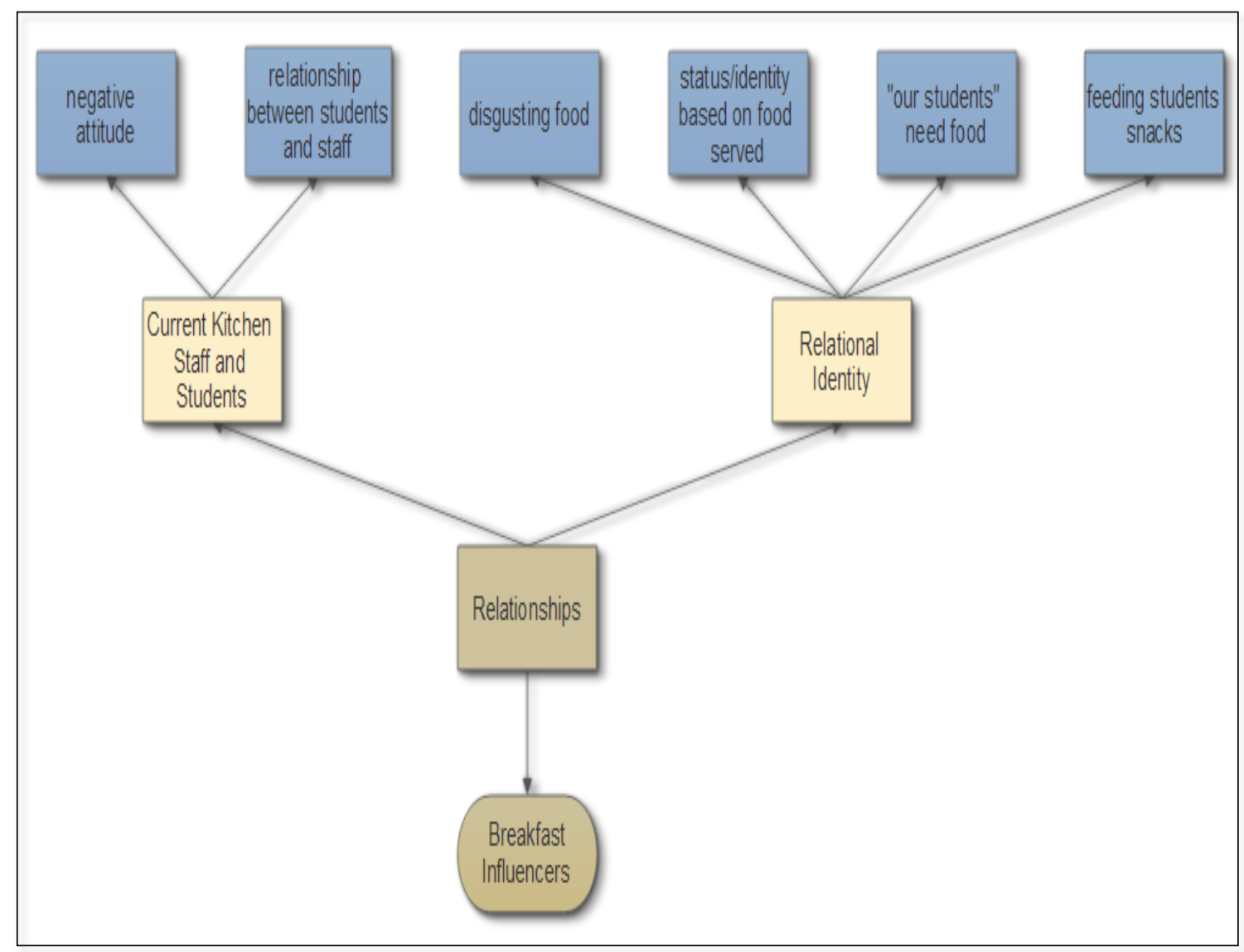

Figure 16. Relationships strand of the thematic network.

\section{Transitions}

The overarching theme, transitions in the school meal programs, is made up of two organizing themes-kitchen staff and federal meal pattern changes. For the kitchen staff theme, transitions with nutrition director and kitchen staff and nostalgia for former nutrition director were the two pattern codes that devised the theme. The second organizing theme, federal meal pattern changes, included three pattern codes: (a) Obama Lunch Plan, (b) confusion about the school meal programs, and (c) school breakfast requirements. Table 11 illustrates the sequence of pattern coding to the overarching 
transitions in the school meal programs theme, and Figure 17 illustrates the relationship strand of the thematic network.

Table 11

Sequence of Pattern Coding to Transitions in the School Meal Programs Theme

\begin{tabular}{|l|l|l|}
\hline Overarching Theme & Minor Theme & Pattern Code \\
\hline \multirow{4}{*}{ Transitions } & Kitchen Staff & Transitions with Nutrition Director and kitchen staff \\
\cline { 2 - 3 } & $\begin{array}{l}\text { Federal Meal Pattern } \\
\text { Changes }\end{array}$ & Obama Lunch Plan \\
\cline { 2 - 3 } & Confusion about the school meal program \\
\cline { 2 - 3 } & School breakfast requirement \\
\hline
\end{tabular}

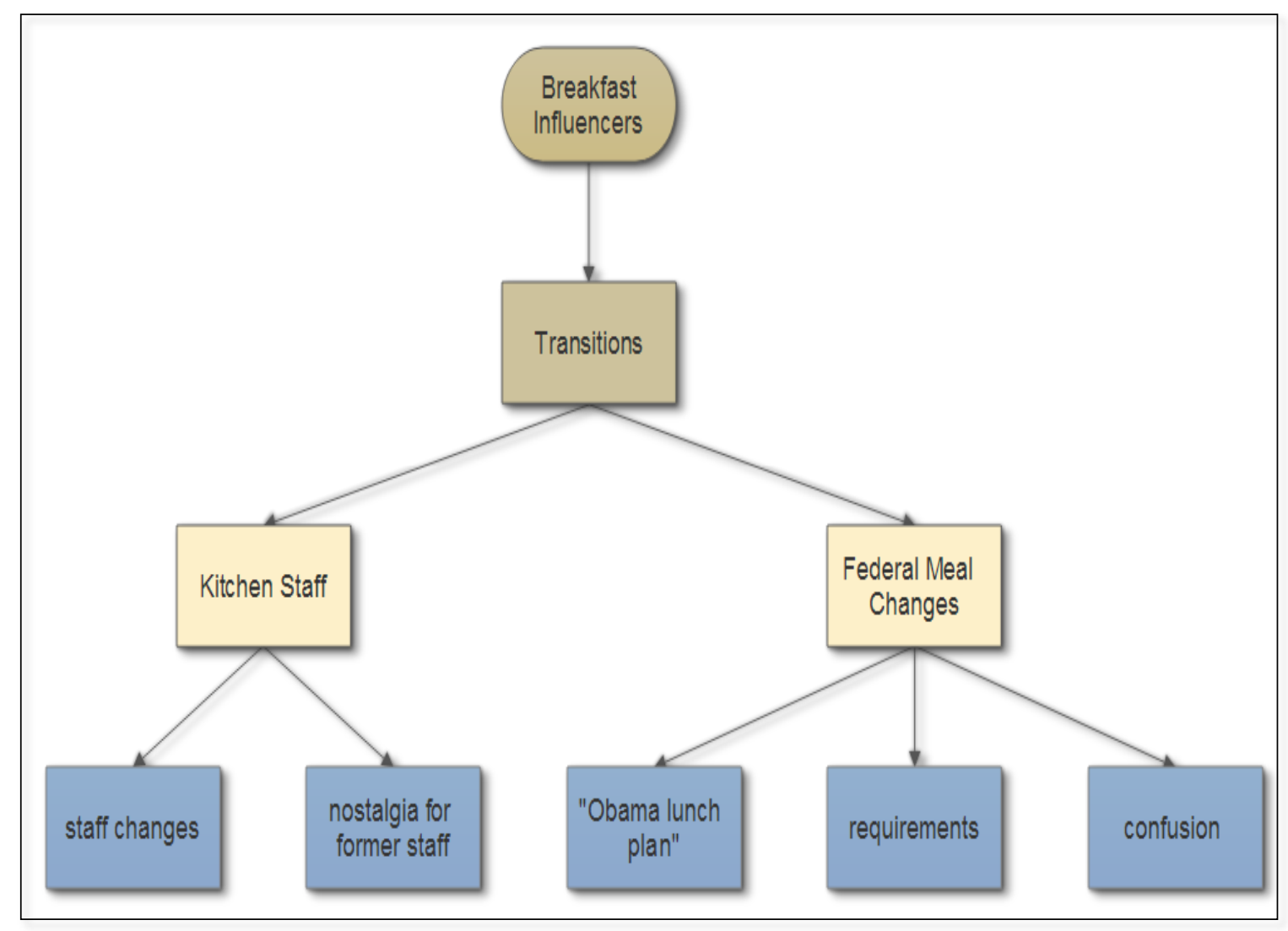

Figure 17. Transitions strand of the thematic network. 


\section{Values}

The overarching theme, value of school breakfast, is comprised of the minor organizing themes - academic and time. The pattern codes for the academic theme are improved learning, inconsistencies in allowing students to eat breakfast in the classroom, and learning/focus. The pattern codes that make up the time theme include how time factors in breakfast eating and time to eat in the morning. Table 12 describes the sequence of pattern coding to the overarching value (of school breakfast), and Figure 18 illustrates the relationship strand of the value thematic network.

Table 12

Sequence of Pattern Coding to Value Theme

\begin{tabular}{|l|l|l|}
\hline Overarching Theme & Minor Theme & Pattern Code \\
\hline \multirow{4}{*}{ Value } & \multirow{3}{*}{ Academic } & Improved learning \\
\cline { 3 - 3 } & & $\begin{array}{l}\text { Inconsistencies in allowing students to eat breakfast in } \\
\text { the classroom }\end{array}$ \\
\cline { 3 - 3 } & \multirow{2}{*}{ Time } & Learning/focus \\
\cline { 2 - 3 } & & How time factors in to breakfast eating \\
\cline { 3 - 3 } & & Time to eat in the morning \\
\hline
\end{tabular}




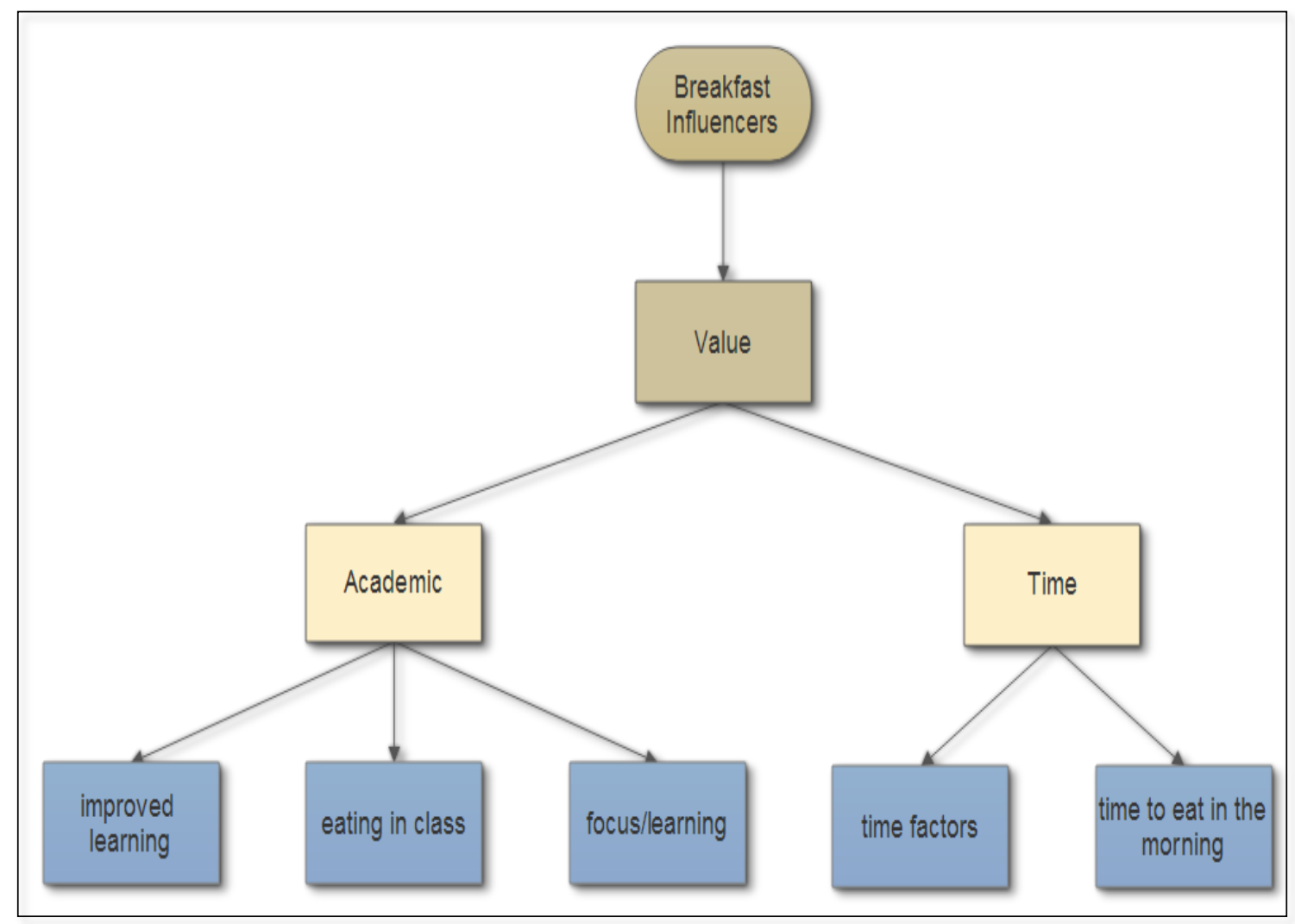

Figure 18. Value strand of the thematic network.

\section{Thematic Network Takeaway}

I am not typically a visual person and generally skip over tables and figures in research papers. However, this process of breaking the data down through the initial coding process and then reassembling it through pattern coding and thematic networks by creating figures and tables was unbelievably valuable to my analysis process. Although this qualitative analysis is subjective, I do believe this process allowed me to step outside of my biases somewhat, and see the data from a slightly more objective perspective. Figure 19 illustrates the overall appearance of the larger thematic network. 

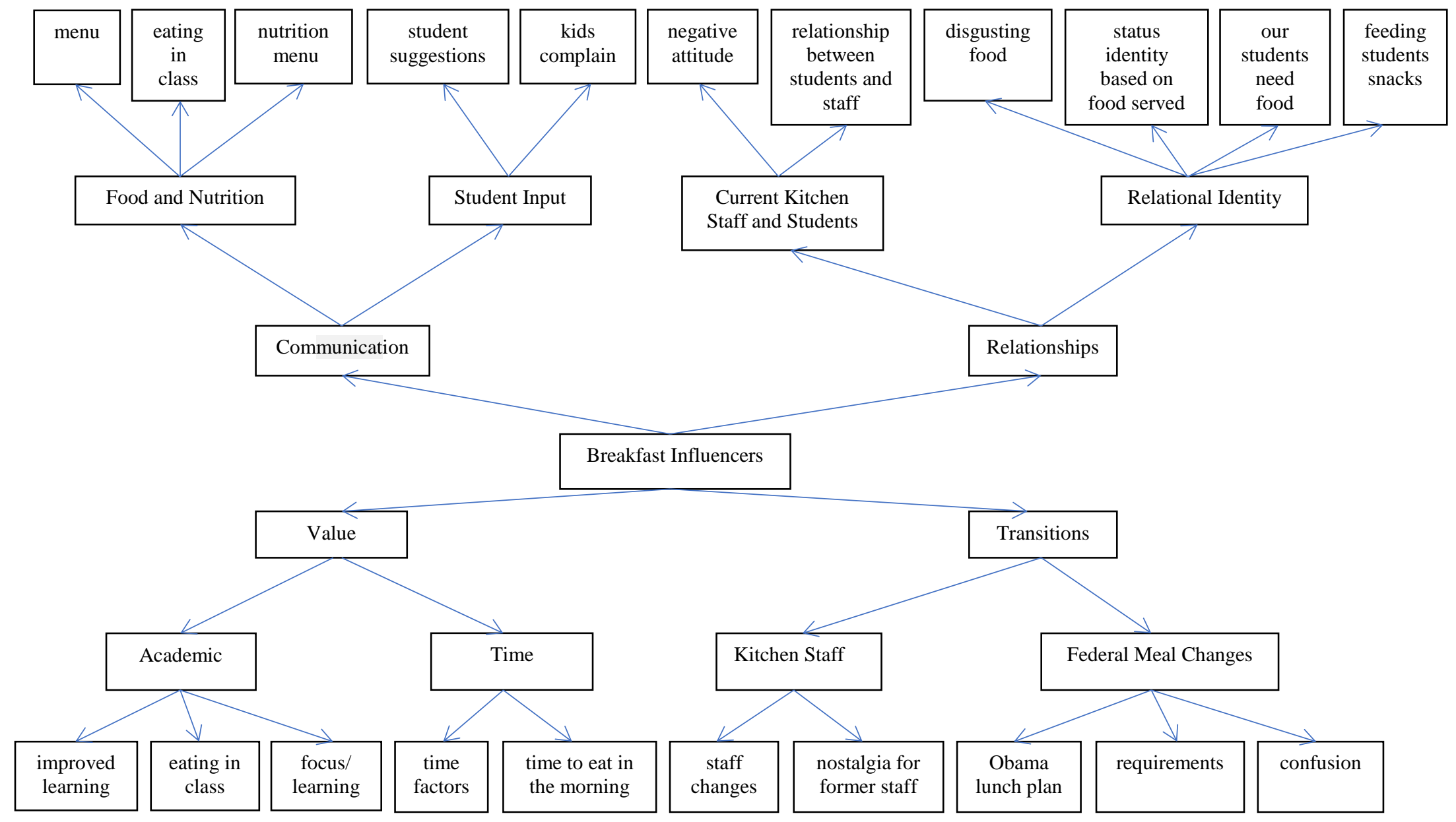

Figure 19. Thematic network overview. 


\section{Interpretation of the Findings}

Because this study included both quantitative and qualitative data collection tools, I begin this section with an interpretation of the quantitative results followed by an interpretation of the qualitative findings. Then, I relate it all back to the theoretical framework, and the initial research problem, which is to explore factors influencing participation in the School Breakfast Program for culturally diverse high school students within a school serving a predominately low-income population.

\section{Interpretation of Quantitative Results}

In this study, I used descriptive statistics to interpret the quantitative questions asked on the staff survey to analyze the participant's perceptions and behaviors linked to nutrition, breakfast eating/skipping, weight maintenance, and food security. These quantitative questions include: (a) 11 questions asked using a Likert scale model, (b) a binary demographic question on gender, (c) and a multiple option question on where staff typically eat breakfast. I will interpret the results of the survey as if the survey results are representative of all employees in the school.

The percentage of males and females that took part in the survey were reflected the percentage of male and female staff at the school—one third male and two thirds female. On a personal level, most (67\%) of the staff typically eat breakfast every day, and nearly a third of the staff eat breakfast a few days a week or not at all. However, almost all the staff shared that eating breakfast helps them perform better at work, and most eat breakfast because it is good for their 
health. Most of the school's staff members do not believe one way or another that eating breakfast helps control weight. Few staff eat breakfast at home on a school/work day. Staff that eat breakfast, tend to eat on the way to school-either food they have brought from home, or food they pick-up on the way to school. Although some staff seem to believe that students who eat breakfast are more alert in class, most of the staff did not seem to notice a difference-possibly because they are unaware which students actually eat breakfast. Close to half of the school staff promote the importance of eating breakfast.

In terms of the school's breakfast program, all staff report that the program is an important resource for their students. However, only about half of staff said that they know much about the program. Similarly, about half of staff members encourage students to take part in the program, and almost all staff believe that the School Breakfast Program is not promoted within the school.

\section{Interpretation of Qualitative Findings}

I interpret the qualitative finds using the thematic networks previously described. I discuss the thematic overarching themes that include: (a) communication, (b) relationships, (c) transitions in the School Breakfast Program, and (d) value of the School Breakfast Program.

Communication. The findings on the topic of communication fall under the two minor organizing themes: lack of communication about food and nutrition, and student communication. The lack of communication organizing theme stems from repeated comments during the staff interviews and student 
focus groups, about the lack of posted weekly or monthly menus. One staff member explained, "Sometimes I would like to eat lunch here, and I would wonder what's being offered and it would just be a surprise."

Lack of communication, including internal and external communication of the school's breakfast program, was another topic that both students and staff mentioned. While some individual staff members believed they themselves promoted the school's breakfast program, the consensus of both staff and students was that the overall the school did a poor job with promotion. Students said there were no promotions, like at other schools of "meatless Fridays." I could find very limited research in peer-reviewed journals on internal—students, staff — or external communications_families, community — about the School Breakfast Program. However, in a study exploring alternative school breakfast practices, internal marketing was mentioned as a strategy (Olsta, 2013).

In addition to issues with lack of communication about the school menus and promotion about nutrition or the School Breakfast Program, there were inconsistencies in communication about whether or not students were allowed to eat breakfast in their first period classroom. The food service manager reported that students were able to eat in their first period class, although in interviews with the administration and teaching staff, I received mixed reports on the practice of allowing students to eat during first period. One staff member raised the question about whether students should be given some time during their first class period to eat: 
I teach first period, and every day many students come into class just as the bell is ringing with their breakfast from the cafeteria. Since eating is not allowed in class, often they cannot eat it. I am wondering if we should allow students to eat during the first 5-10 minutes of the first period class. (School staff member, 2018)

Research exploring alternative school breakfast strategies suggests that allowing students to eat breakfast in the classroom improves students' access to school breakfast, participation rates, and can be successful when a school team representing school nutrition, administration, teachers, custodians, students, and parents work together to plan and implement the practice (Rainville \& Carr, 2008).

Student communication was the second minor theme under the overarching theme of communication. Student communication was based on two root issues. The first is derived from comments during staff interviews that students complain about the food no matter what. For example, one staff member acknowledged, "Kids are picky eaters and they like to complain, so you can take that with a grain of salt." The second came from the students' comments that they wanted to provide suggestions for what was served to them and how to improve the school meals. Several students suggested that a survey might be a good way to provide input. Similar to the earlier study I conducted, youth participatory action research (YPAR) has been found to engage youth and provide insights into an issue from the youth's point of view (Harper et al., 2017; Noonan, 2015; Oregon Health Authority, 2014). 
Relationships. The minor organizing themes, under the overarching relationship theme, included: (a) current kitchen staff and students, and (b) relational identity. The focus of this overarching theme is the perceived relationship between the new school food service staff and the students, and the way the rest of the school staff, excluding food service, views the students in terms of food insecurity. As previously mentioned, a completely new food service crew replaced the previous food service manager at the beginning of the year that this study took place. Within this overarching theme, both students and staff talked about the students' negative feelings toward the new kitchen staff and the relationship between the kitchen staff and the students. When the students were asked if there was anything that made them not want to eat breakfast at school, one of the students answered, "The lunch lady, I do not want to see her in the morning, I am talking about their attitude because it makes you not want to eat." During this comment, the other students nodded in agreement. Separately, a staff member commented,

Our new cafeteria staff, as reported by the students, are short tempered and don't build relationships with the kids. They don't work to help students get what they need because of dietary restrictions. Students have felt yelled at, judged and unheard. I've heard students say they are not going to eat because they don't want to deal with the cafeteria ladies and that is a serious problem. (School staff member, 2018)

To my knowledge, there is no mention of relationships between nutrition service workers and students in the literature. However, studies on social emotional learning and youth suicide prevention do touch on the relationship of 
students with school staff, although specifically the student-teacher relationship (Hall, Fullerton, FitzGerald, \& Green, 2018; Yang, Bear, \& May, 2018).

Relational identity was another theme that emerged. Sluss and Ashforth (2007) described relational identities as "knitting the network of roles and role incumbents together into a social system" (p. 11). They defined relational identification as "the extent to which one defines oneself in terms of a given rolerelationship" (p. 11). In considering the integrated composite theoretical framework, relational identity includes an integration of person- and role-based identities that influence the individual, interpersonal, and collective levels of self (Sluss \& Ashforth, 2007). Cronin, McCarthy, Brennan, and McCarthy (2014) explored food systems, consumerism, and relational identity in terms of obesity, suggesting that the relational identity goes beyond "built" and social forces of the present, and is more relative to the continual occasions, times, spaces or stages consumers traverse through their lives. In this study, three pattern codes defined the organizing theme of relational identity, these included: (a) disgusting food, (b) feeding students snacks during the day, and (c) status/identity based on food served/not cared about through food. Both patterns-disgusting food and status/identity based on food served/not cared about through food-seemed to demonstrate how students saw the adequacy of the food service in terms of doing the job they were hired to do, and how the students saw themselves situated within the school. The students' comments exemplify the point, “They had chunky milk. The fact that this happened is not cool. That means they are not 
even checking or caring." Another student said, "I feel like sometimes the food that we are provided with might be bad and sometimes they say, 'Well this is what we got." and a third student remarked, "I think we need more investment and the lunch people need to be invested in their job and their importance in our education."

Within the relational identity organizing theme two other patterns were included. These include aware "our students" need food, feeding students snacks during the day. It seemed that more than any other topic, the staff I interviewed mentioned that students come into the classroom and administrative offices asking for food. The registrar and others pass out granola bars and other food items to the students throughout the day and often between breakfast and lunch. The attitude of the staff seems to be that these students come from low-income homes and do not always have enough to eat. I have included a few quotes from staff to illustrate the point:

We have had students who at home may not have eaten properly or at all, and we're asking them to do homework and we've had students come in and say, 'I didn't do the homework because I didn't have anything to eat, and I was hungry and tired." (School staff member, 2018)

"They're not eating breakfast, but we also have some snacks throughout the day, granola bars kind of thing and our kids are coming in constantly getting granola bars as well, so that might be a substitute for them of not eating breakfast." Another staff member commented, "We have these granola bars, and if you were here in between classes, because they only give them out in between classes, not during class time, you would just see a steady stream of kids coming through." 
The topic of staff providing snacks to the students did not come up during either of the focus groups, although one student did draw a picture of a granola bar in her DAHSSBT drawing.

Transitions in the school meal programs. The next overarching theme, transitions in the school meal program, reflects upheaval in the food service staff over the last year and includes pattern coding on transitions with nutrition director and kitchen staff, and nostalgia for former nutrition director. Additionally, this overarching theme is also focused on the recent federal guideline changes under the Healthy, Hunger-Free Kids Act of 2010 which is part of the Affordable Health Care Act. One of the students referred to this as the Obama Lunch Plan, which seemed like a good pattern code title.

The transitions with the Nutrition Director and kitchen staff were not smooth at the beginning of the year. During the middle of the year, the nutrition director was replaced, and the kitchen staff stayed on. The previous nutrition director had been at the school for several years and the students and staff reported fond memories of her.

Our former head of the cafeteria was a woman much beloved by the students. She was sweet, affectionate, and motherly with them. Her care showed up in her preparation of the food and treatment of students. (Staff member, 2018).

I got breakfast last year and she never once ran out of food, like never ever. She wanted you to eat. She would make sure you ate and she would come to your table and say, "Does anybody want seconds?" (Student, 2018) 
I feel like she would try to get to know us as students. She would come to the basketball games and the track meets and stuff and just be part of the school. (Student, 2018)

The final organizing theme under the transitions overarching theme is changes in the federal meal guidelines. Although the changes of the Healthy, Hunger-Free Kids Act of 2010 have been phased in over the last few years, there seemed to be confusion over what foods could be served. The three pattern codes listed under this minor organizing theme are labeled: (a) Obama Lunch Plan, (b) confusion about the school meal program, and (c) school breakfast requirements. I heard from several staff and the student focus groups about the coffee cake, one staff member said, 'I'm still a little confused about what's allowed and what's not allowed. We had coffee cake a few times." A student remarked, "When Michelle Obama made all her changes, we had to make a lot of changes so we have nothing white. So all our grains are whole grain, whole grain bread, pasta, stuff like that."

Although these changes, and the confusion surrounding these changes, may have added to the overall negative comments about the school's breakfast program, an evaluation of the School Breakfast Program and National School Lunch Program before and after the implementation of the 2010 Healthy, Hunger-Free Kids Act which required healthier school breakfast options beginning in SY2013-2014, found that there was no negative impact on school meal participation over time. This research suggests that it was likely not the 
strengthened nutrition standards that affected school breakfast participation rates (Vaudrin, Lloyd, Yedidia, Todd, \& Ohri-Vachaspati, 2017).

Value. The overarching theme, value, included to minor organizing themes: academics and time. Both the staff and students pattern codes contributed to each of these organizing themes.

Academics. This organizing theme includes pattern codes labeled, improved learning, inconsistencies in allowing students to eat breakfast in the classroom, and learning/focus. All the staff interviewed said they valued breakfast as a way to improve learning, especially due to their shared belief that breakfast reduces hunger and improves concentration. As one teacher put it, "We've all seen research, and it's proven that when a kid is properly fed, or just has something in their body, and they're not hungry they're able to concentrate more."

However, this value did not always come through with practice. While the food service staff I interviewed believed that students were able to take their breakfast to class and finish eating, the administration has no policy regarding this practice, and it was up to the teacher's discretion. Like the food service staff, most of the staff I interviewed thought that there was consistency among staff, although what they believed with inconsistent. Therefore, some teachers allow students to eat breakfast in class and others do not. This topic is discussed further under the organizing theme of time. 
The third pattern coding, learning/focus, was a pattern code from the student data. Most of the students agreed that they focused better when they'd had something to eat, but a few students questioned this concept, one student remarked, "Some of it I think is mental, too, because we have all heard you should eat breakfast before you take a test and we are mentally thinking, 'oh, I am going to do better because I ate breakfast today." Definitely a good point, on top of the extensive amount of research, including large systematic literature reviews, that suggests eating breakfast contributes to learning (Adolphus et al., 2013; Hoyland, McWilliams, Duff, \& Walton, 2012; Kleinman et al., 1998; Murphy, 2007; Murphy \& Pagano, 2001; Pollitt \& Mathews, 1998; Rampersaud, 2009; Rampersaud et al., 2005; Taras, 2005). A recent study by Askelson et al. (2017) included examining school administrators' perception of school breakfast. Similar to the responses by administration and staff to the survey question in this study, administrators in Askelson et al.'s study said they felt the School Breakfast Program is important resource for students. However, in a study examining parents' perceptions of the School Breakfast Program, the link between the School Breakfast Program and learning was not mentioned (Spruance et al., 2018)

Time. The second organizing theme, under the value of school breakfast overarching theme, is time. This consists of two pattern codes: (a) how time factors in to breakfast eating, and (b) time to eat in the morning. 
How time factors in to breakfast eating was a pattern code from student data. The students talked about their struggle to get to school early enough to have breakfast. One student brought up that students had to sign up each morning if they wanted some special dietary accommodation, like a vegetarian meal for example. The student explained that if she was running late, she not only missed getting breakfast, but also was unable to sign-up and so would not have the accommodation for the lunch meal either.

Time to eat in the morning was a pattern coded from staff data based on their perception of student eating behavior. I heard from almost every staff member that I talked with that time was a major issue for students, and that students often arrived at school saying that they do not have time to eat breakfast at home, and they do not have time to get to school early enough to have breakfast. One staff member commented, “Because they were late, they didn't make it to school on time, so they didn't eat, they lost that chance." While the food service staff said that they have grab-n-go breakfasts for students who arrive late, it does not sound like many students are coming to get the late breakfasts once class has started. Not having enough time in the morning to eat has been frequently reported in the child and adolescent breakfast eating behavior literature (Mullan et al., 2014; Olsta, 2013; Reddan et al., 2002; Sweeney \& Horishita, 2005).

The thematic networks were helpful in synthesizing the data analysis of the qualitative material into manageable selections that capture the relevant topics that emerged from the staff and students. The final data interpretation 
centers on the DAHSSBT. The patterns coded for the analysis of this data were different from the patterns coded for the interviews and focus groups. However, the patterns revealed in the DAHSSBT support the overarching themes and appear to support the idea that students do like breakfast that takes some preparation and includes variety, but often they have to grab something quickly, or do not have time to eat anything at all.

\section{Research Questions}

This study set out with the aim of exploring factors influencing participation in the School Breakfast Program for culturally diverse high school students within a school serving a predominately low-income population. The research questions were designed with the theoretical framework, the integrated composite framework combining ecological systems theory and social cognitive theory, in mind. The research questions sought to identify the factors and systems within the case study that influence breakfast eating behavior, which based on the survey, staff interviews, and focus group questions; these referred mostly to participation in the school's breakfast program. I use the interpretation of the data to answer the two research questions posed at the beginning of the study:

1. How do students at this college-prep high school for underserved students describe the factors - social, economic, physical - that influence their breakfast-eating behavior?

2. How do staff at this college-prep high school for underserved students describe the systems and supports designed to promote breakfast-eating? 


\section{Research Question 1}

The data highlighted in the thematic networks answers some, but not all of the first research question: How do students at this college-prep high school for underserved students describe the factors—social, economic, physical—-that influence their breakfasteating behavior? Putting this question through the lens of the integrated composite framework helped provide a deeper understanding of the influence of systems, within a bounded physical and social environment, on behavior. In terms of the ecological systems theory, the levels that were most influential were the microsystem, where individuals engage directly with each other; the microsystem, the linkages among mesosystems; and the exosystem, the social system in which the individual exists (the school). Additionally, within each level, the interaction between personal factors, behavior, and environmentcomponents of social cognitive theory-played out.

Social factors. Social factors can include the relationships in the school that influence breakfast eating. In this case study, it appears that the negative relationships between students and food service staff, as well as nostalgia for the past nutrition manager negatively influenced the students' decisions to eat breakfast. Similarly, the lack inconsistency in allowing students to eat during first period and the inability of students to bring their breakfast into their homeroom classes negatively impacted their ability to eat in the morning. Communication was a noticeable influencing factor. The students and staff commented that the menus were not posted ahead of time and that the School Breakfast Program, although an important resource, was not promoted within the school or outside the school to the students' families. From the data, it appears that role- 
modeling could be another possible factor. In this case study, role modeling would be seen as a negative support, as the staff do not typically utilize the School Breakfast Program, unlike the lunch program. Another social factor that did not support students participating in the School Breakfast Program was habitual practice of providing the students with granola bars and other snacks throughout the day. Additionally, the students identified that on school days they do not typically have time to eat breakfast at home, and only if they can get to the school early enough they can have breakfast there.

Economic factors. Economic factors did not appear to play a role in terms of the students not feeling that they could not eat breakfast because of the price. While the majority of students in the school receive breakfast for free, some students do pay for their breakfast. It was the perceived quality of the food that influenced what and if the students ate breakfast regardless of whether the students paid for their meal or received it for free. One student, who paid full price for meals, commented that she wanted to be sure the breakfast looked decent before she spent her money on it.

Physical factors. The physical environment of the school could be seen as creating both supports and barriers for eating the school breakfast. The fact that the only place for students to enter the building before the first bell is the back entry through the school cafeteria/gym. As one staff member mentioned, students who arrived early will hang out and talk or study at the cafeteria tables. However a barrier promoted by the physical environment of the school is that the cafeteria is on the lower level while most of the classroom and administrative offices are on the upper level. Instead of sending hungry students to the cafeteria for a grab-n-go breakfast, it appears that they are being given a 
granola bar or another snack that staff members purchase to have on hand, which ultimately hurts the School Breakfast Program by decreasing participation in the program.

\section{Research Question 2}

The second research question, How do staff at this college-prep high school for underserved students describe the systems and supports designed to promote breakfasteating?, is a bit more difficult to answer based on the question itself, as the findings indicate that the School Breakfast Program is not well promoted. The integrated composite framework was similarly impactful to understanding research question 2 . The social system and the lack of consistent practices around breakfast promotion (exosystem level) greatly influenced the answer to this research question. Interestingly, the word "inconsistent" came up in most of the staff interviews when asked about the school's breakfast program.

Systems and supports. Currently, the school seems to be working toward improving the relationship between the staff and students. From the results of the survey, staff members reported that the School Breakfast Program is an important resource for students, but only about half of the staff knew much about the program, and only half encourage students to take part in it. The systems within the school like communication, requirements that menus are posted, consistent policies about eating in class, and providing snacks to students during the school day outside of the school meal program should be discussed as a way of strengthening systems and promoting the School Breakfast Program. One of the most important facilitators for eating breakfast seems to 
be the fact that the students have to enter through the cafeteria door before the start of school. All students walk past the food being served which seems to normalize eating breakfast and reduce stigma. Furthermore, research indicates that there are solutions like alternative breakfast delivery such as universal breakfast, and grab-n-go meals and implementing breakfast after the bell that will improve the systems and supports within the school that should result in many more students participating in the School Breakfast Program (Conklin, Bordi, \& Schaper, 2004; Haines \& Spruance, 2018; Olsta, 2013).

\section{Limitations of the Study and My Role as a Researcher}

The purpose of the study was to explore factors influencing participation in the School Breakfast Program for culturally diverse high school students within a school serving a predominately low-income population. In this section, I discuss the background, limitations, and constraints of my study, along with my positionality as the researcher.

I chose to conduct a case study, and to use a school and those in it, staff and students, as the bounded social and physical system. Although I believe I gained valuable insight from conducting my research within this one school, it also presented limitations. The impact that the students felt from the recent turnover in their food service staff impacted the data to an extent that is likely unique to this particular incident. Additionally, due to confidentiality, I was not able to describe the school in as much detail as I would have liked to include.

I am happy with my decision to conduct a qualitative study, and I believe that I collected rich data from my various collection methods which provided trustworthiness to the research. Trustworthiness is one way researchers can persuade themselves and readers 
that their research findings are worthy of attention (Lincoln \& Guba, 1985). These data collection methods included the staff survey, staff interviews, student focus groups, and the student DAHSSBT. However, I do realize I made some mistakes along the way. For example, the survey questions that used a Likert scale were not all designed in the same direction. Most of the questions used the number 5 as the highest, (for example, strongly agree) and 1 as the lowest, (for example, strongly disagree); however in at least the way one question was written, the Likert-type survey was reversed. Furthermore, when I conducted the DAHSSBT at the beginning of each focus group, I did not ask the first focus group to explain their drawings, I just had them turn them into me when they were finished drawing. I had planned to do the same procedure with the second focus group's DAHSSBT; however, one of the students asked if he could explain his drawing, and all the other students followed suit. I realized that the students' explanations were important to my overall understanding of the picture and helped with the analysis process. I feel that not having the description of the drawings from the first focus group participants was a limitation to this study.

The majority of my study was qualitative in nature that brings a fair amount of subjectivity to the study. As the researcher, my role was extremely important to this study in terms of being aware of my personal bias during interactions with the research participants, and in data collection, interpretation and reporting. I have spent my career as a public health nutritionist passionately working to improve nutrition standards and improve access to government-funded nutrition programs. I am aware that I began the study with a fair amount of bias. Through the dissertation process, and the many, many 
earlier drafts of writing on this topic, I felt like I gained insight into recognizing my inclination to view things in a certain way, and I tried hard to be more objective. Through the process, it almost felt like I was shedding articles of clothing, and when I reread my earlier writing, I am surprised by how one-sided it sounds. I have not fully undressed, but I would like to think I am down to my long underwear, and that I approached my role as a researcher with fewer layers of bias than I might have had at the beginning of this research project. I do believe that the exercise in creating the thematic networks did move the data analysis in a different direction, away from what I thought was important to the study, and closer to what the actual participants were expressing.

The limitations in the study, specifically the case study design, issues with the survey and the DAHSSBT, and my role as a researcher were noted. This study likely contains many other limitations that I am unaware of. I do keep a research notebook that I labeled, "what not to do next time," which contains the limitations that I have caused myself, like turning off the audio recorder too soon, or reversing the order of the Likert scale.

\section{Summary of Analysis}

In this chapter, I described the data analysis process that I used, including how I synthesized the data using the following methods: descriptive statistics for the staff survey; In Vivo coding, pattern coding, and ultimately creating thematic networks using the data from the staff survey, staff interviews, and student focus groups; and pattern coding for the DAHSSBT. I interpreted the data through the lens of the integrated composite model framework to answer the research questions. To my surprise there were 
no obvious differences between the all-female and mixed gender focus group discussions, and weight control and stigma were two topics that did not come up in either of the focus group discussions.

In the next chapter, I synthesize the findings and discuss the notable outcomes. I also situate these findings within the larger context of previous studies similar in scope and discuss how this study may influence the future research on influencing school breakfast participation among adolescents. I conclude with a discussion of the significance of the findings, and the potential for innovations in policy and practice at the school level and beyond. 


\section{CHAPTER 5: DISCUSSION AND CONCLUSION}

For the past 9 years, since I completed the Youth Action Research study, I have had an interest in the high incidence of adolescent breakfast skipping and the low high school participation rate in the School Breakfast Program, which is the research problem behind this study. I designed this qualitative research study with the purpose to explore factors influencing participation in the School Breakfast Program for culturally diverse high school students within a school serving a predominately low-income population. Data were collected through several different methods: a survey and interviews with school staff; and focus groups and DAHSSBT with students. The data were analyzed using In Vivo and pattern coding as first cycle coding methods, and thematic analysis using a thematic network approach as a seconding cycle coding method. Quantitative survey data were analyzed using descriptive statistics. In Chapter 4, I interpreted the data within the context of integrated composite theory in an attempt to answer the study's research questions:

1. How do students at a college-prep high school for underserved students describe the factors - social, economic, physical — that influence their breakfast-eating behavior?

2. How do staff at a college-prep high school for underserved students describe the systems and supports designed to promote breakfast eating?

In Chapter 4, I also included a presentation of the results, interpretation of the findings, and concluded with a discussion of the limitations of the study. 
In this final chapter, I present a synthesis of the findings, including a discussion of major outcomes of the study which include: (a) inconsistent school policies and practices, (b) relational identity, (c) relationships between students and food service staff, (d) students want to be heard, and (e) time. In this chapter, I use the composite integration model to situate this study within the larger context, and discuss the implications for policy and practice in both the field of public health and education.

\section{Synthesis of the Findings}

In this section I discuss the major outcomes of the study. Some of the findings are well documented in the literature along with research on plausible solutions. Other prominent findings from the study are not supported in the research literature, yet could be significant in addressing the problem of adolescent breakfast skipping and low School Breakfast Program participation rates among high school students. The key outcomes that are discussed include: (a) inconsistent school policies and practices, (b) relational identity, (c) relationships between students and food service staff, (d) students want to be heard, and (e) time.

\section{Inconsistent Practices}

As noted in Chapter 4, the majority of the staff interviewed used the word inconsistent while describing the school's breakfast program. I had noticed the frequency of this word while reading through the transcripts. Therefore, it is not a surprise that in opposition to the staff's stated value of the School Breakfast Program as an important resource for students, this study uncovered practices within the school that were inconsistent in their support for the school's breakfast program, and in some cases 
undermined the program all together. I identified three practice issues that warrant discussion. The first is the lack of promotion of the School Breakfast Program within the school, including inconsistent posting of weekly or monthly menus, and lack of messaging about the program to families and the greater community. The second issue is the inconsistency in allowing students to eat during first period class. Finally, I discuss the matter of giving out granola bars and other snacks to students between classes.

Promotion. Posting monthly or weekly menus should be within the job description of the school nutrition director or the lead cafeteria staff. This task in itself would serve to promote the program to students, families, and school staff. Internal promotion within the school as well as promotion about the program to student families and the larger community could increase the visibility, recognition, and importance of the program. The Food Research Action Council provides research-based messaging and best practices for the promotion of School Breakfast Program.

Eating during first period class. All students should have the same opportunity to eat breakfast, and having a consistent school policy could help improve student breakfast eating and participation in the school's breakfast program. The practice of eating breakfast after the school day begins is referred to as "breakfast after the bell" and considered a best practice for improving access to and participation in the School Breakfast Program. Additionally, alternative breakfast practices like Second Chance Breakfast - in which students are offered a second chance to eat breakfast after homeroom or first period (Grab-n-Go style) — are encouraged for middle and high schools as research indicates that many middle and high school students may skip 
breakfast because they are not hungry first thing in the morning (Mullan et al., 2014; Reddan et al., 2002; Sweeney \& Horishita, 2005). Due to the high rate of food insecurity, Oregon and Washington have passed legislation allowing instructional time to be used for students to eat breakfast in their classroom at the start of the school day (Oregon HB 2846; Washington HB 1508).

Providing snacks. The practice of giving snacks to students undermines the School Breakfast Program, by decreasing participation rates. Decreased participation leads to less revenue for the program and in turn impacts the variety and quality of the program's food purchases. If policies allowing late students to pick up a grab-n-go school breakfast and eat during first period class were supported, not only would the school receive federal reimbursement leading to higher revenue and better support for the School Breakfast Program, but it would also be unnecessary for staff to provide students with snacks. Additionally, schools that participate in the School Breakfast Program and National School Lunch Program are required to meet specific nutrition standards for the foods sold in schools. The snacks provided by the staff may not meet the same nutritional requirements (Bhatia, Jones, \& Reicker, 2011).

\section{Relational Identity}

As a reminder, relational identity is defined as the extent to which one defines oneself in terms of a given role-relationship includes an integration of person- and role-based identities that influence the individual, interpersonal, and collective levels of self (Sluss \& Ashforth, 2007). Story et al. (2002) explained that food is inextricably intertwined with issues of identity, self-concept, 
friendship, security, independence, and authority. I have not seen the term relational identity or the concept of identity linked to school food in the research literature; however, studies on stigma tie in well with this concept. As with this study, I witnessed the same relational identity phenomena during the YPAR project I facilitated years ago (cited in Oregon Health Authority, 2014). In that study, I recognized that the students felt that the perceived quality of the food they were served was reflective of their status as students in the larger community. During this study, and the YPAR study, I heard the students rank the perceived quality of their school food with their perceptions of the food quality in other high schools in the area. The food was ranked by socioeconomic status, even though the majority of high schools that were discussed shared a school district kitchen. In both cases, the private schools ranked higher than any of the public schools did. In addition to the food, I believe the relationship with the new food service staff also negatively impacted the students' relational identity. Comments from students like, "I think we need more investment and the lunch people need to be invested in their job and the importance of our education," not only echoes of self-efficacy, but also sounds to me like a cry for a status adjustment, “hey, this isn't us, we don't accept this new lot in life, we have potential!"

\section{Relationships}

The importance of relationships came out loud and clear when both the staff and students were remembering the past nutrition director. One staff 
member said, "She was like our grandma," and the students remembered her fondly and the way that she cared that they ate, and always had enough food for them-she even came back to school to watch their games. Honestly, I wonder if any new food service staff would have had much of a chance following in the footsteps of this beloved staff member. The contrast that the students and staff felt was evident in their remarks.

Although there is research literature around the importance of studentteacher relationships, I am not aware of any literature on relationships between food service staff and students. However, based on this study and comments I hear working with state school nutrition program, the relationships between school food service staff and students are extremely important, especially in terms of the school's social emotional climate. Food service staff are adults in the school who do not assign homework or have academic expectations of the student, which for some students is important. The food service staff are often the first persons many students see at the school in the morning. As the student who in reference to the school food service provider said, "I do not want to see her in the morning, I am talking about her attitude because it makes you not want to eat," a positive attitude and a smile can decrease a student's anxiety and may keep the student engaged in school. As one of my colleagues says, "It's easier to hire a nutrition director with a nice smile and teach the skills needed to run the program, than it is to teach someone with skills to run a nutrition program how to smile." 


\section{Students Want to be Heard}

Youth engagement practices, like taste tests and competitions to name menu items, are known in the field to improve student investment in school meal programs, but the literature is extremely limited on this topic.

Similar to the earlier YPAR study I conducted, the students wanted to have a voice in decisions about food they were offered (cited in Oregon Health Authority, 2014). In the earlier study, I found that it was helpful for the students to be able to sit down with the food service staff and ask questions. Once they had information, their attitude toward the school meal program shifted. For example, once the students learned that the budget for food was extremely limited, they said they had a new appreciation for how good the food actually was. The students also said they felt much better about what was served when they learned that as much as possible, the food purchased was local.

As mentioned, youth engagement can take the form of taste testing, a contest, or participation on a wellness or student advisory council that learns from, and works with, the school food service staff to plan menu items. Additionally, students could add articles about nutrition awareness topics - locally grown or meatless Fridays - to the school newsletter, or work with the school and school food staff to plan and cater a community or family event.

\section{Time}

The issue of high school students not having time to eat in the morning is well documented in the literature (Mullan et al., 2014; Olsta, 2013; Reddan et al., 2002; 
Sweeney \& Horishita, 2005). The time constraints show up in the eating behaviors of the school staff with close to a third reporting that they eat breakfast on the way to work. While traditional School Breakfast Programs can provide students who can get to school early with a meal, alternative practices like breakfast after the bell and second chance breakfast does a better job of giving all students in the school a chance to eat.

Anyone who has worked with or in a school knows that in the larger context the implementation of the suggestions that I have made within each theme are not simple. Anyone who has worked in child nutrition programs understands that implementation of many of these suggestions can be overwhelming, but are possible with support.

\section{The Case Study Situated in the Larger Context}

The integrated composite theory may help situate this study within the greater context. This theoretical model will help consider the overall impact by examining the macro-level influence, physical environmental influences, the social environmental influences, and the individual influences.

\section{Macro-Level Influences}

At the macro-level, the School Breakfast Program is a federally assisted meal program. All children and adolescents in participating schools and residential institutions are eligible for a federally subsidized meal, regardless of family income. The School Breakfast Program is part of the suite of federal Child Nutrition Programs administered at the Federal level by the Food and Nutrition Service. At the state level, the program is generally administered by State education agencies, which operate the program through agreements with local school food authorities in more than 78,000 schools and 
institutions. School breakfasts must meet the applicable recommendations of the Dietary Guidelines for Americans (USDA FNS, 2017a). In 2014, the federal government spent about $\$ 3.7$ billion on meal reimbursement for the School Breakfast Program and fed about 14 million children daily (USDA FNS, 2017a).

The primary legislation for the National School Lunch Program (USDA FNS, 2016) is contained in the Child Nutrition Act (reauthorized as the Healthy, HungerFree Kids Act of 2010). However, the Farm Bill also includes provisions that address school food (Network for Public Health Law, 2011). The Healthy, Hunger-Free Kids Act of 2010 was signed into law by President Barak Obama and has become associated with Michelle Obama's priority to improve the health of American children. The Healthy, Hunger-Free Kids Act of 2010 allowed the USDA FNS (2017b) to make significant changes to the National School Lunch and School Breakfast Programs for the first time in more than 30 years. With additional input of $\$ 4.5$ billion, the objective of the Healthy, Hunger-Free Kids Act of 2010 was to get a handle on the unprecedented rise of childhood obesity and Type II diabetes, and reign-in the high-sugar, high-fat, highsodium foods and beverages being sold and served to American school students. It is no surprise that this Act remains extremely political with both sides of the aisle making halftrue claims. Bottom line, each state, district and school is different, and change, especially when it comes to food and nutrition, takes time.

American school students are bombarded with media promoting foods high in sugar, fat, and salt. These messages influence food preferences and expectations (Schwartz, Kunkel, \& DeLucia, 2013; Story \& French, 2004; Weber, Story, \& Harnack, 
2006). Research and industry records indicate that low-come and minority youth are targeted at higher rates than white youth with unhealthy food marketing (Grier \& Kumanyika, 2008; Isselmann DiSantis et al., 2017; Kumanyika \& Grier, 2006; J. D. Williams, Achterberg, \& Sylvester, 1993). In contrast, the requirements for the School Breakfast Program include relatively strict limits on sodium, calories, saturated fats, and trans fats (USDA FNS, 2017a).

This case study was situated in an area of the Pacific Northwestern United States where residents are experiencing a widening gap in health outcomes and educational achievement. Social determinants such as income, housing, employment, education and access to health care are contributors. For students in this region, this is reflected in high rates of chronic absenteeism, food insecurity, obesity, and a deplorable high school graduation rate.

\section{Physical Environmental Influences}

The physical environmental influences include school food service at the local level. School food services operate as businesses, but unlike private businesses, they must comply with the rules, regulations, and strict nutrition standard requirements. All decisions about what specific foods to serve, and how they are prepared, are made by local school food authorities (USDA FNS, 2017a).

Additionally, school food service departments must operate as nonprofits, yet make enough money to be self-sufficient, of course while dealing with hard-to-please consumers. Food costs, changes in student participation rates, and foods being sold or given away that compete with the program can have devastating economic effects on 
program operations. Furthermore, food service staff typically work earlier hours making it difficult for them to be part of after-school staff meetings, and potentially limiting their engagement and involvement with the rest of the school.

In the focus group, students told me they were upset that the school did not allow Uber Eats to deliver. As the nutrition landscape continues to evolve, the influences of the physical environment will continue to impact adolescent breakfast eating.

\section{Social Environmental Level}

At the social environmental level, interpersonal relationships impact eating behavior. At this moment in history, unlike the 1960s and 1970s of my youth, we are living in an America where sitting down to eat two to three meals a day with family is not the norm (Neumark-Sztainer, Larson, Fulkerson, Eisenberg, \& Story, 2010). In this case study, the importance of relationships was demonstrated both in terms of the relationship between the students and nutrition staff, and also in the way the students perceived their status based on the food that was served to them. The breakfast eating behaviors of adolescents will continue to be influenced by family, friends, and peer networks. This happens through interpersonal influences like modeling, reinforcement, social support, and perceived norms (Story et al., 2002).

\section{Individual Level}

The individual level (intrapersonal) influences vary by student, but include components that are likely representative of high school students outside of this case study such as knowledge of health and nutrition, food preferences, and self-efficacy. In 
this study, self-efficacy took the form of calling out for healthier food choices as an investment in their education.

\section{Reciprocal Determinism}

In this study, the physical environment was extremely valuable to student breakfast behavior and participation in the School Breakfast Program. The act of students entering the school through the cafeteria is a behavioral design that normalized the School Breakfast Program and may have done away with stigma. This type of reciprocal determinism is also seen in the act of giving away the granola bars and other snacks. A well-intended gesture to ensure students have enough to eat impacts the student's behavior in such a way that the staff and students are relying on the snacks instead of the school meal program and creating a culture where students are asking for food.

Additionally, the practice of giving students granola bars and other snacks in the morning instead of sending them to the cafeteria for a federally reimbursable meal - a grab-n-go breakfast for example — negatively impacts the revenue supporting the School Breakfast Program. With less revenue, the school has less money to purchase a variety of high quality foods that appeal to students, resulting in even fewer students eating school breakfast.

\section{Implications for Education and Public Health Practice and Policy}

In this study, I was particularly interested in learning how a college-prep high school serving primarily minority and low-income students, prioritizes the School Breakfast Program as an academic support. Although, as with any case study, my findings were a snapshot of a system during one brief period of time, and the time to 
evaluate the strength of this school's breakfast program was probably not ideal. With that being said, I do think the implications from this study warrant consideration, and can be useful in informing public health and education practice and policy.

This study is just one more in a long list indicating that "time" is a reason reported by students for skipping breakfast. This study provides one more case for alternative breakfast practices like Breakfast After the Bell and Second Chance Breakfast.

This study also points out the importance of relationships between staff and students and the way identity is linked to food. I think the study speaks volumes to the need for youth engagement opportunities and the ability to provide input into decisions made about the food served, and nutrition promotions within the school. Similarly, this study implicates the importance of friendly and nurturing food service staff.

Finally, I would argue that if administrators at a college-prep high school serving low-income students are not prioritizing the School Breakfast Program as an academic support for students, it is likely that administrators in other high schools are likely not recognizing the academic potential of the School Breakfast Program either. The lack of promotion of the School Breakfast Program within the school, as well as outside the school to families and the community was noted as a finding in this case study. I would like to take this a step further and say that promotion of the School Breakfast Program needs to occur at the administrative and school board level as well. Through my work as a public health nutritionist working with schools, I have found that the public health people are screaming about obesity rates and stricter nutrition standards, the food security people are yelling about feeding hungry children, and school administrators are just 
trying to educate the students in their districts and schools. Until administrators are provided with information that speaks to them about the educational potential of the School Breakfast Program - like the potential to improve absenteeism, tardiness, and graduation rates - they will not hear the message as loud and clear as other things they need to pay attention to.

Policy implications include policy at the organizational, state, and federal level. At the organizational level, policies for eating during first period class could be enacted, even in schools who do not provide breakfast service after school begins. Similarly, schools can do away with providing food to students that competes with the school meal programs, like handing out snacks purchased by individual staff members between classes. Adding strategies to strengthen the School Breakfast Program can be included in Local School Wellness Policies and the School Improvement Plan. At the state level, strategies like alternative breakfast delivery systems can be added into the state Every Student Succeeds Act of 2015 plan, as well as the state Chronic Absenteeism Plan. Policy makers in other states may consider Oregon and Washington's lead, and enact legislation providing instructional time for students to eat in the classroom. Furthermore, schools within states that have passed this legislation should consider taking advantage of it if they are not already doing so. The findings of this study, along with many other research studies that preceded it, indicate that the school meal programs are an important resource for students. These studies suggest that policy at the federal level should take the form of continued support for the Healthy, Hunger-Free Kids Act of 2010 and policy makers should reject efforts to decrease funding or to rollback nutrition standards. Furthermore, 
concerted efforts should be made at the federal level, to support states in assisting district implementation of the requirements of the Healthy, Hunger-Free Kids Act of 2010 to support School Breakfast Programs and student nutrition.

\section{Conclusion}

This study emphasizes the need for additional research on academic achievement and student health outcomes in schools that have implemented alternative breakfast practices, like Breakfast After the Bell. Similarly, additional studies on the practicality of implementing Breakfast After the Bell Programs, like administrator support, perceived barriers like scheduling and mess, are needed. This study also indicates the need for future research into participation in the School Breakfast Program as an academic support. Other recommended studies include cultural and media influences on breakfast choice and participation in the School Breakfast Program and how the school's physical environment and traffic patterns, like all students walking through the cafeteria in the morning, influence school breakfast participation and stigma. Additionally, this study suggests a need for research to dig deeper into the topics of relational identity and school meal programs, as well as studies on the value of positive relationships between students and school food service staff.

This study surprised me in that neither stigma nor weight control came up as a reason that students did not eat the school breakfast. Additionally, I did not find noticeable cultural or economic differences among the themes. However, I was impressed with the data analyzation process, and the themes that emerged. It was confirming to see that some of the themes the study produced are supported in the literature. It was equally 
confirming that other themes from the study, while not prevalent in the research literature, are acknowledged in the field-like hiring nurturing staff. And finally, it was a great surprise to realize that one of the themes, the phenomena of relational identity, I had experienced in my previous study. It is this relationship theme, including relational identity, which makes this study unique among other school breakfast studies.

I have only touched the tip of the iceberg with this study on three extremely complex topics: adolescents; eating behavior; and a federal government program. Despite the upheaval within the school nutrition program in the case study school, I feel relatively confident that if I repeated this study in a different high school, many of these same themes would surface. 


\section{REFERENCES}

Adams, E. J., Grummer-Strawn, L., \& Chavez, G. (2003). Food insecurity is associated with increased risk of obesity in California women. The Journal of Nutrition, 133(4), 1070-1074.

Adolphus, K., Lawton, C. L., \& Dye, L. (2013). The effects of breakfast on behaviour and academic performance in children and adolescents. Frontiers in Human Neuroscience. doi:org/10.3389/fnhum.2013.00425

Affenito, S. G. (2007). Breakfast: A missed opportunity. Journal of the American Dietetic Association, 107(4), 565-569. doi:org/10.1016/j.jada.2007.01.011

Affenito, S. G., Thompson, D. R., Barton, B. A., Franko, D. L., Daniels, S. R., Obarzanek, E., . . . Striegel-Moore, R. H. (2005). Breakfast consumption by African-American and white adolescent girls correlates positively with calcium and fiber intake and negatively with body mass index. Journal of the American Dietetic Association, 105(6), 938-945. doi:org/10.1016/j.jada.2005.03.003

Alaimo, K., Olson, C. M., Frongillo Jr., E. A., \& Briefel, R. R. (2001). Food insufficiency, family income, and health in U.S. preschool and school-aged children. American Journal of Public Health, 91(5), 781-786.

Alaimo, K., Olson, C. M., \& Frongillo, E. A. (2002). Family food insufficiency, but not low family income, is positively associated with dysthymia and suicide symptoms in adolescents. The Journal of Nutrition, 132(4), 719-725.

Askelson, N. M., Golembiewski, E. H., Bobst, A., Delger, P. J., \& Scheidel, C. A. (2017). Understanding perceptions of school administrators related to school breakfast in a low school breakfast participation state. Journal of School Health, 87(6), 427-434.

Attride-Stirling, J. (2001). Thematic networks: An analytic tool for qualitative research. Qualitative Research, 1(3), 385-405. doi:org/10.1177/146879410100100307

Auerback, C. F., \& Silverstein, L. B. (2003). Qualitative data. New York, NY: University Press 
Bailey-Davis, L., Virus, A., McCoy, T. A., Wojtanowski, A., Vander Veur, S. S., \& Foster, G. D. (2013). Middle school student and parent perceptions of government-sponsored free school breakfast and consumption: A qualitative inquiry in an urban setting. Journal of the Academy of Nutrition \& Dietetics, $113(2), 251-257$.

Balen, A. H., Anderson, R. A. (2007) Impact of obesity on female reproductive health: British Fertility Society, policy and practice guidelines. Human Fertility, 10(4), 195-206. doi:org/10.1080/14647270701731290

Bandura, A. (1977). Self-efficacy: Toward a unifying theory of behavioral change. Psychological Review, 84(2), 191-215. Retrieved from https://www.uky.edu/ eushe2/Bandura/Bandura1977PR.pdf

Bandura, A. (1986). Fearful expectations and avoidant actions as coeffects of perceived self-inefficacy. American Psychologist, 41(12), 1389-1391.

Bandura, A. (1989). Human agency in social cognitive theory. American Psychologist, 44(9), 1175-1184. doi:org/10.1037/0003-066X.44.9.1175

Bandura, A. (1998). Health promotion from the perspective of social cognitive theory. Psychology and Health, 13(4), 623-649. doi:org/10.1080/08870449808407422

Bandura, A. (2004). Health promotion by social cognitive means. Health Education and Behavior, 31(2), 143-164. doi:org/10.1177/1090198104263660

Bandura, A., O'Leary, A., Taylor, C. B., Gauthier, J., \& Gossard, D. (1987). Perceived self-efficacy and pain control: Opioid and nonopioid mechanisms. Journal of Personality and Social Psychology, 53(3), 563.

Baranowski, T., Perry, C. L., \& Parcel, G. S. (2002). How individuals, environments, and health behavior interact. Health Behavior and Health Education: Theory, Research, and Practice, 3, 165-184.

Bartfeld, J. (2010). School Breakfast Program: Participation and impacts. Collingdale, PA: Diane Publishing. Retrieved from https://books.google.com/books?hl= en\&lr=\&id=gGuWhHNwKYwC\&oi=fnd\&pg=PA3\&dq=The+School+Breakfast + Program+Participation+and+Impacts\&ots=5hIasQvZTG\&sig=G2ihFswUwvoM5 RwUa1d_kQwP4Qs

Barton, B. A., Eldridge, A. L., Thompson, D., Affenito, S. G., Striegel-Moore, R. H., Franko, D. L., . . . Crockett, S. J. (2005). The relationship of breakfast and cereal consumption to nutrient intake and body mass index: The National Heart, Lung, and Blood Institute Growth and Health study. Journal of the American Dietetic Association, 105(9), 1383-1389. doi:org/10.1016/j.jada.2005.06.003 
Basch, C. E. (2011a). Breakfast and the achievement gap among urban minority youth. Journal of School Health, 81(10), 635-640.

Basch, C. E. (2011b). Healthier students are better learners: A missing link in school reforms to close the achievement gap. Journal of School Health, 81(10), 593-598. doi:org/10.1111/j.1746-1561.2011.00632.x

Berkey, C. S., Rockett, H. R. H., Gillman, M. W., Field, A. E., \& Colditz, G. A. (2003). Longitudinal study of skipping breakfast and weight change in adolescents. International Journal of Obesity, 27(10), 1258-1266. doi:org/10.1038/ sj.ijo.0802402

Bernstein, L., McLaughlin, J. E., Crepinsek, M. K., \& Daft, L. M. (2004). Evaluation of the School Breakfast Program pilot project: Final report (Report No. CN-04SBP). Retrieved from https://www.fns.usda.gov/evaluation-school-breakfastprogram-pilot-project

Best, J. R., Miller, P. H., \& Naglieri, J. A. (2011). Relations between executive function and academic achievement from ages 5 to 17 in a large, representative national sample. Learning and Individual Differences, 21(4), 327-336. doi:org/10.1016/ j.lindif.2011.01.007

Beydoun, M. A., \& Wang, Y. (2010). Pathways linking socioeconomic status to obesity through depression and lifestyle factors among young U.S. adults. Journal of Affective Disorders, 123(1-3), 52-63. doi:org/10.1016/j.jad.2009.09.021

Bhargava, A., Jolliffe, D., \& Howard, L. L. (2008). Socio-economic, behavioural and environmental factors predicted body weights and household food insecurity scores in the Early Childhood Longitudinal Study-Kindergarten. British Journal of Nutrition, 100(02), 438-444.

Bhatia, R., Jones, P., \& Reicker, Z. (2011). Competitive foods, discrimination, and participation in the National School Lunch Program. American Journal of Public Health, 101(8), 1380-1386. doi:org/10.2105/AJPH.2011.300134

Bhattacharya, J., Currie, J., \& Haider, S. J. (2006). Breakfast of champions? The School Breakfast Program and the nutrition of children and families. Journal of Human Resources, 41(3), 445-466. doi:org/10.3368/jhr.XLI.3.445

Boney, C. M., Verma, A., Tucker, R., \& Vohr, B. R. (2005). Metabolic syndrome in childhood: Association with birth weight, maternal obesity, and gestational diabetes mellitus. Pediatrics, 115(3), e290-e296. doi:org/10.1542/peds.20041808 
Boschloo, A., Ouwehand, C., Dekker, S., Lee, N., de Groot, R., Krabbendam, L., \& Jolles, J. (2012). The relation between breakfast skipping and school performance in adolescents. Mind, Brain and Education, 6(2), 81-88. doi:org/10.1111/j.1751228X.2012.01138.X

Boyatzis, R. E. (1998). Thematic analysis and code development: Transforming qualitative information. London, England: Sage.

Briefel, R. R., \& Johnson, C. L. (2004). Secular trends in dietary intake in the United States. Annual Review of Nutrition, 24(1), 401-431. doi:org/10.1146/annurev. nutr.23.011702.073349

Bronfenbrenner, U. (1977). Toward an experimental ecology of human development. American Psychologist, 32(7), 513-531. doi:org/10.1037/0003-066X.32.7.513

Bronfenbrenner, U. (1979). The ecology of human development: Experiments by nature and design. Cambridge, MA: Harvard University Press.

Bronfenbrenner, U. (2009). The ecology of human development. Cambridge, MA: Harvard University Press.

Bronte-Tinkew, J., Zaslow, M., Capps, R., Horowitz, A., \& McNamara, M. (2007). Food insecurity works through depression, parenting, and infant feeding to influence overweight and health in toddlers. The Journal of Nutrition, 137(9), 2160-2165.

Brooks-Gunn, J., Johnson, A. D., \& Leventhal, T. (2010). Disorder, turbulence, and resources in children's homes and neighborhoods. Retrieved from http://psycnet.apa.org.proxy.lib.pdx.edu/books/12057/010

Campbell, B. (1998). Realism versus constructivism: Which is a more appropriate theory for addressing the nature of science in science education? Electronic Journal of Science Education, 3(1). Retrieved from http://ejse.southwestern.edu/article/view/ $7597 / 5364$

Case, A., \& Paxson, C. (2006). Children's health and social mobility. The Future of Children, 16(2), 151-173.

Casey, P. H., Simpson, P. M., Gossett, J. M., Bogle, M. L., Champagne, C. M., Connell, C., . . . Weber, J. (2006). The association of child and household food insecurity with childhood overweight status. Pediatrics, 118(5), e1406-e1413. doi:org/ 10.1542/peds.2006-0097 
Casey, P. H., Szeto K., Lensing, S., Bogle, M., \& Weber, J. (2001). Children in foodinsufficient, low-income families: Prevalence, health, and nutrition status. Archives of Pediatrics and Adolescent Medicine, 155(4), 508-514. doi:org/ 10.1001/archpedi.155.4.508

Chambers, D. W. (1983). Stereotypic images of the scientist: The draw-a-scientist test. Science Education, 67(2), 255-265. doi:org/10.1002/sce.3730670213

Centers for Disease Control and Prevention. (2008). Community health and program services (CHAPS): Health disparities among racial/ethnic populations. Atlanta, GA: U.S. Department of Health and Human Services.

Chambers, D. W. (1983). Stereotypic images of the scientist: The draw-a-scientist test. Science Education, 67(2), 255-265. doi:org/10.1002/sce.3730670213

Cohen, B., Evers, S., Manske, S., Bercovitz, K., \& Edward, H. G. (2003). Smoking, physical activity and breakfast consumption among secondary school students in a southwestern Ontario community. Canadian Journal of Public Health $=$ Revue Canadienne De Sante Publique, 94(1), 41-44.

Conklin, M. T., Bordi, P. L., \& Schaper, M. A. (2004). Grab 'n' go breakfast increases participation in the School Breakfast Program. Journal of Child Nutrition and Management, 28(1), 0-0. Retrieved from https://schoolnutrition.org/ uploadedFiles/5_News_and_Publications/4_The_Journal_of_Child_Nutrition_and _Management/Spring_2004/7-conklin.pdf

Cook, T. D., \& Campbell, D. T. (1979). Quasi-experimentation: Design and analysis for field settings. Chicago, IL: Rand McNally.

Cook, J. T., Frank, D. A., Levenson, S. M., Neault, N. B., Heeren, T. C., Black, M. M., .. Chilton, M. (2006). Child food insecurity increases risks posed by household food insecurity to young children's health. The Journal of Nutrition, 136(4), 1073-1076.

Cooper, S. B., Bandelow, S., \& Nevill, M. E. (2011). Breakfast consumption and cognitive function in adolescent schoolchildren. Physiology \& Behavior, 103(5), 431-439. doi:org/10.1016/j.physbeh.2011.03.018

Cooper, S. B., Bandelow, S., Nute, M. L., Morris, J. G., \& Nevill, M. E. (2012). Breakfast glycaemic index and cognitive function in adolescent school children. British Journal of Nutrition, 107(12), 1823-1832. doi:org/10.1017/ S0007114511005022

Creswell, J. W. (2009). Editorial: Mapping the field of mixed methods research. Journal of Mixed Methods Research, 3(2), 95-108. doi:org/10.1177/1558689808330883 
Creswell, J. W., Hanson, W. E., Clark Plano, V. L., \& Morales, A. (2007). Qualitative research designs: Selection and implementation. The Counseling Psychologist, 35(2), 236-264. doi:org/10.1177/0011000006287390

Creswell, J. W., Plano Clark, V. L., Gutmann, M. L., \& Hanson, W. E. (2003). Advanced mixed methods research designs. In A. Tashakkori and C. Teddlie (Eds.), Handbook on mixed methods in the behavioral and social sciences (pp. 209-240). Thousand Oaks, CA: Sage.

Croll, J. K., Neumark-Sztainer, D., \& Story, M. (2001). Healthy eating: What does it mean to adolescents? Journal of Nutrition Education, 33(4), 193-198. doi:org/10.1016/S1499-4046(06)60031-6

Crosnoe, R. (2006). Health and the education of children from racial/Ethnic minority and immigrant families. Journal of Health and Social Behavior, 47(1), 77-93.

Cronin, J., McCarthy, M., Brennan, M., \& McCarthy, S. (2014). The bigger society: Considering lived consumption experiences in managing social change around obesity. European Journal of Marketing , 48(9/10), 1558-1578. doi:org/10.1108/ EJM-02-2013-0065

Cullen, K. W., Eagan, J., Baranowski, T., Owens, E., \& de Moor, C. (2000). Effect of a la carte and snack bar foods at school on children's lunchtime intake of fruits and vegetables. Journal of the American Dietetic Association, 100(12), 1482-1486. doi:org/10.1016/S0002-8223(00)00414-4

Cusatis, D. C., \& Shannon, B. M. (1996). Influences on adolescent eating behavior. Journal of Adolescent Health, 18(1), 27-34. doi:org/10.1016/1054139X(95)00125-C

Delva, J., O’Malley, P. M., \& Johnston, L. D. (2006). Racial/ethnic and socioeconomic status differences in overweight and health-related behaviors among American students: National trends 1986-2003. Journal of Adolescent Health, 39(4), 536-545. doi:org/10.1016/j.jadohealth.2006.02.013

Devaney, B., \& Fraker, T. (1989). The dietary impacts of the School Breakfast Program. American Journal of Agricultural Economics, 71(4), 932-948.

Devaney, B., \& Stuart, E. (1998). Eating breakfast: Effects of the School Breakfast Program. Retrieved from https://eric.ed.gov/?id=ED427860

Drake, A. J., \& Reynolds, R. M. (2010). Impact of maternal obesity on offspring obesity and cardiometabolic disease risk. Reproduction, 140(3), 387-398. doi:org/ 10.1530/REP-10-0077 
Drewnowski, A., \& Specter, S. E. (2004). Poverty and obesity: The role of energy density and energy costs. The American Journal of Clinical Nutrition, 79(1), 6-16.

Dunifon, R., \& Kowaleski-Jones, L. (2003). The Influences of participation in the national School Lunch Program and food insecurity on child well-being. Social Service Review, 77(1), 72-92. doi:org/10.1086/345705

Dwyer, J. (1995). The school nutrition dietary assessment study. American Journal of Clinical Nutrition, 61(1S), 173S-177S

Eden, A. N. (2005). Iron deficiency and impaired cognition in toddlers. Pediatric Drugs, 7(6), 347-352. doi:org/10.2165/00148581-200507060-00003

Egerter, S., Braveman, P., Sadegh-Nobari, T., Grossman-Kahn, R., \& Dekker, M. (2009). Education matters for health. Princeton, NJ: RWJF Commission to Build a Healthier America.

Eicher-Miller, H. A., Mason, A. C., Weaver, C. M., McCabe, G. P., \& Boushey, C. J. (2009). Food insecurity is associated with iron deficiency anemia in U.S. adolescents. The American Journal of Clinical Nutrition. doi:org/10.3945/ ajcn.2009.27886

Eisenmann, J. C., Gundersen, C., Lohman, B. J., Garasky, S., \& Stewart, S. D. (2011). Is food insecurity related to overweight and obesity in children and adolescents? A summary of studies, 1995-2009. Obesity Reviews, 12(5), e73-e83. doi:org/ 10.1111/j.1467-789X.2010.00820.x

Evans, G. W., Gonnella, C., Marcynyszyn, L. A., Gentile, L., \& Salpekar, N. (2005). The role of chaos in poverty and children's socioemotional adjustment. Psychological Science, 16(7), 560-565. doi:org/10.1111/j.0956-7976.2005.01575.x

Every Student Succeeds Act of 2015, Pub. L. No. 114-95 § 114 Stat. 1177. (2015).

Feeding America. (2014). Hunger in America 2014. Retrieved from https://www.feedingamerica.org/research/hunger-in-america

Fielding, N. G., \& Fielding, J. L. (1986). Linking data. Thousand Oaks, CA: Sage.

Food Research and Action Center. (n.d.). School Breakfast Program. Retrieved January 5, 2017, from http://frac.org/programs/school-breakfast-program

Food Research and Action Center. (2018). School-breakfast-scorecard: School year 2016-2017. Retrieved from http://www.frac.org/wp-content/uploads/schoolbreakfast-scorecard-sy-2016-2017.pdf 
Fram, M. S., Frongillo, E. A., Fishbein, E. M., \& Burke, M. P. (2014). Roles for schools and school social workers in improving child food security. Children and Schools, 36(4), 231-239. doi:org/10.1093/cs/cdu018

Fram, M. S., Ritchie, L. D., Rosen, N., \& Frongillo, E. A. (2015). Child experience of food insecurity is associated with child diet and physical activity. The Journal of Nutrition, 145(3), 499-504. doi:org/10.3945/jn.114.194365

Gauvain, M., \& Cole, M. (2004). Readings on the development of children. New York, NY: Macmillan.

Glanz, K., Rimer, B. K., \& Lewis, F. M. (2002). Health behavior and health education: Theory, research, and practice. San Francisco, CA: Jossey-Bass.

Glanz, K., Rimer, B. K., \& Viswanath, K. (2008). Health behavior and health education: Theory, research, and practice. Hoboken, NJ: Wiley.

Gleason, P. M., \& Dodd, A. H. (2009). School Breakfast Program but not School Lunch Program participation is associated with lower body mass index. Journal of the American Dietetic Association, 109(2), S118-S128.

Gleason, P., \& Suitor, C. (2001). Children's diets in the mid-1990s: Dietary intake and its relationship with school meal participation (Report No. CN-01-CD1). Mathematica Policy Research. Retrieved from https://ideas.repec.org/p/mpr/mprres/8db693ba4d8640ec87d978a342a6ec5d.html

Glesne, C. (2015). Becoming qualitative researchers: An introduction (5 $5^{\text {th }}$ ed.). Boston, MA: Pearson.

Greene, J. C. (2008). Is mixed methods social inquiry a distinctive methodology? Journal of Mixed Methods Research, 2(1), 7-22. doi:org/10.1177/1558689807309969

Grier, S. A., \& Kumanyika, S. K. (2008). The context for choice: Health implications of targeted food and beverage marketing to African Americans. American Journal of Public Health, 98(9), 1616-1629. doi:org/10.2105/AJPH.2007.115626

Gross, S. M., Bronner, Y., Welch, C., Dewberry-Moore, N., \& Paige, D. M. (2004). Breakfast and lunch meal skipping patterns among fourth-grade children from selected public schools in urban, suburban, and rural Maryland. Journal of the American Dietetic Association, 104(3), 420-423. doi:org/10.1016/ j.jada.2003.12.014

Gundersen, C. G., \& Garasky, S. B. (2012). Financial management skills are associated with food insecurity in a sample of households with children in the United States. The Journal of Nutrition, 142(10), 1865-1870. doi:org/10.3945/jn.112.162214 
Gundersen, C., Garasky, S., \& Lohman, B. J. (2009). Food insecurity is not associated with childhood obesity as assessed using multiple measures of obesity. The Journal of Nutrition, 139(6), 1173-1178. doi:org/10.3945/jn.109.105361

Gundersen, C., Lohman, B. J., Eisenmann, J. C., Garasky, S., \& Stewart, S. D. (2008). Child-specific food insecurity and overweight are not associated in a sample of 10- to 15-year-old low-income youth. The Journal of Nutrition, 138(2), 371-378.

Haas, S. A. (2006). Health selection and the process of social stratification: The effect of childhood health on socioeconomic attainment. Journal of Health and Social Behavior, 47(4), 339-354. doi:org/10.1177/002214650604700403

Haas, S. A., \& Fosse, N. E. (2008). Health and the educational attainment of adolescents: Evidence from the NLSY97. Journal of Health and Social Behavior, 49(2), 178-192.

Haesly, B., Nanney, M. S., Coulter, S., Fong, S., \& Pratt, R. J. (2014). Impact on staff of improving access to the School Breakfast Program: A qualitative study. The Journal of School Health, 84(4), 267-274. doi:org/10.1111/josh.12142

Haines, A., \& Spruance, L. A. (2018). Parent support for breakfast after the bell programs in a state with very low breakfast participation. Journal of Child Nutrition and Management, 42(1). Retrieved from https://schoolnutrition.org/uploadedFiles/ 5_News_and_Publications/4_The_Journal_of_Child_Nutrition_and_Management /Spring_2018/Parent-Support-for-Breakfast-After-the-Bell-Programs-in-a-Statewith-Very-Low-Breakfast-Participation-Spring2018.pdf

Hall, M., Fullerton, L., FitzGerald, C., \& Green, D. (2018). Suicide risk and resiliency factors among Hispanic teens in New Mexico: Schools can make a difference. Journal of School Health, 88(3), 227-236.

Harper, K., Sands, C., Angarita Horowitz, D., Totman, M., Maitín, M., Rosado, J. S., ... Alger, N. (2017). Food justice youth development: Using Photovoice to study urban school food systems. Local Environment, 22(7), 791-808. doi:org/ 10.1080/13549839.2016.1274721

Haycock, K. (2001). Closing the achievement gap. Educational Leadership, 58(6), 6-11.

Healthy, Hunger-Free Kids Act of 2010, P.L. 111-296. (n.d.). Retrieved from https://www.gpo.gov/fdsys/pkg/PLAW-111publ296/content-detail.html

Hearst, M. O., Shanafelt, A., Wang, Q., Leduc, R., \& Nanney, M. S. (2016). Barriers, benefits, and behaviors related to breakfast consumption among rural adolescents. Journal of School Health, 86(3), 187-194. doi:org/10.1111/josh.12367 
Heckman, J. J. (2008). Schools, skills, and synapses (Working Paper No. 14064). National Bureau of Economic Research. doi:org/10.3386/w14064

Howe, K. R. (2004). A critique of experimentalism. Qualitative Inquiry, 10(4), 42-61.

Hoyland, A., Dye, L., \& Lawton, C. L. (2009). A systematic review of the effect of breakfast on the cognitive performance of children and adolescents. Nutrition Research Reviews, 22(2), 220. doi:org/10.1017/S0954422409990175

Hoyland, A., McWilliams, K. A., Duff, R. J., \& Walton, J. L. (2012). Breakfast consumption in UK schoolchildren and provision of school breakfast clubs. Nutrition Bulletin, 37(3), 232-240. doi:org/10.1111/j.1467-3010.2012.01973.x

Huang, J., \& Vaughn, M. G. (2015). Household food insecurity and children's behaviour problems: New evidence from a trajectories-based study. British Journal of Social Work, 46(4), 993-1008. doi:org/10.1093/bjsw/bcv033

Isselmann DiSantis, K., Kumanyika, S., Carter-Edwards, L., Rohm Young, D., Grier, S. A., \& Lassiter, V. (2017). Sensitizing black adult and youth consumers to targeted food marketing tactics in their environments. International Journal of Environmental Research and Public Health, 14(11). doi:org/10.3390/ ijerph14111316

Jenkins, S., \& Horner, S. D. (2005). Barriers that influence eating behaviors in adolescents. Journal of Pediatric Nursing, 20(4), 258-267. Retrieved from doi:org/10.1016/j.pedn.2005.02.014

Johnson, R. B., \& Onwuegbuzie, A. J. (2004). Mixed methods research: A research paradigm whose time has come. Educational Researcher, 33(7), 14-26. doi:org/10.3102/0013189X033007014

Jones S. J., Jahns L., Laraia B.A., \& Haughton B. (2003). Lower risk of overweight in school-aged food insecure girls who participate in food assistance: Results from the panel study of income dynamics child development supplement. Archives of Pediatrics and Adolescent Medicine, 157(8), 780-784. doi:org/10.1001/ archpedi.157.8.780

Jyoti, D. F., Frongillo, E. A., \& Jones, S. J. (2005). Food insecurity affects school children's academic performance, weight gain, and social skills. The Journal of Nutrition, 135(12), 2831-2839.

Kant, A. K., \& Graubard, B. I. (2011). 20-Year trends in dietary and meal behaviors were similar in U.S. children and adolescents of different race/ethnicity. The Journal of Nutrition, 141(10), 1880-1888. doi:org/10.3945/jn.111.144915 
Kelder, S. H., Perry, C. L., Klepp, K. I., \& Lytle, L. L. (1994). Longitudinal tracking of adolescent smoking, physical activity, and food choice behaviors. American Journal of Public Health, 84(7), 1121-1126.

Keski-Rahkonen, A., Kaprio, J., Rissanen, A., Virkkunen, M., \& Rose, R. J. (2003). Breakfast skipping and health-compromising behaviors in adolescents and adults. European Journal of Clinical Nutrition, 57(7), 842-853. doi:org/10.1038/ sj.ejen. 1601618

Kleinman, R. E., Murphy, J. M., Little, M., Pagano, M., Wehler, C. A., Regal, K., \& Jellinek, M. S. (1998). Hunger in children in the United States: Potential behavioral and emotional correlates. Pediatrics, 101(1), e3-e3.

Koivusilta, L., Arja, R., \& Andres, V. (2003). Health behaviours and health in adolescence as predictors of educational level in adulthood: A follow-up study from Finland. Social Science and Medicine, 57(4), 577-593. doi:org/ 10.1016/S0277-9536(02)00405-7

Kumanyika, S., \& Grier, S. (2006). Targeting interventions for ethnic minority and lowincome populations. Future Child, 16. doi:org/10.1353/foc.2006.0005

Kushner, R., Lawrence, V., \& Kumar, S. (2013). Practical manual of clinical obesity. Boston, MA: Wiley-Blackwell. doi:org/10.1002/9781118643570.ch14

Ladson-Billings, G. (2006). From the achievement gap to the education debt: Understanding achievement in U.S. Schools. Educational Researcher, 35(7), 3-12. doi:org/10.3102/0013189X035007003

Lambert, L. G., Raidl, M., Carr, D. H., Safaii, S., \& Tidwell, D. K. (2007). School nutrition directors' and teachers' perceptions of the advantages, disadvantages, and barriers to participation in the School Breakfast Program. Journal of Child Nutrition \& Management: A Publication of the American School Food Service Association. Retrieved from http://agris.fao.org/agrissearch/search.do?recordID=US201301665486

Larson, N. I., \& Story, M. T. (2011). Food insecurity and weight status among U.S. children and families: A review of the literature. American Journal of Preventive Medicine, 40(2), 166-173. doi:org/10.1016/j.amepre.2010.10.028

Lee, J. S., \& Frongillo, E. A. (2001). Nutritional and health consequences are associated with food insecurity among U.S. elderly persons. The Journal of Nutrition, 131(5), 1503-1509. 
Leos-Urbel, J., Schwartz, A. E., Weinstein, M., \& Corcoran, S. (2013). Not just for poor kids: The impact of universal free school breakfast on meal participation and student outcomes. Economics of Education Review, 36, 88-107. doi:org/10.1016/ j.econedurev.2013.06.007

Leung, B. M., Wiens, K. P., \& Kaplan, B. J. (2011). Does prenatal micronutrient supplementation improve children's mental development? A systematic review. BMC Pregnancy and Childbirth, 11(1), 12. doi:org/10.1186/1471-2393-11-12

Lincoln, Y. S., \& Guba, E. G. (1985). Naturalistic Inquiry. Thousand Oaks, CA: Sage.

Lindström, B., \& Eriksson, M. (2006). Contextualizing salutogenesis and Antonovsky in public health development. Health Promotion International, 21(3), 238-244. doi:org/10.1093/heapro/dal016

Lipsky, L. M., Haynie, D. L., Liu, D., Chaurasia, A., Gee, B., Li, K., . . . Simons-Morton, B. (2015). Trajectories of eating behaviors in a nationally representative cohort of U.S. adolescents during the transition to young adulthood. International Journal of Behavioral Nutrition and Physical Activity, 12(1), 138-149. doi:org/10.1186/ s12966-015-0298-X

Livingood, W. C., Monticalvo, D., Bernhardt, J. M., Wells, K. T., Harris, T., Kee, K., ... Woodhouse, L. D. (2017). Engaging adolescents through participatory and qualitative research methods to develop a digital communication intervention to reduce adolescent obesity. Health Education \& Behavior, 44(4), 570-580.

Logan, C. W., Connor, P., Harvill, E. L., Harkness, J., Nisar, H., Checkoway, A., . . Enver, A. (2014). Community eligibility provision evaluation: Nutrition assistance program report. Alexandria, VA: U.S. Department of Agriculture.

Lorig, K. R., Ritter, P., Stewart, A. L., Sobel, D. S., Brown, B. W. Jr., Bandura, A., . . Holman, H.R. (2001). Chronic disease self-management program: 2-year health status and health care utilization outcomes. Medical Care, 39(11), 1217-1223. Retrieved from http://journals.lww.com.proxy.lib.pdx.edu/lww-medicalcare/ Fulltext/2001/11000/Chronic_Disease_Self_Management_Program_2_Year.8. aspx

Lorig K. R., Sobel, D. S., Stewart, A. L., Brown, B. W. Jr., Bandura, A., Ritter, P., . . Holman, H. R. (1999). Evidence suggesting that a chronic disease selfmanagement program can improve health status while reducing hospitalization: A randomized trial Medical Care, 37(1), 5-14. Retrieved from http://journals.lww. com.proxy.lib.pdx.edu/lww-medicalcare/Fulltext/1999/01000/Evidence_ Suggesting_That_a_Chronic_Disease.3.aspx 
Lyons, A.-A., Park, J., \& Nelson, C. H. (2008). Food insecurity and obesity: A comparison of self-reported and measured height and weight. American Journal of Public Health, 98(4), 751-757. doi:org/10.2105/AJPH.2006.093211

MacDonald, N.E. (2003). Age limits and adolescents. Paediatrics and Child Health, 8(9), 577.

Marples, C. A. (1995). Factors affecting students' participation in the Cincinnati public schools lunch program. Adolescence, 30(119), 745-754.

Maxwell, J. (1992). Understanding and validity in qualitative research. Harvard Educational Review, 62(3), 279-301. doi:org/10.17763/haer.62.3. 8323320856251826

Maxwell, J. A. (2012). Qualitative research design: An Interactive Approach. Thousand Oaks, CA: Sage.

McAuley, E., Jerome, G. J., Elavsky, S., Marquez, D. X., \& Ramsey, S. N. (2003). Predicting long-term maintenance of physical activity in older adults. Preventive medicine, 37(2), 110-118.

McLeroy, K. R., Bibeau, D., Steckler, A., \& Glanz, K. (1988). An ecological perspective on health promotion programs. Health Education Quarterly, 15(4), 351-377.

McLoyd, V. C., Kaplan, R., Purtell, K. M., Bagley, E., Hardaway, C. R., \& Smalls, C. (2009). Poverty and socioeconomic disadvantage in adolescence. In R. M. Lerner\& L. Steinberg(Eds.), Handbook of Adolescent Psychology (pp. 444-492). Hoboken, NJ: Wiley. doi:org/10.1002/9780470479193.adlpsy002014

Merriam, S. B. (1998). Qualitative research and case study applications in education: Revised and expanded from "case study research in education." San Francisco, CA: Jossey-Bass.

Mirzaei, A., Ghofranipour, F., Ghazanfari, Z., \& Ahmadi Vasmehjini, A. (2016). The study of primary schoolchildren eating breakfast status in Ilam: A pilot study. Journal of Basic Research in Medical Sciences, 3(1), 3-9.

Montez, J. K., Hummer, R. A., \& Hayward, M. D. (2012). Educational attainment and adult mortality in the United States: A systematic analysis of functional form. Demography, 49(1), 315-336. doi:org/10.1007/s13524-011-0082-8

Morgan, D. L. (2007). Paradigms lost and pragmatism regained: Methodological implications of combining qualitative and quantitative methods. Journal of Mixed Methods Research, 1(1), 48-76. doi:org/10.1177/2345678906292462 
Morgan, D. L. (2014). Pragmatism as a paradigm for social research. Qualitative Inquiry, 20(8), 1045-1053. doi:org/10.1177/1077800413513733

Mullan, B., Wong, C., Kothe, E., O’Moore, K., Pickles, K., \& Sainsbury, K. (2014). An examination of the demographic predictors of adolescent breakfast consumption, content, and context. BMC Public Health, 14, 264. doi:org/10.1186/1471-245814-264

Murphy, J. M. (2007). Breakfast and learning: An updated review. Current Nutrition \& Food Science, 3(1), 3-36.

Murphy, J. M., Pagano, M. E., Patton, K., Hall, S., Marinaccio, J., \& Kleinman, R. (2000). The Boston Public Schools Universal Breakfast Program: Final evaluation report. Boston, MA: Massachusetts General Hospital,.

Murphy, J., \& Pagano, M. (2001). Effects of a universally free, in classroom breakfast program: Final Report from the Third Year of the Maryland Meals for Achievement Evaluation. Baltimore, MD: Maryland State Department of Education.

Must, A., Spadano, J., Coakley, E. H., Field, A. E., Colditz, G., \& Dietz, W. H. (1999). The disease burden associated with overweight and obesity. JAMA, 282(16), 1523-1529. doi:org/10.1001/jama.282.16.1523

Neinstein, L. S., \& Kaufman, F. R. (1996). Normal physical growth and development. In S. Lawrence \& L. S. Neinstein (Eds.), Adolescent health care: A practical guide (3rd ed.; pp. 3-39). Baltimore, MD: Williams \& Wilkins.

Network for Public Health Law. (2011). How the Farm Bill effects public health. Retrieved October 8, 2018, from https://www.networkforphl.org/_asset/ 76kz89/Farm-Bill-and-Public-Health-FINAL.pdf

Neumark-Sztainer, D. (2006). Eating among teens: Do family mealtimes make a difference for adolescents' nutrition? New Directions for Child and Adolescent Development, (111), 91-105.

Neumark-Sztainer, D., French, S. A., Hannan, P. J., Story, M., \& Fulkerson, J. A. (2005). School lunch and snacking patterns among high school students: Associations with school food environment and policies. International Journal of Behavioral Nutrition and Physical Activity, 2(14). doi:org/10.1186/1479-5868-2-14

Neumark-Sztainer, D., Larson, N. I., Fulkerson, J. A., Eisenberg, M. E., \& Story, M. (2010). Family meals and adolescents: What have we learned from Project EAT (Eating Among Teens)? Public Health Nutrition, 13(07), 1113-1121. doi:org/10.1017/S1368980010000169 
Neumark-Sztainer, D., Story, M., Perry, C., \& Casey, M. A. (1999). Factors influencing food choices of adolescents: Findings from focus-group discussions with adolescents. Journal of the American Dietetic Association, 99(8), 929-937. doi:org/10.1016/S0002-8223(99)00222-9

Nicklas, T. A., Morales, M., Linares, A., Yang, S.-J., Baranowski, T., De Moor, C., \& Berenson, G. (2004). Children's meal patterns have changed over a 21-year period: The Bogalusa Heart Study. Journal of the American Dietetic Association, 104(5), 753-761. doi:org/10.1016/j.jada.2004.02.030

Nicklas, T. A., O'Neil, C. E., \& Berenson, G. S. (1998). Nutrient contribution of breakfast, secular trends, and the role of ready-to-eat cereals: A review of data from the Bogalusa Heart Study. The American Journal of Clinical Nutrition, 67(4), 757S-763S.

Nicklas, T. A., O’Neil, C., \& Myers, L. (2004). The importance of breakfast consumption to nutrition of children, adolescents, and young adults. Nutrition Today, 39(1), $30-39$.

Nicklas, T. A., Reger, C., Myers, L., \& O'Neil, C. (2000). Breakfast consumption with and without vitamin-mineral supplement use favorably impacts daily nutrient intake of ninth-grade students. Journal of Adolescent Health, 27(5), 314-321. doi:org/10.1016/S1054-139X(00)00113-0

Niemeier, H. M., Raynor, H. A., Lloyd-Richardson, E. E., Rogers, M. L., \& Wing, R. R. (2006a). Fast food consumption and breakfast skipping: Predictors of weight gain from adolescence to adulthood in a nationally representative sample. Journal of Adolescent Health, 39(6), 842-849. doi:org/10.1016/j.jadohealth.2006.07.001

Niemeier, H. M., Raynor, H. A., Lloyd-Richardson, E. E., Rogers, M. L., \& Wing, R. R. (2006b). Fast food consumption and breakfast skipping: Predictors of weight gain from adolescence to adulthood in a nationally representative sample. Journal of Adolescent Health, 39(6), 842-849. doi:org/10.1016/j.jadohealth.2006.07.001

Noonan, J. (2015). When soda is a social justice issue: Design and documentation of a participatory action research project with youth. Educational Action Research, 23(2), 194-206. doi:org/10.1080/09650792.2014.990988

Nord, M., Andrews, M., \& Carlson, S. (2005). Household food security in the United States, 2004.

Olson, C. M. (1999). Nutrition and health outcomes associated with food insecurity and hunger. The Journal of Nutrition, 129(2), 521S-524S. 
Olsta, J. (2013). Bringing breakfast to our students: A program to increase school breakfast participation. Journal of School Nursing, 29(4), 263-270.

Oregon Enrolled House Bill 2846, $78^{\text {th }}$ Assembly (2015). Retrieved from https://olis.leg.state.or.us/liz/2015R1/Downloads/MeasureDocument/HB2846

Oregon Health Authority. (2014). 2014 The Institute for Community Research's participatory action research curriculum adapted for Oregon. Retrieved from https://www.oregon.gov/oha/PH/HEALTHYPEOPLEFAMILIES/YOUTH/ Documents/CurriculumYPAR2014.pdf

Palloni, A. (2006). Reproducing inequalities: Luck, wallets, and the enduring effects of childhood health. Demography, 43(4), 587-615. doi:org/10.1353/dem.2006.0036

Peterson, K., Davison, M. L., Wahlstrom, K., Himes, J., Stevens, M., Seo, Y. S., ... Hansen, A. (2004). Fastbreak to learning School Breakfast Program: A report of the fourth year results, 2002-03.

Pollitt, E., \& Mathews, R. (1998). Breakfast and cognition: An integrative summary. The American Journal of Clinical Nutrition, 67(4), 804S-813S.

Popkin, S. J., Scott, M. M., \& Galvez, M. M. (2016, September 12). Impossible choices: Teens and food insecurity in America. Retrieved from http://www.urban.org/ research/publication/impossible-choices-teens-and-food-insecurity-america

Poppendieck, J. (2010). Free for all: Fixing school food in America (1st ed.). Berkley, CA.: University of California Press. Retrieved from http://www.jstor.org/stable/ 10.1525/j.ctt1pn8qf

Rainville, A. J., \& Carr, D. H. (2008). In-classroom breakfast: Best practices in three school districts. Journal of Child Nutrition and Management, 32(2). Retrieved from https://schoolnutrition.org/NewsPublications/JCNM/2008/Fall/

Rampersaud, G. C. (2009). Benefits of breakfast for children and adolescents: Update and recommendations for practitioners. American Journal of Lifestyle Medicine, 3(2), 86-103. doi:org/10.1177/1559827608327219

Rampersaud, G. C., Pereira, M. A., Girard, B. L., Adams, J., \& Metzl, J. D. (2005). Breakfast habits, nutritional status, body weight, and academic performance in children and adolescents. Journal of the American Dietetic Association, 105(5), 743-760. doi:org/10.1016/j.jada.2005.02.007 
Reddan, J., Wahlstrom, K., \& Reicks, M. (2002). Children's perceived benefits and barriers in relation to eating breakfast in schools with or without universal school breakfast. Journal of Nutrition Education and Behavior, 34(1), 47-52. doi:org/ 10.1016/S1499-4046(06)60226-1

Reitan, R. M. (1992). Trail making test: Manual for administration and scoring. Tucson, AZ: Reitan Neuropsychology Laboratory.

Richard, L., Gauvin, L., \& Raine, K. (2011). Ecological models revisited: Their uses and evolution in health promotion over two decades. Annual Review of Public Health, 32(1), 307-326. doi:org/10.1146/annurev-publhealth-031210-101141

Rose, D., Habicht, J.-P., \& Devaney, B. (1998). Household participation in the Food Stamp and WIC Programs increases the nutrient intakes of preschool children. The Journal of Nutrition, 128(3), 548-555.

Saksvig, B. I., Gittelsohn, J., Harris, S. B., Hanley, A. J., Valente, T. W., \& Zinman, B. (2005). A pilot school-based healthy eating and physical activity intervention improves diet, food knowledge, and self-efficacy for native Canadian children. The Journal of nutrition, 135(10), 2392-2398.

Saldaña, J. (2015). The coding manual for qualitative researchers. Thousand Oaks, CA: Sage.

Sallis, J. F., Calfas, K. J., Alcaraz, J. E., Gehrman, C., \& Johnson, M. F. (1999). Potential mediators of change in a physical activity promotion course for university students: Project GRAD. Annals of Behavioral Medicine, 21(2), 149.

Sallis, J. F., Cervero, R. B., Ascher, W., Henderson, K. A., Kraft, M. K., \& Kerr, J. (2006). An ecological approach to creating active living communities. Annual Review of Public Health, 27. doi:org/10.1146/annurev.publhealth. 27.021405.102100

Sandler, R. B., Slemenda, C. W., LaPorte, R. E., Cauley, J. A., Schramm, M. M., Barresi, M. L., \& Kriska, A. M. (1985) Postmenopausal bone density and milk consumption in childhood and adolescence. The American Journal of Clinical Nutrition, 42, 270-274. Retrieved from http://www.scirp.org/(S(lz5mqp453 edsnp55rrgjct55))/reference/ReferencesPapers.aspx?ReferenceID=1257695

Scheier, L. M. (2005). What is the hunger-obesity paradox? Journal of the American Dietetic Association, 105(6), 883-885.

Schlundt, D. G., Hill, J. O., Sbrocco, T., Pope-Cordle, J., \& Sharp, T. (1992). The role of breakfast in the treatment of obesity: A randomized clinical trial. The American Journal of Clinical Nutrition, 55(3), 645-651. 
School Nutrition Assocation (n.d.). School meal trends and stats. Retrieved October 19, 2018, from https://schoolnutrition.org/AboutSchoolMeals/ SchoolMealTrendsStats/

School Nutrition Association. (2016). The state of school nutrition 2016. Retrieved from https://schoolnutrition.org/uploadedFiles/Resources_and_Research/Research/201 6OperationsReportExecutiveSummary.pdf

Schram, T. H. (2006). Conceptualizing and proposing qualitative research. Upper Saddle River, NJ: Pearson Merrill Prentice Hall.

Schwartz, M. B., Kunkel, D., \& DeLucia, S. (2013). Food marketing to youth: Pervasive, powerful, and pernicious. Communication Research Trends, 32(2), 4-13.

Shanafelt, A., Hearst, M. O., Wang, Q., \& Nanney, M. S. (2016). Food insecurity and rural adolescent personal health, home, and academic environments. Journal of School Health, 86(6), 472-480. doi:org/10.1111/josh.12397

Shonkoff, J. P., \& Levitt, P. (2010). Neuroscience and the future of early childhood policy: Moving from why to what and how. Neuron, 67(5), 689-691. doi:org/10.1016/j.neuron.2010.08.032

Siega-Riz, A. M., Carson, T., \& Popkin, B. (1998). Three squares or mostly snacksWhat do teens really eat? Journal of Adolescent Health, 22(1), 29-36. doi:org/10.1016/S1054-139X(97)00125-0

Siega-Riz, A. M., Popkin, B. M., \& Carson, T. (1998). Trends in breakfast consumption for children in the United States from 1965-1991. The American Journal of Clinical Nutrition, 67(4), 748S-756S.

Sjöberg, A., Hallberg, L., Höglund, D., \& Hulthén, L. (2003). Meal pattern, food choice, nutrient intake and lifestyle factors in The Göteborg Adolescence Study. European Journal of Clinical Nutrition, 57(12), 1569-1578. doi:org/10.1038/sj.ejcn.1601726

Skalicky, A., Meyers, A. F., Adams, W. G., Yang, Z., Cook, J. T., \& Frank, D. A. (2006). Child food insecurity and iron deficiency anemia in low-income infants and toddlers in the United States. Maternal and Child Health Journal, 10(2), 177. doi:org/10.1007/s10995-005-0036-0

Slack, K. S., Holl, J. L., McDaniel, M., Yoo, J., \& Bolger, K. (2004). Understanding the risks of child neglect: An exploration of poverty and parenting characteristics. Child Maltreatment, 9(4), 395-408. doi:org/10.1177/1077559504269193 
Slopen, N., Fitzmaurice, G., Williams, D. R., \& Gilman, S. E. (2010). Poverty, food insecurity, and the behavior for childhood internalizing and externalizing disorders. Journal of the American Academy of Child and Adolescent Psychiatry, 49(5), 444-452. doi:org/10.1016/j.jaac.2010.01.018

Sluss, D. M., \& Ashforth, B. E. (2007). Relational identity and identification: Defining ourselves through work relationships. The Academy of Management Review, 32(1), 9-32. doi:org/10.2307/20159278

Song, W. O., Chun, O. K., Obayashi, S., Cho, S., \& Chung, C. E. (2005). Is consumption of breakfast associated with body mass index in U.S. adults? Journal of the American Dietetic Association, 105(9), 1373-1382. doi:org/10.1016/ j.jada.2005.06.002

Spear, B. A. (2002). Adolescent growth and development. Journal of the American Dietetic Association, 102(3), S23-S29. doi:org/10.1016/S0002-8223(02)90418-9

Spruance, L. A., Harrison, C., Brady, P., Woolford, M., \& LeBlanc, H. (2018). Who eats school breakfast? Parent perceptions of school breakfast in a state with very low participation. Journal of School Health, 88(2), 139-149.

Stake, R. E. (1995). The art of case study research. Thousand Oaks, CA: Sage.

Stang, J., Kong, A., Story, M., Eisenberg, M. E., \& Neumark-Sztainer, D. (2007). Food and weight-related patterns and behaviors of Hmong adolescents. Journal of the American Dietetic Association, 107(6), 936-941. doi:org/10.1016/ j.jada.2007.03.003

Stevenson, C., Doherty, G., Barnett, J., Muldoon, O. T., \& Trew, K. (2007). Adolescents' views of food and eating: Identifying barriers to healthy eating. Journal of Adolescence, 30(3), 417-434. doi:org/10.1016/j.adolescence.2006.04.005

Story, M., \& Alton, I. (1996, July). Adolescent nutrition: Current trends and critical issues. Topics in Clinical Nutrition, 11(3). doi:org/10.1097/00008486-19960600000008

Story, M., \& French, S. (2004). Food advertising and marketing directed at children and adolescents in the U.S. International Journal of Behavioral Nutrition and Physical Activity, 1(1), 3. doi:org/10.1186/1479-5868-1-3

Story, M., Kaphingst, K. M., Robinson-O’Brien, R., \& Glanz, K. (2008). Creating healthy food and eating environments: Policy and environmental approaches. Annual Review of Public Health, 29(1), 253-272. doi:org/10.1146/annurev. publhealth.29.020907.090926 
Story, M., \& Neumark-Sztainer, D. (1996). School-based nutrition education programs and services for adolescents. Adolescent Medicine, 7(2), 287-302.

Story, M., Neumark-Sztainer, D., \& French, S. (2002). Individual and environmental influences on adolescent eating behaviors. Journal of the American Dietetic Association, 102(3, Supplement), S40-S51. doi:org/10.1016/S00028223(02)90421-9

Story, M., \& Resnick, M. D. (1986). Adolescents' views on food and nutrition. Journal of Nutrition Education, 18(4), 188-192. doi:org/10.1016/S0022-3182(86)80015-2

Sweeney, N. M., \& Horishita, N. (2005). The breakfast-eating habits of inner city high school Students. The Journal of School Nursing, 21(2), 100-105. org/10.1177/10598405050210020701

Taras, H. (2005). Nutrition and student performance at school. Journal of School Health, 75(6), 199-213. doi:org/10.1111/j.1746-1561.2005.00025.x

Timlin, M. T., Pereira, M. A., Story, M., \& Neumark-Sztainer, D. (2008). Breakfast eating and weight change in a 5-year prospective analysis of adolescents: Project EAT (Eating Among Teens). Pediatrics, 121(3), e638-e645. doi:org/10.1542/peds.2007-1035

Townsend, M. S., Peerson, J., Love, B., Achterberg, C., \& Murphy, S. P. (2001). Food insecurity is positively related to overweight in women. The Journal of Nutrition, 131(6), 1738-1745.

Turrell, G., Hewitt, B., Patterson, C., Oldenburg, B., \& Gould, T. (2002). Socioeconomic differences in food purchasing behaviour and suggested implications for dietrelated health promotion. Journal of Human Nutrition and Dietetics, 15(5), 355-364. doi:org/10.1046/j.1365-277X.2002.00384.x

United States Department of Agriculture, Economic Research Service. (2017). Definitions of food security. Retrieved March 5, 2017, from https://www.ers.usda.gov/topics/food-nutrition-assistance/food-security-in-theus/definitions-of-food-security.aspx

United States Department of Agriculture, Food and Nutrition Service. (2002). Provision 2 guidance: National School Lunch and School Breakfast Programs. Retrieved from https://fns-prod.azureedge.net/sites/default/files/Prov2Guidance.pdf

United States Department of Agriculture, Food and Nutrition Service. (2012). School nutrition dietary assessment study-IV. (2012). Retrieved from https://fnsprod.azureedge.net/sites/default/files/SNDA-IV_Vol1Pt1_0.pdf 
United State Department of Agriculture, Food and Nutrition Service. (2016). National School Lunch Program and School Breakfast Program: Nutrition standards for all foods sold in school as required by the Healthy, Hunger-Free Kids Act of 2010. (2016). Retrieved October 14, 2018, from https://www.federalregister.gov/ documents/2016/07/29/2016-17227/national-school-lunch-program-and-schoolbreakfast-program-nutrition-standards-for-all-foods-sold-in

United States Department of Agriculture, Food and Nutrition Service. (2017a). School Breakfast Program (SBP) fact sheet. Retrieved October 13, 2018, from https://www.fns.usda.gov/sbp/fact-sheet

United States Department of Agriculture, Food and Nutrition Service (2017b). School meals: Healthy, Hunger-Free Kids Act. Retrieved October 7, 2018, from https://www.fns.usda.gov/school-meals/healthy-hunger-free-kids-act

Vaudrin, N., Lloyd, K., Yedidia, M. J., Todd, M., \& Ohri-Vachaspati, P. (2017). Impact of the 2010 U.S. Healthy, Hunger-Free Kids Act on school breakfast and lunch participation rates between 2008 and 2015. American Journal of Public Health, 108(1), 84-86. doi:org/10.2105/AJPH.2017.304102

Vogt, W. P., Gardner, D. C., \& Haeffele, L. M. (2012). When to use what research design. New York, NY: Guilford Press.

Washington House Bill 1508. (2017). Retrieved from http://lawfilesext.leg.wa.gov/ Biennium/2017-18/Htm/Bills/House\%20Bills/1508-S.E.htm

Weber, K., Story, M., \& Harnack, L. (2006). Internet food marketing strategies aimed at children and adolescents: A content analysis of food and beverage brand web sites. Journal of the American Dietetic Association, 106(9), 1463-1466. doi:org/10.1016/j.jada.2006.06.014

Whitaker, R. C., Phillips, S. M., \& Orzol, S. M. (2006). Food insecurity and the risks of depression and anxiety in mothers and behavior problems in their preschool-aged children. Pediatrics, 118(3), e859-e868. doi:org/10.1542/peds.2006-0239

World Health Organization. (n.d.). What is overweight and obesity? Retrieved October 3, 2018, from https://www.who.int/dietphysicalactivity/childhood_what/en/

Williams, J. D., Achterberg, C., \& Sylvester, G. P. (1993). Target marketing of food products to ethnic minority youth. Annals of the New York Academy of Sciences, 699(1), 107-114. doi:org/10.1111/j.1749-6632.1993.tb18842.x 
Williams, P. (2007). Breakfast and the diets of Australian children and adolescents: An analysis of data from the 1995 National Nutrition Survey. International Journal of Food Sciences and Nutrition, 58(3), 201-216. doi:org/10.1080/ 09637480701198075

Winicki, J., \& Jemison, K. (2003). Food insecurity and hunger in the kindergarten classroom: Its effect on learning and growth. Contemporary Economic Policy, 21(2), 145-157. doi:org/10.1093/cep/byg001

Yang, C., Bear, G. G., \& May, H. (2018). Multilevel associations between school-wide social-emotional learning approach and student engagement across elementary, middle, and high schools. School Psychology Review, 47(1), 45-61.

Zapata, L. B., Bryant, C. A., McDermott, R. J., \& Hefelfinger, J. A. (2008). Dietary and physical activity behaviors of middle school youth: The Youth Physical Activity and Nutrition Survey. Journal of School Health, 78(1), 9-18. doi:org/10.1111/ j.1746-1561.2007.00260.x 


\section{APPENDIX A: CONSENT FORMS}

\section{PARENTAL PERMISSION}

\section{How is Breakfast Part of the Academic Equation in a College-Preparatory High School for Underserved Students}

Your child is invited to participate in a research study conducted by Jennifer Young from Portland State University in Portland, Oregon. The researcher hopes to learn about attitudes, perceptions and behaviors of school staff and students in regards to breakfast eating and the School Breakfast Program. This study is being conducted in partial fulfillment of the requirements for doctoral degree, and is under the supervision of Dannelle D. Stevens, Professor Emeritus from the Department of Curriculum and Instruction in the Graduate School of Education, at Portland State University. Your child was selected as a possible participant in this study because he/she has knowledge of the school's social and physical environment, and will be able to provide valuable information and insight about the topic being studied.

If you decide to let your child participate, participate in a one-hour focus group. All of these activities will take place on the school campus in a classroom or office to ensure privacy. The focus groups will be audio-recorded, to ensure a record of what was said for the data collection process.

While participating in this study, it is possible your child may experience some uncomfortable feelings while talking about eating behaviors. Students will be encouraged to consult the school counselor to discuss unsettling feelings about eating behaviors. If a participant discloses information relating to serious topics of concern, such as an eating disorder, the co-researcher will inform the principal investigator and the appropriate authorities.

Your child may not receive any direct benefit from taking part in this study, but the study may help to increase knowledge which may help others in the future.

Your child will receive $\$ 25$. In cash or a gift card for participating in this study.

Any information that is obtained in connection with this study and that can be linked to your child or identify your child will be kept confidential. This information will be kept confidential by not using student's real names and not identifying the students who are 
part of the study. All data such as audio-recordings and transcripts of the audio will be kept on a private, password-protected computer and hard copies will be kept in a locked file cabinet.

Your child's participation is voluntary. He/she does not have to take part in this study, and it will not affect his/her grades or relationship with De La Salle or Portland State University. You may also withdraw your permission for your child to participate from this study at any time without affecting his/her grades or relationship with De La Salle or Portland State University. Likewise, your child may withdraw his/her assent at any time without affecting his/her grades or relationship with De La Salle or Portland State University.

If you have questions or concerns about your child's participation in this study, contact Jennifer Young at youngj@pdx.edu or (503) 789-3005. If you have concerns about your child's rights as a research subject, please contact the PSU Office of Research Integrity, Market Center Building Ste. 620, Portland State University, (503) 725-2227.

Your signature indicates that you have read and understand the above information and agree to let your child take part in this study. The researcher should provide you with a copy of this form for your own records.

Participant Signature

Participant Printed Name
Date

Investigator Signature

Date

Investigator Printed Name 


\section{MODEL CONSENT FOR USE WITH YOUTH AGED 13-18 OR OTHER SENSITIVE POPULATIONS}

\section{How is Breakfast Part of the Academic Equation in a College-Preparatory High School for Underserved Students?}

Jennifer Young, from the Graduate School of Education at Portland State University is doing a research study on student breakfast eating and the support School Breakfast Program.

\section{What Will I Have To Do?}

If you decide to take part in this project, we will ask you to:

- Participate in a survey

- Be part of a focus group

- Participate in draw a high school student test

\section{Are There Any Risks?}

There are risks to discussing eating behaviors in front of your peers. You do not have to take part in this study. If you do agree to take part, you may feel uncomfortable because of what you are asked to do. You don't have to answer any questions you don't want to. And if you don't want to go on, you can stop. If you are upset after the study and need to talk with someone, you can call Dannelle D. Stevens at the Portland State University, Graduate School of Education.; she is the person leading the project in Portland. She can be reached at (503) 705-9828.

\section{What Will I Get in Return?}

- You will receive $\$ 25.00$ as compensation for taking part in this study. You will receive the money at the end of the survey. It is our way of saying "Thank you for your time."

- Knowing you are helping others. Many people feel good about helping others. We can learn so much from you about how to support nutrition programs.

\section{What Are You Doing To Protect Me?}

Your privacy is very important to us. We have done many things to protect you:

- We won't tell anyone if you take part in this study or not.

- When we talk to you, it will be in a private place. This means no one will be able to overhear what you tell us.

- Your name and what you tell us will be kept confidential to the extent allowed by law. (By "kept confidential" we mean that the names of people who take part in the study will not be given to anyone else. And it means that we will only reveal what you say in a way that no one could ever guess or know it was you who said it.) If, in the course of the study, you disclose that you are, or are intending to, harm yourself or others, we are ethically and legally required to notify the appropriate authorities. 
- Only staff from the research project will know what you say.

- Your name and other personal information, which we need in order to keep track of who we talk to, will be kept in a locked file cabinet or in a locked file on the computer so that no one other than the research staff will be able to see it. For example, this form (which has your name on it) will be kept in a locked file cabinet.

- When we write or talk about what we learned in this study, we will leave things out so no one will be able to tell who we are talking about.

\section{Any Questions?}

If you have any questions about this study, this form, or the study, you can talk to the person leading the project in Portland, [insert name of P.I. and telephone \#]. You can also contact the Office of Research Integrity of Portland State University about your rights as a research participant (someone who takes part in a study). Hours are 9:00 a.m. to 5:00 p.m. The office is located at Portland State University, Market Center Building, Ste. 620, Portland, OR 97201. The telephone number is (503) 725-2227

\section{If I Sign, What Does It Mean?}

This is a consent form. Your signature below means that:

- You have read and understand what this form says.

- You are willing to take part in the study.

- You know that you do not have to take part in this study. And even if you agree, you can change your mind and stop at any time. No problem

- Although this study at your school, taking part in this study has nothing to do with your grades, and there is no expectation from the school that you participate in the study. If you agree to take part or if you say no, they won't know and it won't matter. They will treat you the same.

- You will get a copy of this form to keep for yourself.

Participant Signature

Date

Participant name, printed

Interviewer/Witness/Legal Guardian Signature

Date

Interviewer/Witness/Legal Guardian name, printed 


\author{
The Portland State University \\ Consent to Participate in Research
}

\title{
How is Breakfast Part of the Academic Equation in a College-Preparatory High School for Underserved Students?
}

November 14, 2017

\section{Introduction}

You are being asked to participate in a research study that is being done by Dannelle D. Stevens, who is the Principal Investigator, and Jennifer L. Young, co-researcher, from the Department of Curriculum and Instruction in the Graduate School of Education], at Portland State University in Portland, Oregon. This research is studying school breakfast and student and staff breakfast eating attitudes and behaviors.

You are being asked to participate in this study because you have knowledge of the school's social and physical environment, and because you observe the student population on a daily basis.

This form will explain the research study, and will also explain the possible risks as well as the possible benefits to you. We encourage you to talk with your family and friends before you decide to take part in this research study. If you have any questions, please ask one of the study investigators.

\section{What will happen if I decide to participate?}

If you agree to participate, the following things will happen:

- You will be asked to complete a 10-minute survey

- You may be invited to participate in a focus group or individual interview.

How long will I be in this study? The study will be conducted for roughly nine weeks. Your participation in the study will be limited to the activities you decide to participate in listed above (survey, focus group, interview)

Participation in the survey will take 10 minutes. Participation in focus group will take one hour. Individual interviews will take between 15 and 30 minutes.

\section{What are the risks or side effects of being in this study?}

There are risks of stress, emotional distress, inconvenience and possible loss of privacy and confidentiality associated with participating in a research study.

For more information about risks and discomforts, ask the investigator. 
What are the benefits to being in this study?

Benefits to being in the study include participating in and learning about research methods. Providing information to a research project that add to the research literature and can help provide support to changes in nutrition policy

\section{How will my information be kept confidential?}

We will take measures to protect the security of all your personal information, but we cannot guarantee confidentiality of all study data. The survey data will not include identifying information, only a summary of the data will be discussed. Likewise, photos from the Photovoice project will not include names or faces in the photos. Focus group members will choose pseudonyms, and their real names or identifying information will not be used. Quotes for the study will use chosen pseudonyms and all participants will be contacted for permission to use quotations. Individual interviews with staff will not include names or job titles or other identifying information. Focus groups and interviews will be conducted in a place that provides privacy.

Participation in a focus group does not allow for the same level of confidentiality as other forms of research. The investigator can only be responsible for the confidentiality of the data collected by that investigator, and confidentiality may be breached by others in the focus group. As a participant in the focus group, you are encouraged not to speak of what was discussed during the group once the group has ended.

Information contained in your study records is used by study staff. The Portland State University Institutional Review Board (IRB) that oversees human subject research and/or other entities may be permitted to access your records, and there may be times when we are required by law to share your information. It is the investigator's legal obligation to report child abuse, child neglect, elder abuse, harm to self or others or any life-threatening situation to the appropriate authorities, and; therefore, your confidentiality will not be maintained.

Your name will not be used in any published reports about this study.

Will I be paid for taking part in this study?

A small stipend will be given to those who participate in the focus group and individual interviews.

Can I stop being in the study once I begin?

Your participation in this study is completely voluntary. You have the right to choose not to participate or to withdraw your participation at any point in this study without penalty or loss of benefits to which you are otherwise entitled.

\section{Whom can I call with questions or complaints about this study?}

If you have any questions, concerns or complaints at any time about the research study, researcher, Jennifer Young, or her associates will be glad to answer them at 503-789-3005. 
Whom can I call with questions about my rights as a research participant?

If you have questions regarding your rights as a research participant, you may call the PSU Office for Research Integrity at (503) 725-2227 or 1(877) 480-4400. The ORI is the office that supports the PSU Institutional Review Board (IRB). The IRB is a group of people from PSU and the community who provide independent oversight of safety and ethical issues related to research involving human participants. For more information, you may also access the IRB website at https://sites.google.com/a/pdx.edu/research/integrity.

\section{CONSENT}

You are making a decision whether to participate in this study. Your signature below indicates that you have read the information provided (or the information was read to you). By signing this consent form, you are not waiving any of your legal rights as a research participant.

You have had an opportunity to ask questions and all questions have been answered to your satisfaction. By signing this consent form, you agree to participate in this study. A copy of this consent form will be provided to you.

\section{Name of Adult Subject (print) Signature of Adult Subject Date}

\section{INVESTIGATOR SIGNATURE}

This research study has been explained to the participant and all of his/her questions have been answered. The participant understands the information described in this consent form and freely consents to participate.

$\overline{\text { Name of Investigator/ Research Team Member (type or print) }}$

(Signature of Investigator/ Research Team Member)

Date 


\section{APPENDIX B: STAFF SURVEY QUESTIONS}

\section{Sample Questions for Staff Survey Breakfast Study}

1. On a typical school/work day, how often do you eat breakfast?

Every day

Most days

Some days

1-2 days

Never

2. On a typical weekend day, I eat breakfast

At home alone

At home with family

On the way to school

At work/ the school-purchased on the way or brought from home

Purchased at the school

I don't eat breakfast on a typical school/work day

Other

I don't eat breakfast on a typical school/work day

3. Eating breakfast helps me perform better at work

$\begin{array}{llll}\text { Strongly Disagree } & \text { Disagree } & \text { Agree } & \text { Strongly Agree }\end{array}$ 
4. I eat breakfast because it is important for my health.

Strongly Disagree $\quad$ Disagree $\quad$ Agree $\quad$ Strongly Agree

5. Eating breakfast helps me control my weight.

Strongly Disagree $\quad$ Disagree $\quad$ Agree $\quad$ Strongly Agree

6. I notice that the students who eat breakfast are more alert in class than those who skip breakfast.

Strongly Disagree $\quad$ Disagree $\quad$ Agree $\quad$ Strongly Agree

Unknown

7. I think the School Breakfast Program is an important resource for students

Strongly Disagree $\quad$ Disagree $\quad$ Agree $\quad$ Strongly Agree

Unknown

8. I am very familiar with our school's breakfast program

Strongly Disagree $\quad$ Disagree $\quad$ Agree $\quad$ Strongly Agree

Unknown

9. I encourage students to take part in the School Breakfast Program

Often Sometimes Never

10. The school promotes the importance of eating breakfast

Strongly Disagree $\quad$ Disagree $\quad$ Agree $\quad$ Strongly Agree

11. The school encourages students to take part in the School Breakfast Program

Strongly Disagree $\quad$ Disagree $\quad$ Agree $\quad$ Strongly Agree

12. In my role within the school, I promote the importance of eating breakfast

Strongly Disagree $\quad$ Disagree $\quad$ Agree $\quad$ Strongly Agree 
13. Please provide your additional thoughts on the School Breakfast Program at your school:

14. What is your gender?

\section{Female}

Male

Other

15. Use this space if there is any additional information you would like to add: 


\section{APPENDIX C: SEMI-STRUCTURED INTERVIEW QUESTIONS FOR ADMINISTRATORS AND STAFF}

Thank you for taking the time to meet with me today. My name is Jennifer Young and I am a doctoral candidate in the Graduate School of Education at Portland State University. This interview is part of the research that I am conducting for my dissertation-which is focused on adolescent nutrition, school breakfast and student and staff breakfast eating attitudes and behaviors. With that being said, please answer based on what you know to be true, and not based on what you think I might like to hear. Your knowledge of the school and experiences are what I want to learn about. This interview should take no more than 30 minutes.

I would like to record our interview so that I don't miss anything. I will also be taking notes during the interview. If this is okay with you, then I will ask you to read through and sign this consent form (hand consent form). Do you have any questions?

\section{Move into interview once the consent form has been signed.}

Okay, let's get started.

1. Please tell me your job title and about your role in the school?

2. How long have you worked at this school?

3. What can you tell me about the breakfast eating habits of students at the school?

a. How do you know this?

4. How are you involved with the School Breakfast Program?

5. Tell me about the program.

6. Please tell me one thing that you see as a positive in the program.

7. Please tell me one thing that you see as a negative about the program.

8. What else is there about the program that you have noticed? 
9. Explain how breakfast and the School Breakfast Program is promoted in the school?

a. To students, staff, others?

10. Do you eat breakfast at school?

i. Why or why not?

ii. Do you know of other staff members that eat breakfast at school?

1. Explain

11. Using a Likert scale of one to five, with one being the least and five being the most, how much do you believe that student nutrition is considered as a support for academic success?

a. Explain

12. Using the same Likert scale, with one being the least and five being the most, how much do you believe that student nutrition is considered as a support for academic success within the school culture or climate?

a. Explain

13. Is there anything else that you would like to add about nutrition, breakfast eating, or something that came to mind while we were talking?

Thank you so much for your time. As an appreciation, I would like to give you this small gift card, and for my records, I will need you to sign that you received it. 


\section{APPENDIX D: FOCUS GROUP AND DAHSSBT SCRIPT ${ }^{2}$}

\section{School Breakfast Study Focus Group Script and Questions}

\section{Introduction}

Hello everyone and thank you for agreeing to be part of the focus group today. My name is Jennifer Young, and I am a researcher from Portland State University. The reason for the focus group is to get information about breakfast. I would like to hear about if, where, and when you typically eat breakfast, and to learn from you about the School Breakfast Program at your school. I am going to ask you all questions and everyone will have a chance to answer.

The information that you share here is important because you are the experts and I am here to learn from all of you.

\section{House Keeping}

Here are a few things that you should know before we begin:

- The focus group will last about an hour.

- You only have to answer questions or talk if you want to.

- I will be taking notes

- I would like to audiotape what you say so that we don't miss anything important and so that we can go back and listen to the discussion. If you still want to be part of the focus group, and agree to be audiotaped, I will have you sign and turn-in your consent form before we begin. If you are under 18, I will also need to collect the consent form that your parent signed as well. No one should feel like they have to do this-it is okay if you decide you don't want to be part of this discussion.

- The identities of all of you will remain confidential. So when you introduce yourself please make up a name that you will go by.

$\bigcirc$ At the beginning of the focus group we will do a drawing exercise. It doesn't matter if you are a good or bad artist. I will tell you more about this in a few minutes.

2 Source: adapted from InSites: Tips for Conducting Focus Groups via http://www.insites.org/CLIP_v1_site/downloads/PDFs/TipsFocusGrps.4D.8-07.pdf 


\section{Ground rules}

To allow our conversation to flow more freely, I'd like to go over some ground rules.

- What is shared in the room, stays in the room

- We will be recording this session so we don't miss anything.

- Please keep everything you hear today confidential.

- Students will choose an alias name before the focus group begins. This alias name will be used during the focus group.

- There are no right or wrong answers

- Everyone's ideas and experiences are valuable.

- It's important to hear all sides-including both positives and negatives.

- We will not always agree, but we must always show respect for one another.

- You are the experts and we want to hear from you

- Everyone doesn't have to answer every single question, but everyone will be given the opportunity to do so.

- Only one person should talk at a time, so we can hear each other and the audio comes out clearly.

- I may call on you if I haven't heard from you in a while.

Also, please let me know if you need to take a break.

\section{Are there any questions?}

\section{Introduction of participants}

Before we start, please take your pen and write your alias name on your name tag and put it on. (Facilitator passes out name tags). We will be addressing each other by our alias names today. If you get confused and say the person's real name, just correct it as soon as you realize it. It will not be a problem.

- Our first question will help us get to know each other a bit. Let's go around the room and please answer the following three questions.

a. What is your alias name?

b. What is your year in school? Example, freshman, sophomore, junior, senior.

c. When you were little, what was your favorite thing to eat for breakfast?

\section{Draw-a-Student-Test (5 minutes)}

This next question is not really a question at all-it is the drawing exercise I mentioned a few minutes ago. I have given you all some colored pens. Please take a few minutes and draw-in any way you want-your image of a high school student with his or her breakfast. Each of you will have your own ideas about this. Please do not look to others. Just spend the next five minutes creating your own 
personal drawing. Please label the drawing with your alias name. I will collect them when you're done or in five minutes, and then we will continue with the focus group questions.

\section{Focus Group Questions (45 minutes)}

1. Tell me about your experience eating breakfast here at school? $(7 \mathrm{~min})$

a. How often do you eat breakfast at school?

b. Do you eat breakfast on days that you go to work?

c. Tell me something that you really like about the school breakfast

d. Tell me something that you wish you could change

e. Is there anything else that either makes you want to eat breakfast at school or not eat the school breakfast?

2. For those of you who said you did not eat breakfast today ... (7 min)

a. When was the first time that you ate today?

b. What did you have to eat?

b. Is this typical for you on a school day?

d. Why did you skip breakfast today?

3. Tell me which people in your life have the most influence over whether or not you eat breakfast in the morning and what you eat for breakfast. (6 min)

4. Do you think eating breakfast helps you do better in school? (5 min.)

e. Explain

5. How do students at your school find out about the School Breakfast Program? (5 min.)

f. How is the program promoted at your school?

i. Explain 
6. Is there anything additional you would like to add to our discussion? (5 min.)

\section{Thank everyone. Review confidentiality Closing (2 minutes)}

Thank you all for coming today and talking about breakfast. I appreciate your time. Please remember that the information that was shared today is confidential, and should not be discussed with others who were not part of the focus group. Please be sure that you all have given me your drawings. To thank you for your time today I have \$15 each for you. I will need to sign this clipboard saying that you have received the money. 